\title{
QUASI-ONE-DIMENSIONAL SCRAMJET COMBUSTOR FLOW SOLVER USING THE NUMERICAL PROPULSION SYSTEM SIMULATION
}

by

\author{
LONG VU \\ Presented to the Faculty of the Graduate School of \\ The University of Texas at Arlington in Partial Fulfillment \\ of the Requirements \\ for the Degree of
}

MASTER OF SCIENCE IN AEROSPACE ENGINEERING

THE UNIVERSITY OF TEXAS AT ARLINGTON

May 2018 
Copyright (C) by Long Vu 2018

All Rights Reserved 


\section{Acknowledgements}

I would like to thank my parents and my grandparents for their financial and emotional support during my study. I would also like to thank my supervisor professor Dr. Donald Wilson for his guidance and thesis committee members: Dr. Luca Maddalena and Dr. Brian Dennis for their ideas and feedback on the research work.

I would like extend my thanks to Nandakumar Vijayakumar for his help and suggestions.

I would also like to thank all my new friends I have made along the way: James Phan, Peter Dao, Erin Doyle, Vinny Williams... for their help and support.

May 15, 2018 


\begin{abstract}
QUASI_ONE_DIMENSIONAL SCRAMJET COMBUSTOR FLOW SOLVER USING THE NUMERICAL PROPULSION SYSTEM SIMULATION
\end{abstract}

Long $\mathrm{Vu}, \mathrm{MS}$

The University of Texas at Arlington, 2018

Supervising Professor: Donald R. Wilson

The flow field inside a scramjet engine combustor involves complex phenomena such as fuel-air mixing, combustion chemistry, and flow separation. In order to determine the properties of the flow along the length of the combustor, mass, momentum and energy balance equations are solved simultaneously using a numerical method. While a full three dimensional computational simulation gives detailed results with high order of accuracy, it demands a great amount of time and computational resource. A low order analysis produces a fast overall picture of the combustor operation which in turn provides valuable information suitable for the preliminary design process. This research work aims to describe the analysis process of the scramjet combustor in which a quasi-onedimensional, multi-species, reacting real gas model of the flow is developed to address the limitations in previous researches. The Numerical Propulsion System Simulation (NPSS), into which the NASA Chemical Equilibrium with Applications (CEA) code is integrated, is utilized as the platform to perform the analysis. The analytical model is validated by comparison with experimental data from previous researches. The results obtained by this method are expected to shed some light on the advantages of using detailed chemistry with lower order analysis to calculate scramjet engine performance. 
Table of Contents

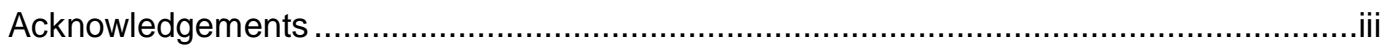

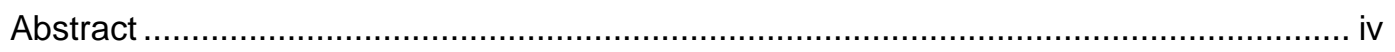

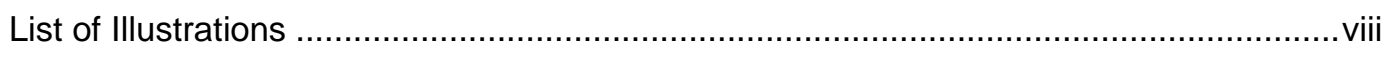

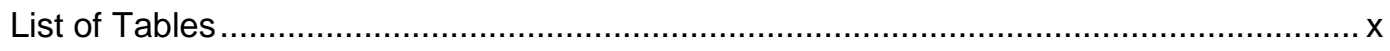

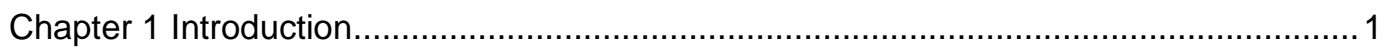

1.1 Ramjet, Scramjet and Dual-mode Scramjet ............................................... 1

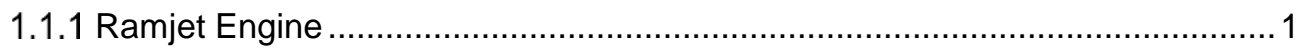

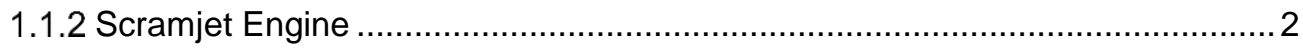

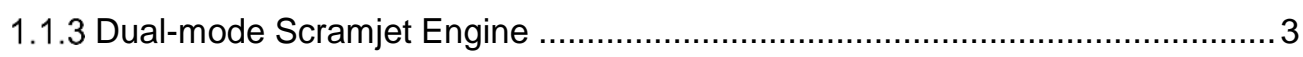

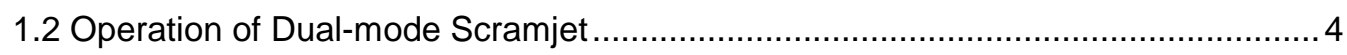

1.2.1 Dual-mode Scramjet Combustor .......................................................... 4

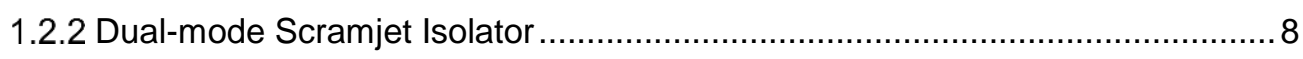

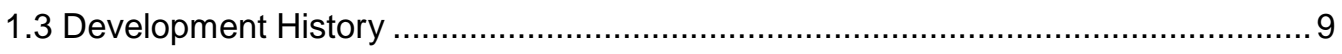

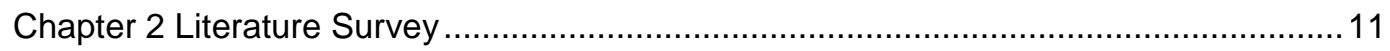

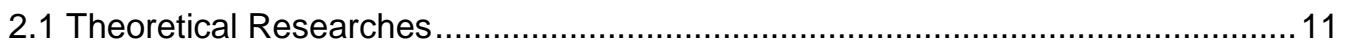

2.1.1 Heiser and Pratt's Approach ........................................................... 11

2.1.2 Ram-Scram Transition and Flame/Shock-Train Interactions in a

Model Scramjet Experiment .................................................................... 12

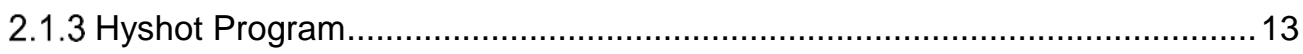

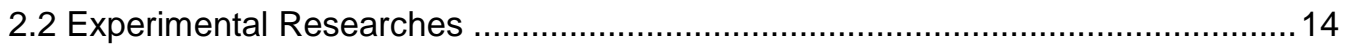

2.2.1 Free Piston Shock Tunnel Experiment at University of

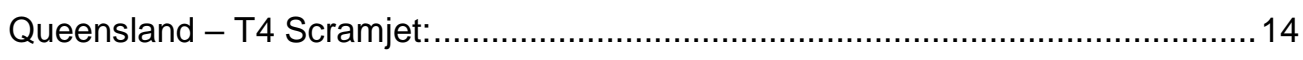

2.2.2 Hyshot 2 Scramjet Flight Experiment .................................................. 15

2.2.3 Investigation of the Isolator Flow of Scramjet Engines ................................ 17 
Chapter 3 The Numerical Propulsion System Simulation (NPSS)

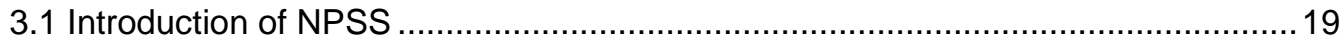

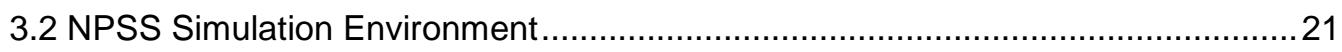

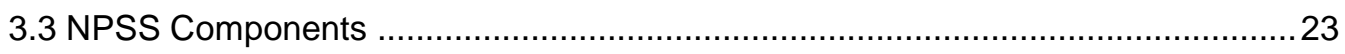

3.3.1 Architecture, code language and basic objects......................................23

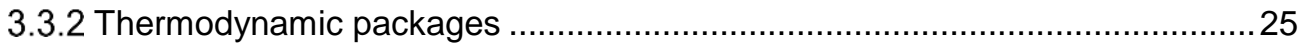

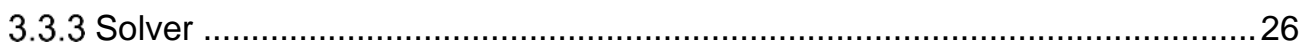

Chapter 4 Quasi-one-dimensional Scramjet Isolator and Combustor Model ..................28

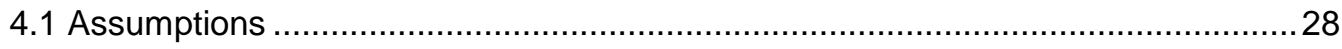

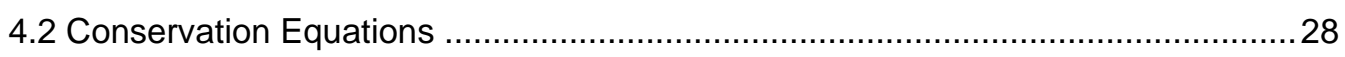

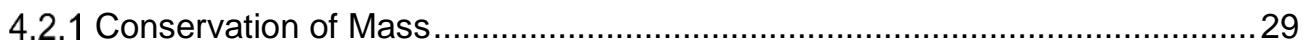

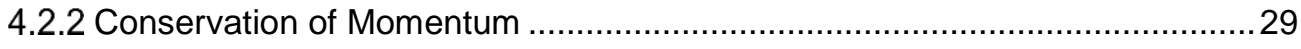

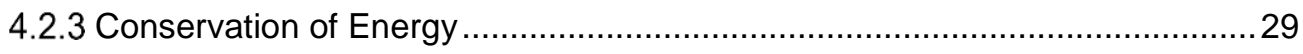

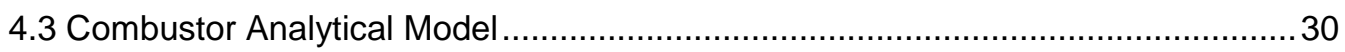

4.3.1 Algebraic Manipulation Involving the Conservation Equations …...................30

4.3.2 Friction Coefficient........................................................................ 32

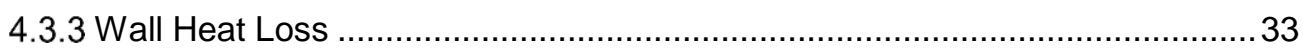

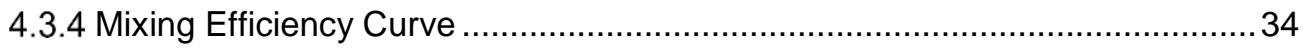

4.3.5 NPSS Calculation Procedure ….......................................................... 35

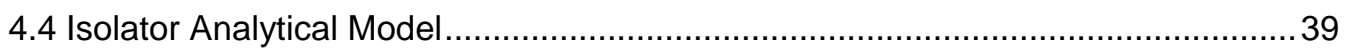

4.4.1 Empirical Formula of Pressure Distribution ..................................................39

4.4.2 NPSS Calculation Procedure …........................................................ 40

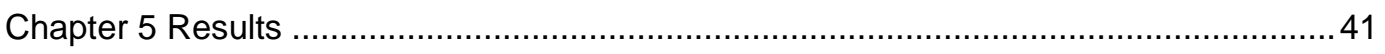

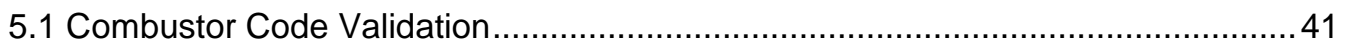

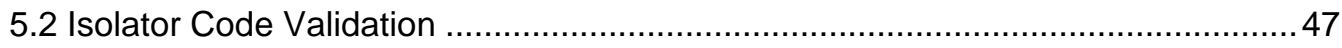


Chapter 6 Conclusion.

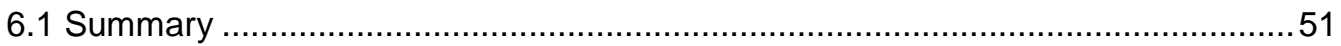

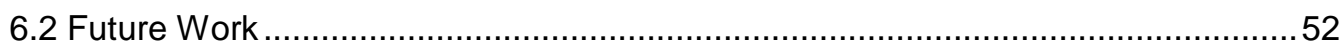

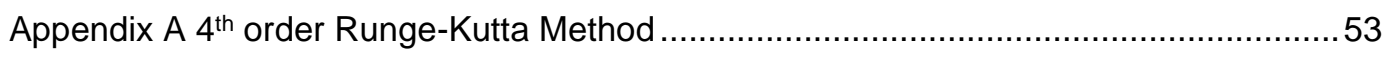

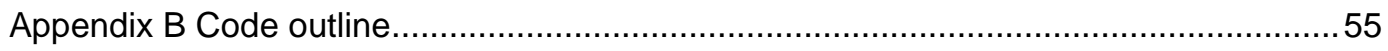

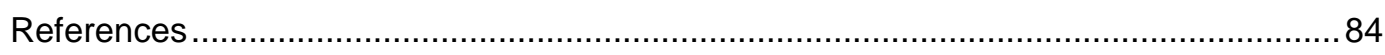

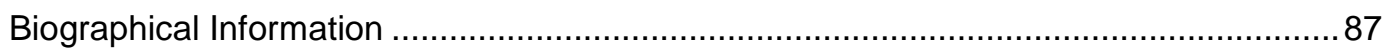




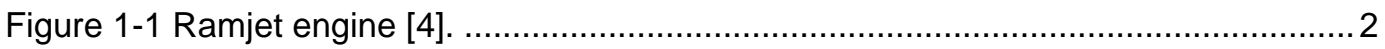

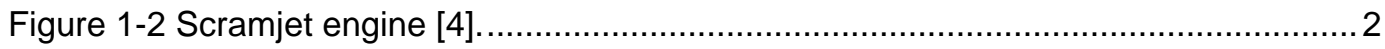

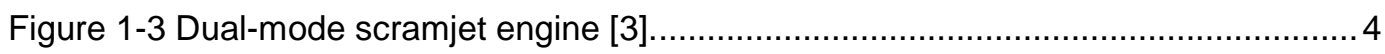

Figure 1-4 Typical changes in flow properties through the combustor in scramjet mode

[6].

Figure 1-5 Typical changes in flow properties through the combustor in transition

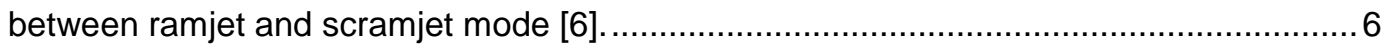

Figure 1-6 Typical changes in flow properties through the combustor in ramjet mode [6]. 7

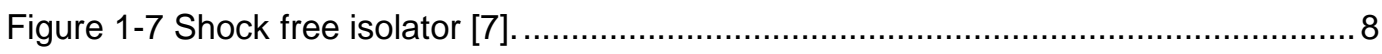

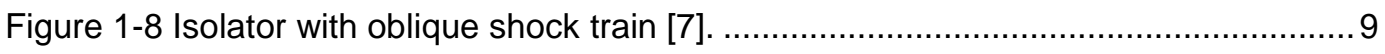

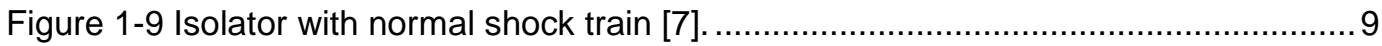

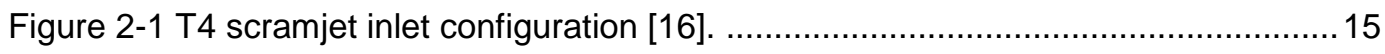

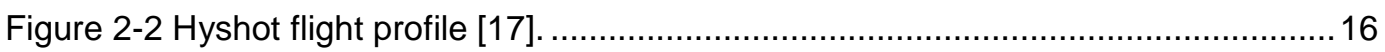

Figure 2-3 Combustor instrumentation layout [17] .................................................. 17

Figure 2-4 Drawing of the hypersonic shock tunnel TH2 [18].................................... 17

Figure 3-1 Hybrid Simulation: 3-Dimensional Low Pressure Subsystem Model Coupled to

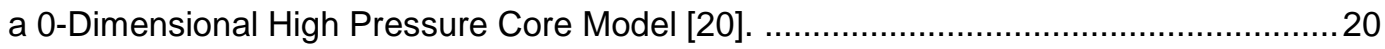

Figure 3-2 Illustration of the NPSS Multidisciplinary Framework [21] ............................22

Figure 3-3 NPSS Object-Oriented Open Architecture [22] ........................................24

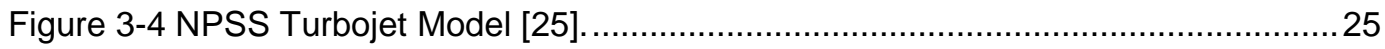

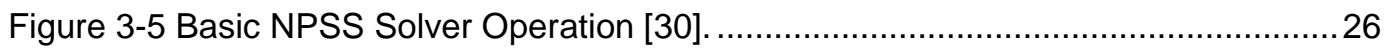

Figure 4-1 Schematic of elemental control volume for burner analysis [7] .....................28

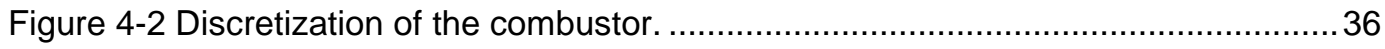

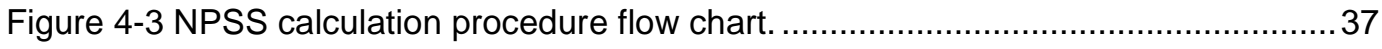




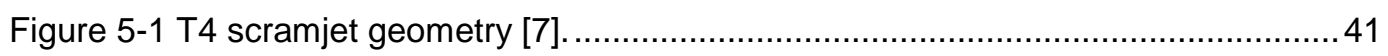

Figure 5-2 Pressure distribution comparison for Case 1 - T4 experiment. ...................... 43

Figure 5-3 Pressure distribution comparison for Case 2 - T4 experiment. ...................... 43

Figure 5-4 Pressure distribution comparison for Case 3 - T4 experiment. ...................... 44

Figure 5-5 Schematic of Hyshot 2 scramjet geometry (dimensions are in millimeters) [17].

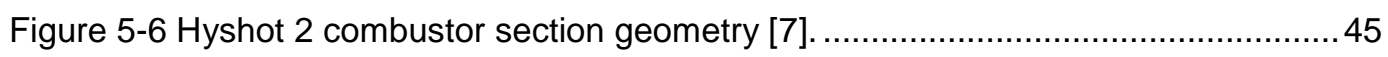

Figure 5-7 Pressure distribution comparison for Case 1 - Hyshot 2. ............................ 46

Figure 5-8 Pressure distribution comparison for Case 2 - Hyshot 2. ............................ 47

Figure 5-9 Heated isolator experiment setup [7] .................................................. 48

Figure 5-10 Pressure distribution comparison for the isolator - Fisher.......................... 49 


\section{List of Tables}

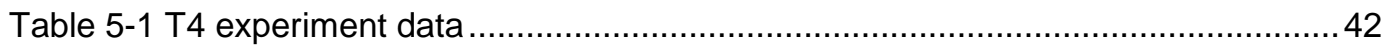

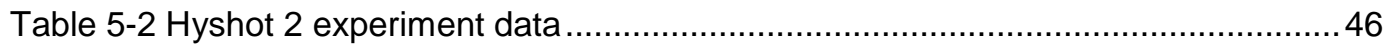

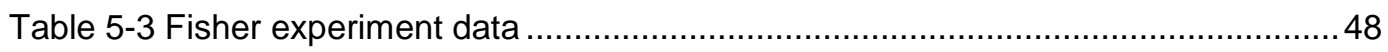

Table 5-4 Ma3 comparison - Fisher experiment ……........................................... 50 
Chapter 1

Introduction

Numerous programs aiming to develop aircraft capable of supersonic or hypersonic flight first appeared in the late 1950's and early 1960's and have developed unceasingly ever since [1]. Rocket propelled vehicles are not a practical option due to the need of an onboard oxidizer tank, resulting in low specific impulse [2]. A more promising choice for these high speed missions is an air breathing propulsion system and the best suitable air breathing engine cycle for moderate supersonic flight is the ramjet, and for hypersonic flight the scramjet or supersonic combustion ramjet, a variant of the ramjet engine cycle.

\subsection{Ramjet, Scramjet and Dual-mode Scramjet}

\subsubsection{Ramjet Engine}

Different from other types of air breathing engine like turbojets and turbofans, the ramjet engine doesn't rely on turbo machinery but uses shockwaves for compression. As air passes through the engine inlet, it is compressed by shockwaves and decelerated to a subsonic speed before entering the combustor where fuel is injected and burnt. The combustion products are then accelerated through a nozzle to create thrust. Ramjet engines can only operate efficiently up to about Mach 6 [3]. At flight Mach numbers above 6 , to achieve subsonic flow to the combustor, the compression ratio has to increase to a value at which shock losses become substantial and the airflow temperature is so high that oxygen dissociation begins to occur hence, less energy is available for conversion into thrust [2]. 


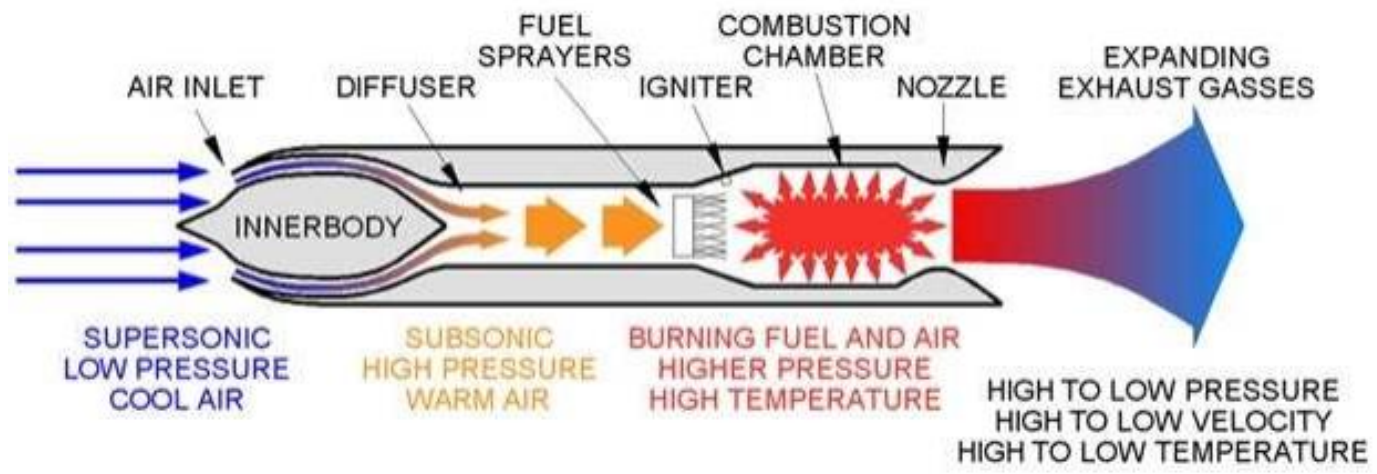

Figure 1-1 Ramjet engine [4].

A ramjet engine has four components: inlet inner body, diffuser, combustor and nozzle. The combustion process takes place at subsonic speed.

\subsubsection{Scramjet Engine}

In order to sustain a usable amount of thrust at higher speed, the air entering the combustor has to be at lower pressure and temperature, but still moving at a supersonic speed. This modification to the ramjet engine is called supersonic combustion ramjet, or scramjet. Ground tests of scramjet engines have shown the potential to reach a maximum speed up to at least Mach 15 [2].

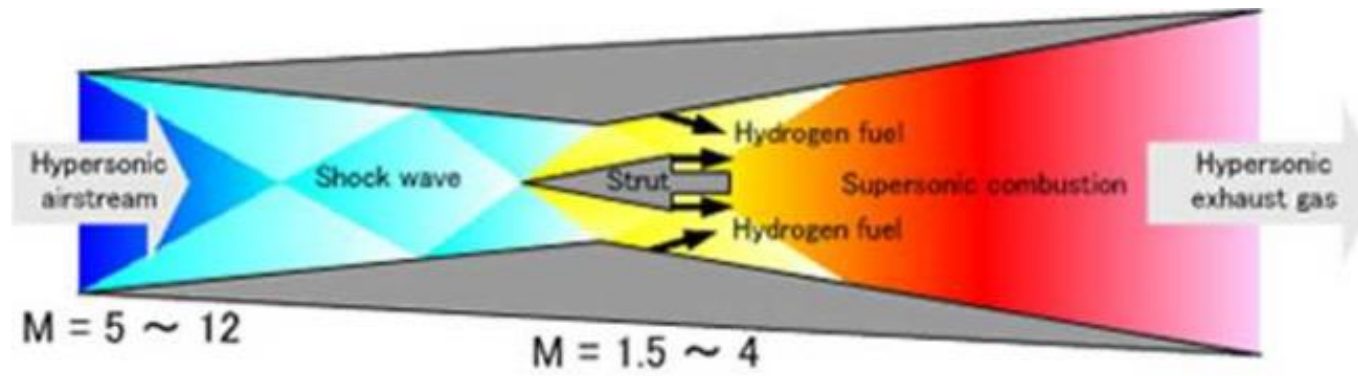

Figure 1-2 Scramjet engine [4].

A scramjet engine also consists of four major parts: inlet, isolator, combustor and nozzle. However, the combustion process happens at supersonic speed. 
Nevertheless, scramjet engines still present some drawbacks due to the basic requirements for an air breathing engine and the limits relating to high airspeed:

- Scramjet needs a working atmosphere dense enough to create large thrust, which places an upper bound constraint of the flight corridor for scramjet propelled vehicles.

- Scramjet propelled vehicles are not able to operate at a low altitude due to high thermal load on the aircraft structure when it flies at a very high speed.

- Scramjets are unable to produce static thrust and only become operationally efficient at supersonic Mach numbers, thus incapable of taking off on their own and they need high initial speed for air compression.

These constraints require a complex launch system for a scramjet vehicle. Such systems typically consists of a carrier aircraft (for take - off) and a rocket to bring the initial flight Mach number of the scramjet-powered aircraft to about Mach 5. Despite these disadvantages, scramjet engines are still seen as a bright prospect of hypersonic cruise and ascent to low-earth-orbit thanks to its light weight and airplane like operation [2].

\subsubsection{Dual-mode Scramjet Engine}

Curran and Stull introduced the idea of the dual-mode scramjet engine in 1963 [5]. Ramjet and scramjet engines differ from each other in the speed of the flow inside the combustor, subsonic for ramjet and supersonic for scramjet. The dual-mode scramjet combines these two flow characteristics in one combustor that can operate in both regimes depending on the airspeed of the aircraft, hence the name dual-mode scramjet. Therefore, the dual-mode scramjet has a wider operational Mach number range. This leads to increased application potential and the possibility of a hypersonic aircraft that can take off by itself with the help of a turbojet. This turbojet can be used to take the aircraft to about Mach 3, then the dual-mode scramjet can be used at higher airspeed. 


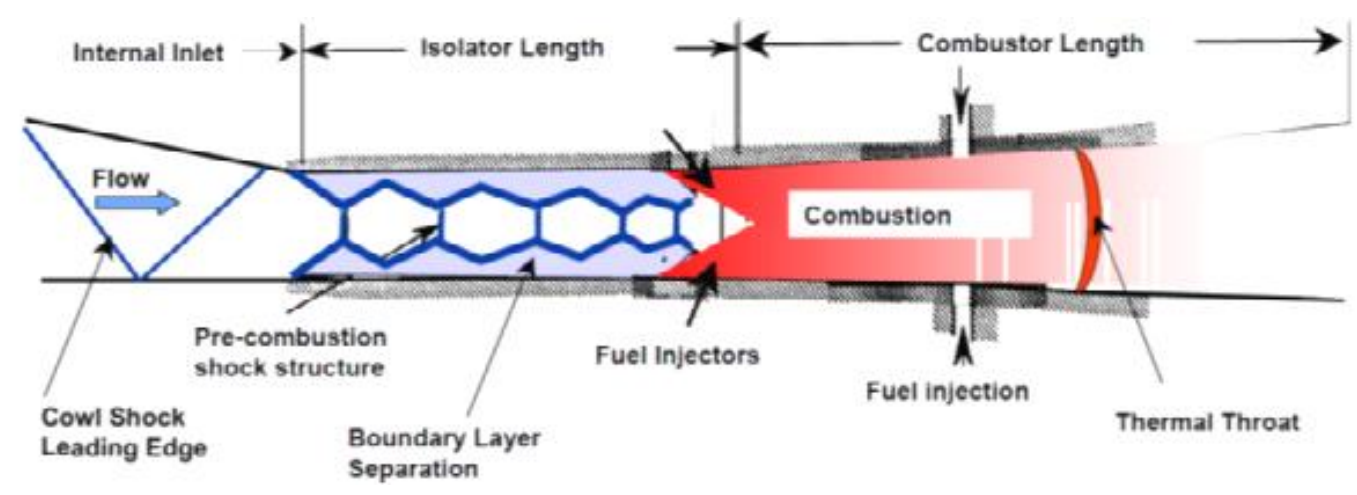

Figure 1-3 Dual-mode scramjet engine [3].

Nonetheless, the combination of the two flow regimes in one configuration introduces some complex phenomena in the isolator and the combustor, which lead to design and analysis challenges. The flow in the isolator has an intricate structure called the shock train, formed by the interaction between the inlet exhaust conditions and the combustor high back pressure, in conjunction with boundary layer separation. This separation region can spread into the combustor, rendering the flow analysis of this component more complicated as it switches from ramjet mode to scramjet mode. The overview of the operation of the isolator and the combustor in a dual-mode scramjet is described in the next section.

\subsection{Operation of Dual-mode Scramjet}

\subsubsection{Dual-mode Scramjet Combustor}

There are two major factors that determine flow properties in the combustor: heat addition and the change of the combustor area [1].

Regarding heat addition, the Rayleigh flow model shows that:

- At subsonic speed, the flow is accelerated by heat addition.

- At supersonic speed, the flow is decelerated by heat addition.

Regarding area change:

- At subsonic speed, the flow is decelerated as the area increases. 
- At supersonic speed, the flow is accelerated as the area increases.

In scramjet mode, flow enters the combustor at supersonic speed. It is then slowed down to a minimum speed and accelerated again all the way to the combustor outlet.

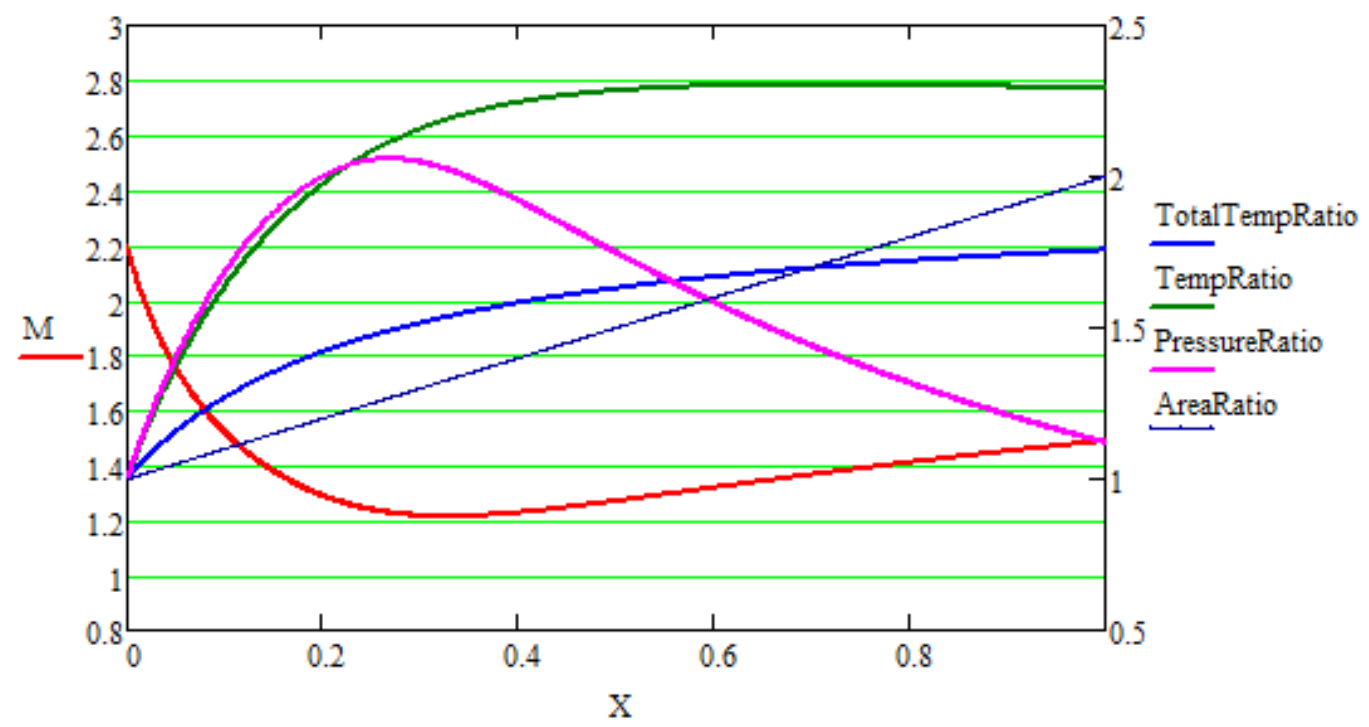

Figure 1-4 Typical changes in flow properties through the combustor in scramjet mode

[6].

To grasp a general view of these changes, let us divide the combustor into two regions: Region 1: from the front of the combustor to the point where the flow reaches its minimum speed, region 2: from that point to the back of the combustor.

In region 1 , the effect of slowing down a supersonic flow brought about by heat addition is dominant (note the high slope of the blue line) since it is closer to the fuel injectors. For that reason, the supersonic entry flow is decelerated.

In region 2, the rate of heat addition decreases substantially, thus, the effect of speeding up the flow from the increasing area becomes dominant. Therefore, the flow is accelerated. 
In the scramjet mode, the minimum speed of the flow is still in the supersonic regime, meaning the flow remains supersonic throughout the combustor.

When the minimum Mach number is equal to 1 , there is the transition between the two modes of the dual-mode scramjet engine.

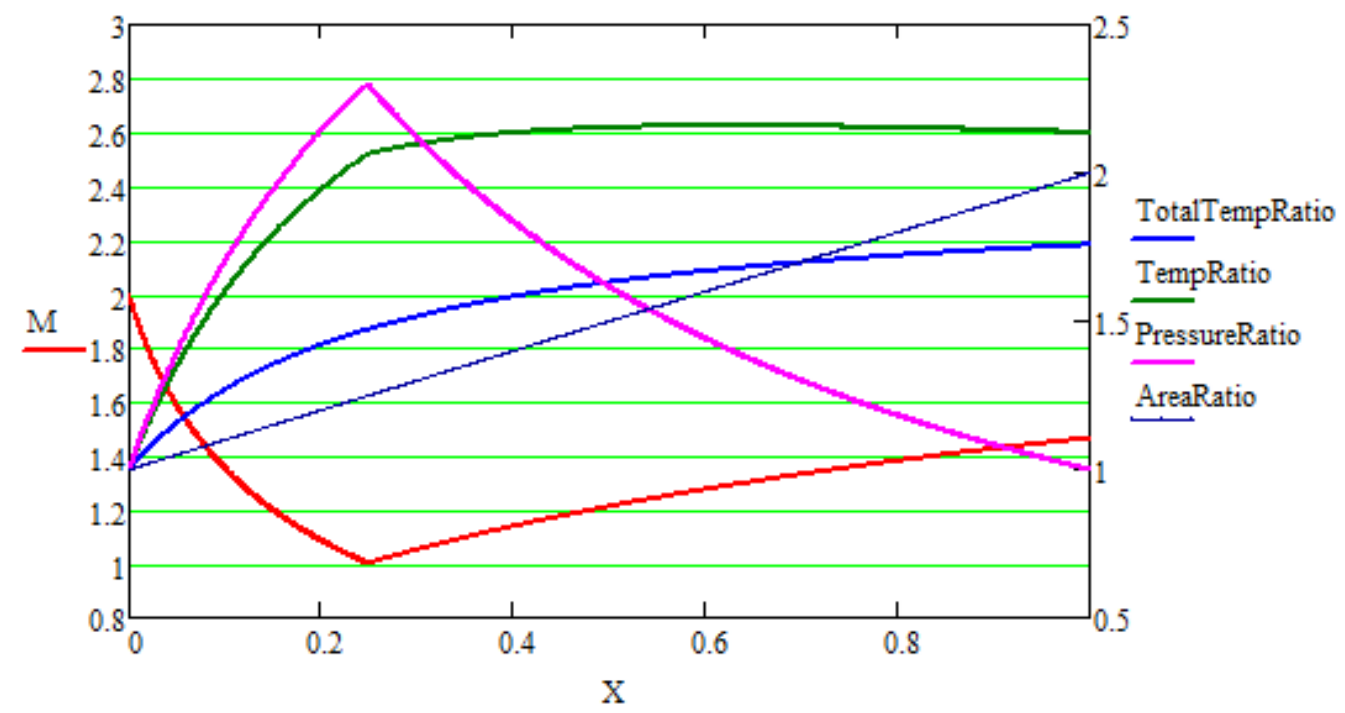

Figure 1-5 Typical changes in flow properties through the combustor in transition between ramjet and scramjet mode [6].

At this condition, the entry Mach number to the combustor is designated as $M_{3 m}$ [1].

In ramjet mode, the entry Mach number to the combustor is subsonic. Through the combustor, the flow is accelerated until it exits the combustor at supersonic speed. 


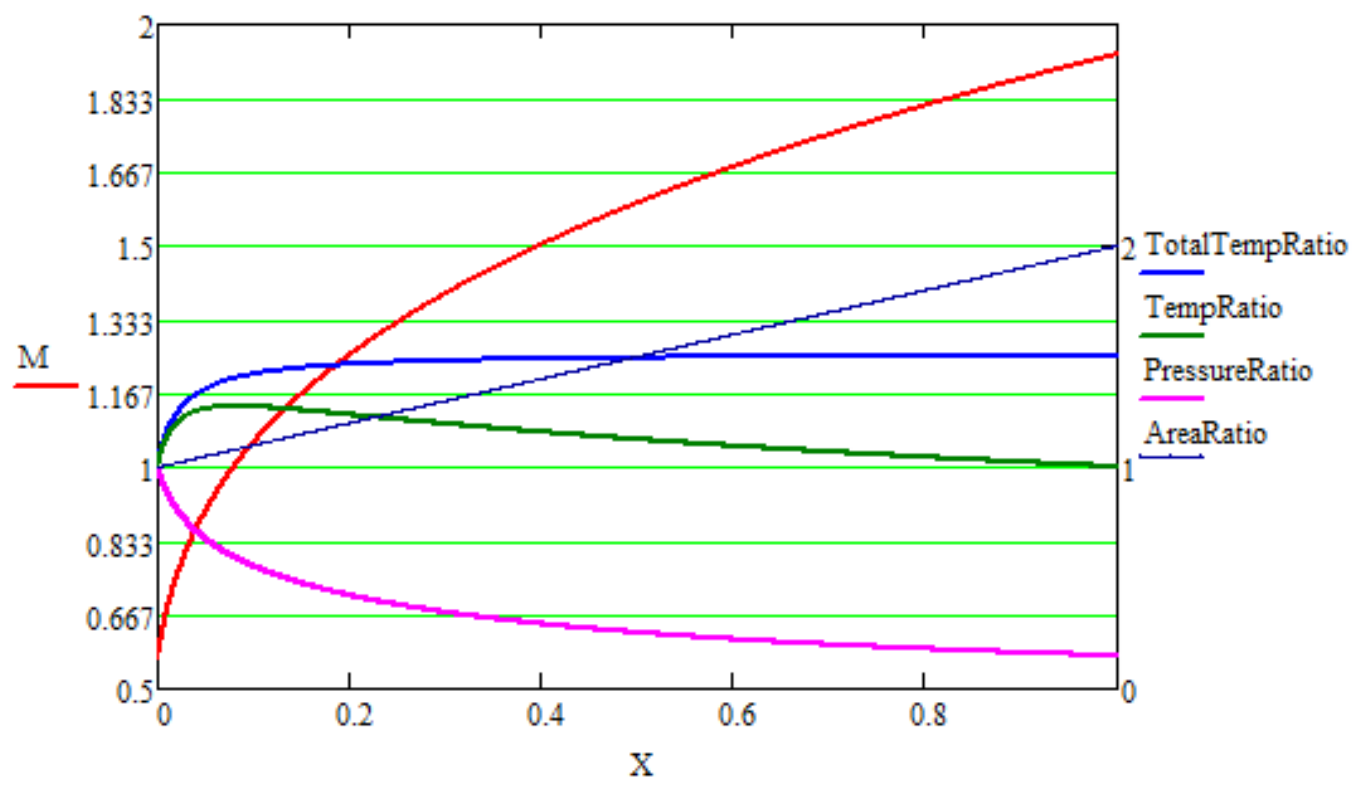

Figure 1-6 Typical changes in flow properties through the combustor in ramjet mode [6].

The combustor is divided again into two regions: Region 1: from the front of the combustor to the point where the flow reaches sonic speed, region 2: the remaining part of the combustor.

In region 1, the effect of speeding up subsonic flow caused by heat addition is dominant so the flow is accelerated.

In region 2, the flow enters supersonic regime and thus is slowed down by heat addition alone. However, as the rate of heat addition decreases substantially, the effect of the increasing area becomes dominant. Therefore, the flow continues to be accelerated.

At the sonic point, the flow experiences a similar phenomenon to its passage through a physical throat. However, this is brought about entirely by heat addition as there is no physical throat in a dual-mode scramjet combustor. The sonic point is, for that reason, called the thermal throat [1]. 
When calculating flow properties through the combustor, determining the position of the thermal throat is a critical task as it serves as a starting point to calculate flow properties at other points in the combustor.

Let us call the entry Mach number to the combustor $\mathrm{M}_{3 \mathrm{p}}[1]$.

\subsubsection{Dual-mode Scramjet Isolator}

The flow in the isolator will behave according to flow properties at the front (Station 2) and the back (Station 3) of the isolator.

It has been discovered that the isolator cannot operate with any arbitrary combination of flow properties at position 2 and 3; there is a limit. With a certain $\mathrm{M}_{2}$, the isolator cannot generate a $M_{3}$ below the value equal to the downstream Mach number of a normal shock wave with the upstream Mach number $M_{2}$ [1]. In other words, for a predetermined $M_{3 p}$, the condition under which the isolator and the whole engine can operate is $M_{2}>M_{2 x}$, with $M_{2 x}$ being the Mach number of the flow that will create the Mach number $M_{3 p}$ after a normal shock wave [1].

When the limit mentioned above is satisfied, the isolator can operate in either one of the three following modes:

- Shock free mode: This is the mode where flow properties are essentially unchanged all the way through the isolator and there is no shock train in the isolator.

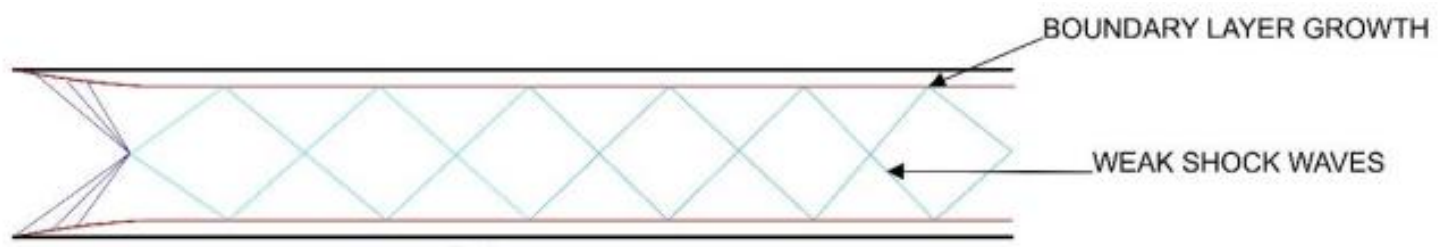

Figure 1-7 Shock free isolator [7].

- Oblique shock train mode: When $P_{3}$ is greater than $P_{2}$ but the difference between the two is not too great, an oblique shock train will form in the isolator. 


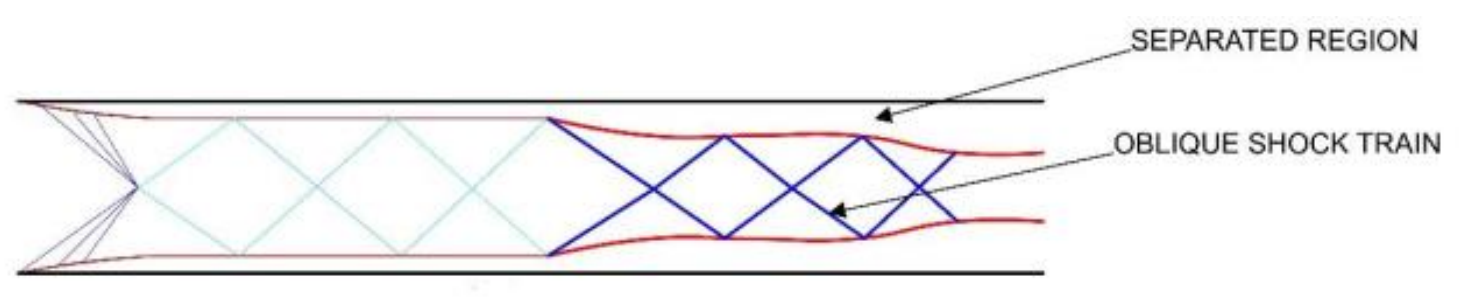

Figure 1-8 Isolator with oblique shock train [7].

- Normal shock train mode: When the difference between $P_{3}$ and $P_{2}$ is large enough, a normal shock train will form in the isolator.

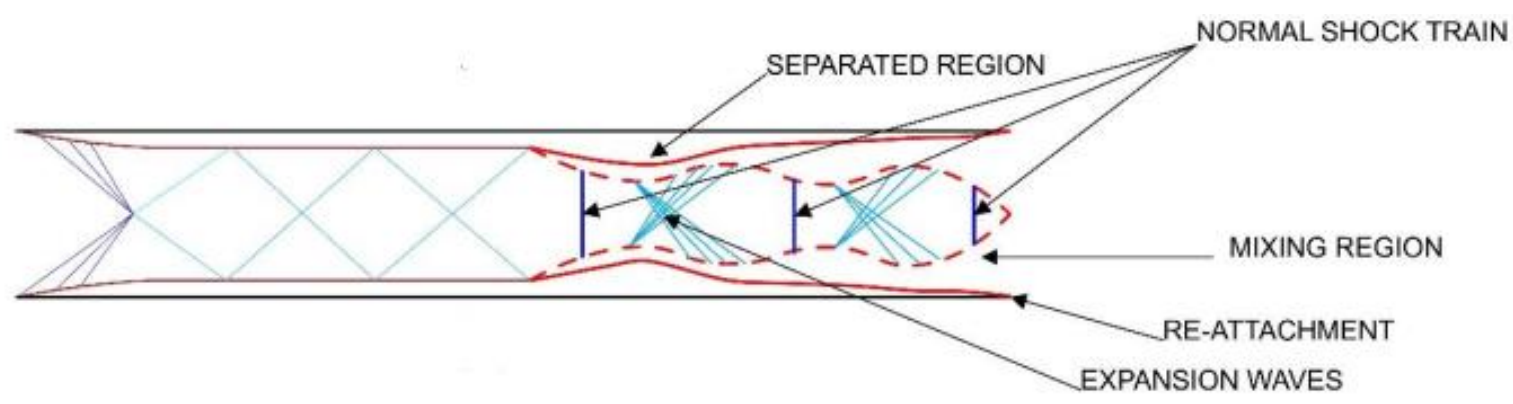

Figure 1-9 Isolator with normal shock train [7].

The operation of the dual-mode scramjet engine can be summed up as follows:

- When $M_{2}<M_{2 x}$, the engine cannot operate.

- When $M_{2}$ is between $M_{2 x}$ and $M_{3 m}$, the engine will operate in the ramjet mode.

- When $M_{2}>M_{3 m}$, the engine will operate in the scramjet mode.

\subsection{Development History}

The first scramjet development program was the NASA Hypersonic Research Engine (HRE) program which started in 1964, with about 52 tests completed [6]. After this, many other programs in several countries such as Russia, France and Germany also began. Three prominent projects with successful flight test were the HyShot program by the University of Queensland in Australia that marked the first flight of a scramjet propelled aircraft in July 2002 [6], the Hyper-X program [9] and the X-51 program [10]. 
The aircraft designed in the Hyper-X program is called X-43. It has made two successful flight tests, the first one took place on March 2004 with the aircraft reaching a speed of Mach 7 and the second one on November 2004. In this second flight, X-43 got to nearly Mach 10, which set a new speed record [7]. The X-51 program gave birth to the X-51A Waverider, whose final flight took place on May $1^{\text {st }}$ 2013. In this flight, the aircraft reached a top speed of Mach 5.1 and travelled on its own scramjet powered engine for four minutes, making the record for longest scramjet powered flight [12].The most recent project involving scramjets is the SR-72, the successor of the SR-71 Blackbird. SR-72 is a hybrid turbojet - scramjet propelled aircraft which is expected to enter service by 2030 [8]. 
Chapter 2

Literature Survey

There have been a number of studies which approach scramjet combustion with different analysis methods in the past. Presented in this section are some works on this subject in the literature. The focus is on the methods used for developing a quasi-onedimensional flow model of the flow through scramjet combustors and experimental results that will be used to validate the quasi-one-dimensional code.

\subsection{Theoretical Researches}

\subsubsection{Heiser and Pratt's Approach}

This approach is presented in the Hypersonic Airbreathing Propulsion book by William H. Heiser and David T. Pratt. The flow through the combustor is governed by the following ordinary differential equation (ODE) [1]:

$$
\frac{d M}{d x}=M\left(\frac{1+\frac{\gamma_{b}-1}{2} M^{2}}{1-M^{2}}\right)\left[-\left(\frac{1}{A} \frac{d A}{d x}\right)+\frac{1+\gamma_{b} M^{2}}{2}\left(\frac{1}{T_{t}} \frac{d T_{t}}{d x}\right)\right]
$$

This ODE is the result of Shapiro's generalized one-dimensional flow analysis in which the three conservation equations, the equation of state, Mach number and the second law of thermodynamics are algebraically manipulated with an ideal gas assumption into a set of ODE's, each of which is the derivative of a flow property such as Mach number, pressure, temperature, etc. calculated in terms of changes in area, mass flow rate, total temperature and the effects of friction and body forces $[4,11]$.

This governing Mach number equation demonstrates the main characteristics of the flow through a scramjet combustor, which is dictated by the two major driving terms: combustor area variation and total temperature distribution. However, it neglects the effects of wall friction, drag caused by internal struts or fuel jets and mass changes as 
fuel is being added and mixed into the flow [1]. Moreover, this equation doesn't take into account flow separation, which is an important behavior of the flow as the combustion process generates a high back pressure causing an adverse pressure gradient that separates the flow. Heiser and Pratt addressed this phenomenon by a constant impulse function method rather than incorporating it into the ODE $[1,4]$. Thus, the variation of the core flow area in the separation zone is unknown since no position variable is involved in the control volume analysis.

\subsubsection{Ram-Scram Transition and Flame/Shock-Train Interactions in a Model Scramjet}

\section{Experiment}

The flow model as presented in Heiser and Pratt's book is applied in this analysis to study the transition between ramjet and scramjet mode. In ramjet mode, the incoming flow to the combustor is at subsonic speed, therefore, it passes through the sonic point called the thermal throat situated inside the combustor. This point results in a singularity in equation (2.1) when the Mach number goes to 1 . The position of the thermal throat is determined by solving the following equation $[1,12]$ :

$$
\left(\frac{1}{A} \frac{d A}{d x}\right)=\frac{1+\gamma_{b}}{2}\left(\frac{1}{T_{t}} \frac{d T_{t}}{d x}\right)
$$

Equation (2.1) is used to solve in the upstream direction from the thermal throat for the Mach number at the entry of the combustor $M_{2}$. The static pressure at this position is then calculated by Heiser and Pratt's low-order model of the isolator [12]. Once $p_{2}$ is obtained, the following ODE, from Shapiro's work, is solved downstream from the thermal throat to determine the pressure profile of the combustor [12]:

$$
\frac{1}{p} \frac{d p}{d x}=\frac{\gamma M^{2}}{1-M^{2}} \frac{1}{A} \frac{d A}{d x}-\frac{\gamma M^{2}\left(1+\frac{1-\gamma}{2} M^{2}\right)}{1-M^{2}} \frac{1}{T_{t}} \frac{d T_{t}}{d x}
$$


Wall friction and mass addition are neglected and the gas is assumed to consist of a single species and to be calorically perfect [12]. Moreover, the flow is assumed to only separate inside the isolator, whereas, it has been found that separation zone also reaches inside the combustor [16].

\subsubsection{Hyshot Program}

This is another approach based on the classical quasi-one-dimensional gas dynamics by Shapiro [16]. This work was done as part of the HyShot program at the University of Queensland in Australia that has successfully launched a test flight on July $30^{\text {th }}, 2002[16]$.

Michael K. Smart developed a Mach number distribution ODE as Heiser and Pratt did but incorporated the effect of friction into the ODE. The following ODE is for the case where the back pressure is not high enough to cause flow separation [16]:

$$
\frac{d M^{2}}{M^{2}}=\frac{2\left(1+\frac{\gamma-1}{2} M^{2}\right)}{1-M^{2}} \frac{d A}{A}+\frac{\left(1+\gamma M^{2}\right)\left(1+\frac{\gamma-1}{2} M^{2}\right)}{1-M^{2}} \frac{d T_{t}}{T_{t}}+\frac{\gamma M^{2}\left(1+\frac{\gamma-1}{2} M^{2}\right)}{1-M^{2}} 4 C_{f} \frac{d x}{D}
$$

When the flow does separate, a new set of ODE's was used. The notable part of this approach is taking into account flow separation by introducing another variable $A_{c}-$ the core flow area. Another ODE for the distribution of the ratio between the core flow area and the geometric area was developed [16]:

$$
\begin{gathered}
\frac{d M^{2}}{M^{2}}=-\left(1+\frac{\gamma-1}{2} M^{2}\right)\left(\frac{d p / p}{\frac{\gamma M^{2}}{2} \frac{A_{c}}{A}}+\frac{4 C_{f} \frac{d x}{D}}{\frac{A_{c}}{A}}+\frac{d T_{t}}{T_{t}}\right) \\
\frac{d\left(A_{c} / A\right)}{A_{c} / A}=\left\{\frac{1-M^{2}\left[1-\gamma\left(1-A_{c} / A\right)\right]}{\gamma M^{2} A_{c} / A}\right\} \frac{d p}{p}+\left[\frac{1+(\gamma-1) M^{2}}{2 A_{c} / A}\right] 4 C_{f} \frac{d x}{D}+\left(1+\frac{\gamma-1}{2} M^{2}\right) \frac{d T_{t}}{T_{t}}
\end{gathered}
$$


This new ODE in conjunction with the Mach number distribution ODE are to be solved simultaneously by a numerical method. In order to do so, the pressure distribution term in equation (2.5) and equation (2.6) needs to be an explicit term. It is defined by the following empirical formula developed by Ortwerth [17, 18]:

$$
\frac{d p}{d x} \approx \frac{89}{D_{H}} C_{f 0}\left(\frac{\rho u^{2}}{2}\right)
$$

This model is a lot more comprehensive than the previous one, therefore, offers more accurate results and better captures the physics of the flow inside a scramjet combustor. Nonetheless, it still uses the ideal gas assumption whose accuracy decreases when the temperature in the combustor becomes higher at faster air speed.

\subsection{Experimental Researches}

\subsubsection{Free Piston Shock Tunnel Experiment at University of Queensland - T4 Scramjet:}

The free piston shock tunnel uses a free piston to adiabatically compress the driver gas. A shock wave propagates and reflects from the end wall of the shock tube after the primary diaphragm rupture. This creates a high enthalpy test gas inside the reservoir. The enthalpy and pressure of the gas in the reservoir can reach up to 2-15 $\mathrm{MJ} / \mathrm{kg}$ and 10-80 MPa respectively [16]. The test gas is fed into a nozzle downstream of the shock tube, where supersonic or hypersonic flow is generated. The duration of such flow to the test section can reach up to several milliseconds [16].

In order to achieve flows of different Mach number of $4,6,8$ and 10 , several axisymmetric hypersonic nozzles with different exit to throat area ratios are used. For the conducted experiment, the Mach 4 nozzle is used [16]. The flow passes through a pair of wedges with parallel side plates, then goes through a short duct forming a throat of Mach 2.5. Downstream of this section is the start of the scramjet combustor, where the fuel injector is situated [16]. 


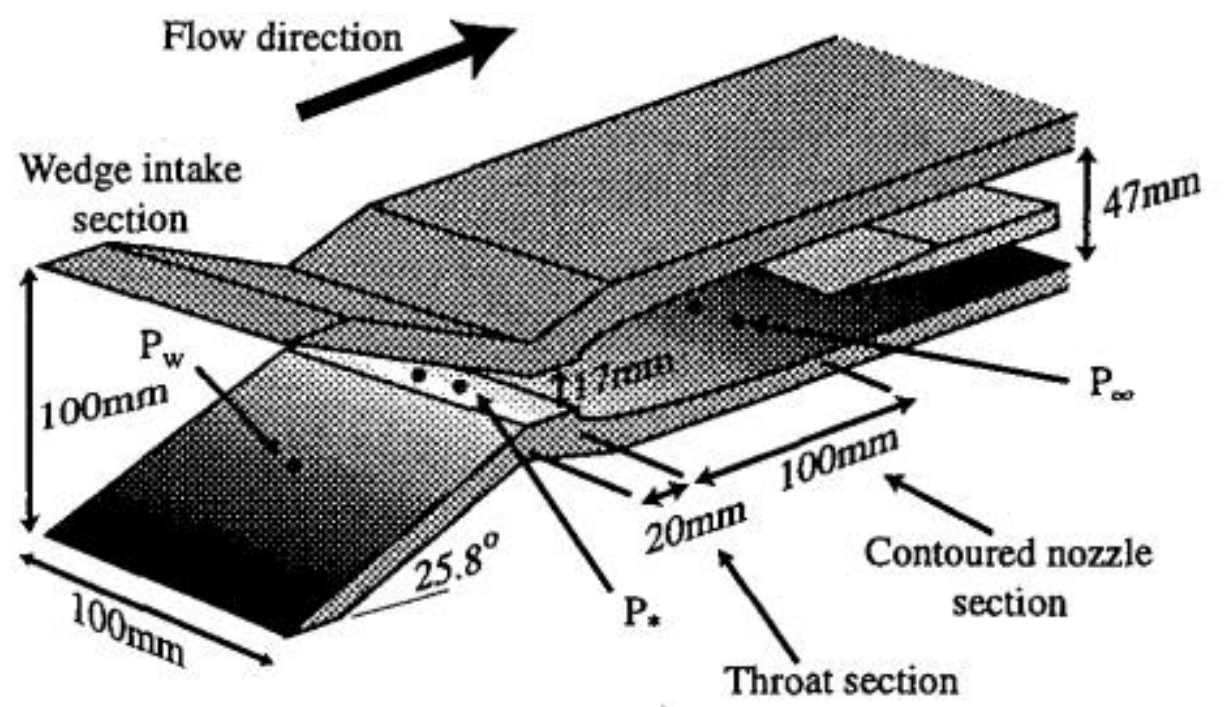

Figure 2-1 T4 scramjet inlet configuration [16].

This configuration generates a supersonic flow of Mach 2.5 with a total pressure of $1 \mathrm{MPa}[16]$.

Pressure transducers are used to measure the wall pressure. There are 35 pressure transducers $20 \mathrm{~mm}$ apart of one another [16].

\subsubsection{Hyshot 2 Scramjet Flight Experiment}

The Center of Hypersonic at the University of Queensland has conducted scramjet testing in the Mach 7 to Mach 8 range in shock tunnels for many years [17]. A simplified combustor designed based on the shock tunnel testing is used for two flight tests which took place at the Woomera Prohibited Area Test Range in central Australia [17]. The first flight test was on October $30^{\text {th }} 2001$ but was a failure, a second successful launch followed on July $30^{\text {th }} 2002[17]$.

The test flights implement a two-stage Terrier-Orion Mk70 rocket as the booster, bringing the payload and the second stage Orion motor to a maximum altitude of more than $300 \mathrm{~km}$ [17]. The payload and the second stage motor follow a parabolic 
trajectory and reenter the atmosphere at 25 to $35 \mathrm{~km}$ with the speed of above Mach 7.5

[17]. The reentry provides a useful flight conditions to test the scramjet combustor.

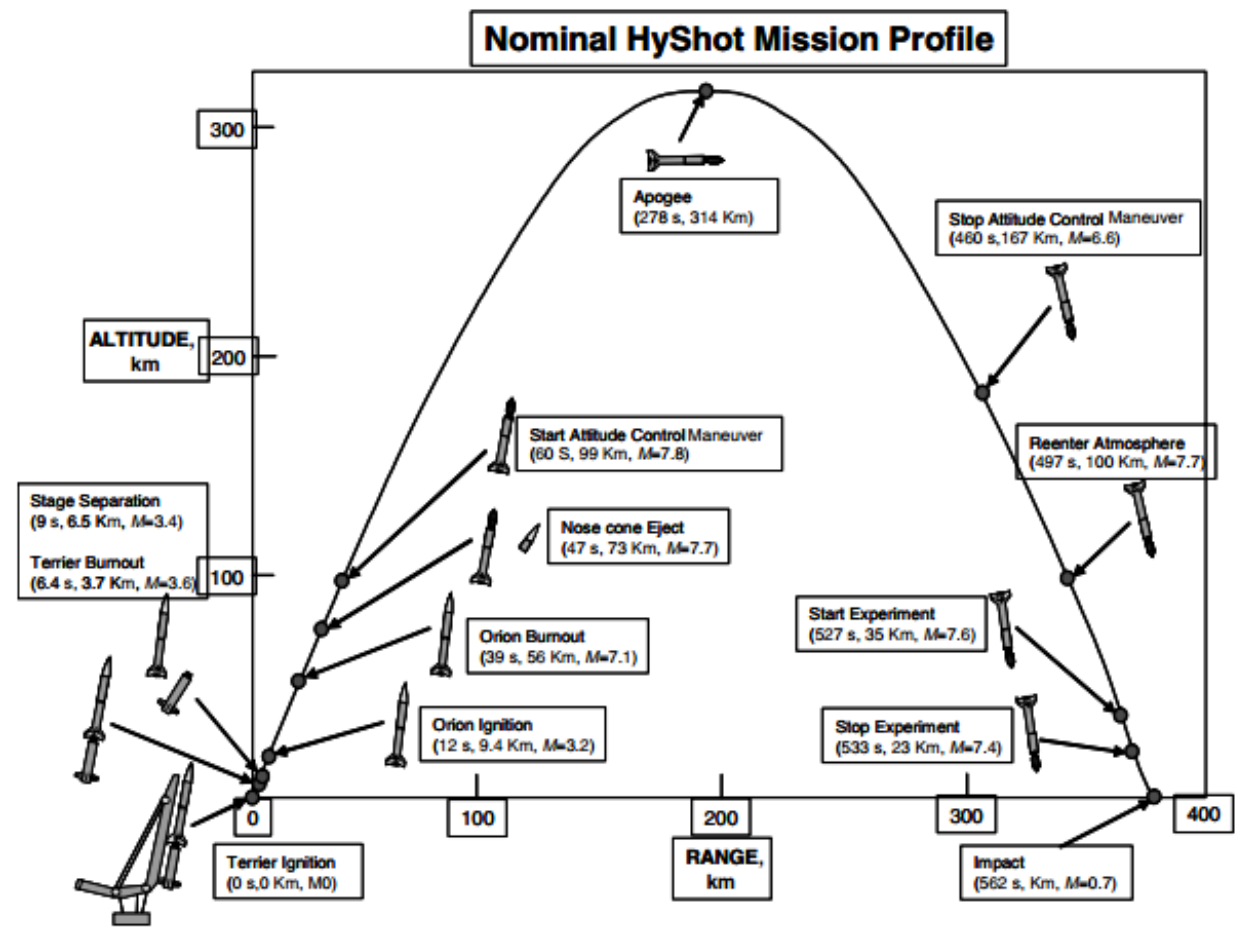

Figure 2-2 Hyshot flight profile [17].

The pressure transducers in use are SenSym $19 \mathrm{C}$ series and SenSym $13 \mathrm{~mm}$ series. There are in total 14 pressure measurements along the wall of the combustor. 13 of which are on the center line starting at $103.6 \mathrm{~mm}$ from the combustor entrance and 22 $\mathrm{mm}$ apart of each other. Another measurement is made $25 \mathrm{~mm}$ offset from the center line, $290.6 \mathrm{~mm}$ from the combustor entrance [17]. 


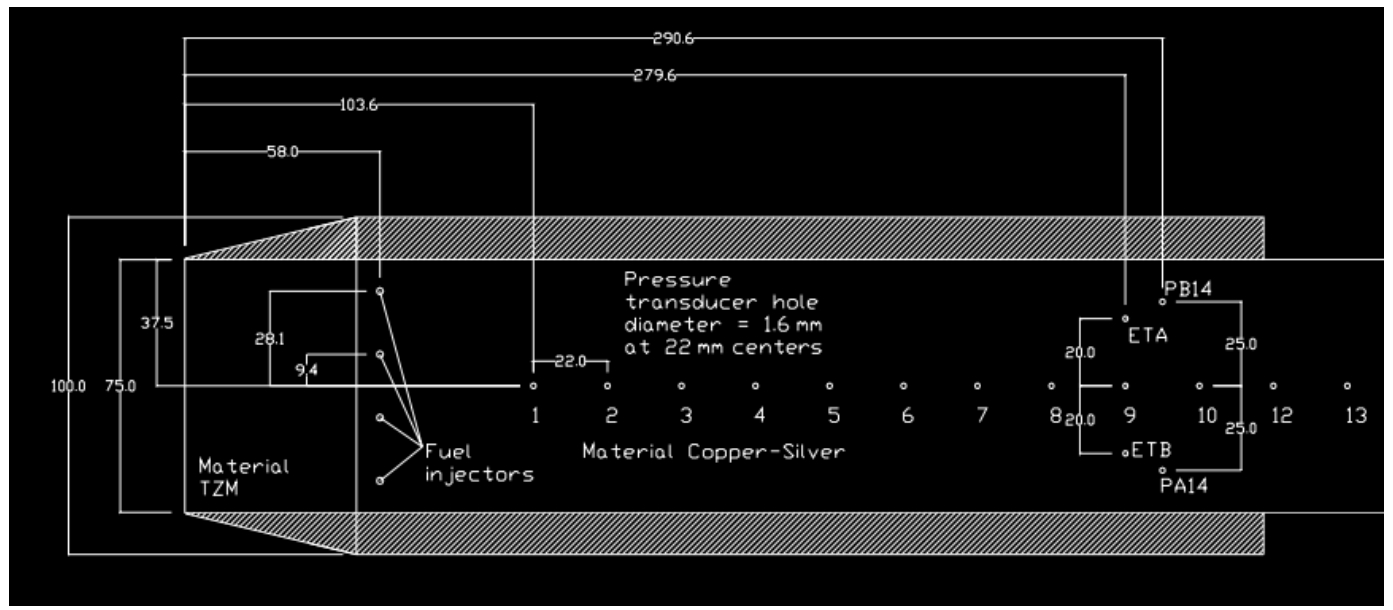

Figure 2-3 Combustor instrumentation layout [17].

Data are sampled approximately every 2 milliseconds through 48 analog and 4 digital channels [17].

\subsubsection{Investigation of the Isolator Flow of Scramjet Engines}

This research performs the experiments involving flow through a scramjet isolator. The experiments are done in the reflected shock tunnel TH2 at the Shock Wave Laboratory. Helium is used as the working gas [18].

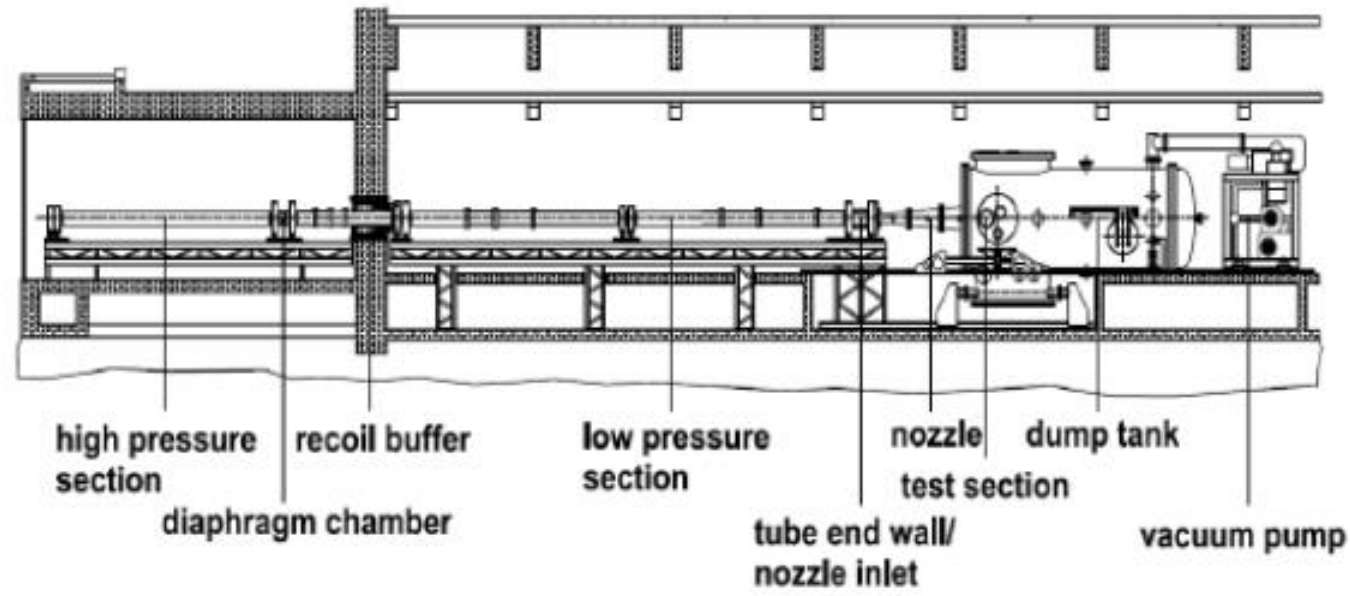

Figure 2-4 Drawing of the hypersonic shock tunnel TH2 [18]. 
The TH2 shock tunnel comprises of three major sections: the high pressure section, the low pressure section and the nozzle \& test section. The high pressure section and the low pressure section function as a shock tube that drives the test gas. The test gas is accelerated through the nozzle to the required Mach number in the test section [18].

Pressure probes prove to provide signal that is much more suitable to determine the flow structure inside the isolator [18]. Kulite XCQ-080 pressure transducers are used in the experiment. These pressure transducers have small membrane diameter of 0.7 $\mathrm{mm}$, thus, their natural frequency is relatively high, ranging from 300 to $500 \mathrm{kHz}$, which makes them suitable for short measurement time of approximately 1 millisecond [18].

Probes with operating range of $1.7,7$ and 17 bar are needed for the experiment. 17 bar probes are used in the pitot rake, 7 bar probes are used to measure wall pressure in the shock train region and 1.7 bar probes are used in the upstream region of the isolator [18]. 


\section{Chapter 3}

The Numerical Propulsion System Simulation (NPSS)

This chapter provides a description of the Numerical Propulsion System Simulation (NPSS) - the platform of the quasi-one-dimensional scramjet combustor code.

\subsection{Introduction of NPSS}

The simulation of a propulsion system is an intricate process that involves numerous phenomena from different disciplines. A software devoted to this task needs to not only have the ability to perform analysis with a low order of fidelity at system level to achieve basic understanding of the whole system without having to establish a geometry, but also be capable of zooming to a high enough level of fidelity to accurately simulate the phenomena happening within each component. In addition, the interaction between disciplines must be taken into consideration.

While a full system simulation with high order of fidelity will eventually give detailed results that capture the entire physics of the system, it requires a large amount of computational resources and takes a long time to reach the final results. For this reason, it is complicated and unwieldy for establishing a basic understanding of the system in question [1]. Low order cycle analysis, on the other hand, will provide fast and simple results that are essential for preliminary analysis of the system. These can also help anticipate possible problems that will occur during subsequent detailed design process [19].

The capability of zooming into different components with different levels of fidelity is called multifidelity analysis. An example of multifidelity analysis is shown in Figure 3-1, where the high pressure core of the engine (i.e. compressor, combustor and turbine) is modeled as a zero-dimensional, aerothermodynamic cycle analysis that is conducted through the use of component performance maps and the low pressure subsystem (i.e. 
inlet, fan, core inlet, bypass duct, nozzle) is modeled in 3-dimensions using a CFD turbomachinery code [20].

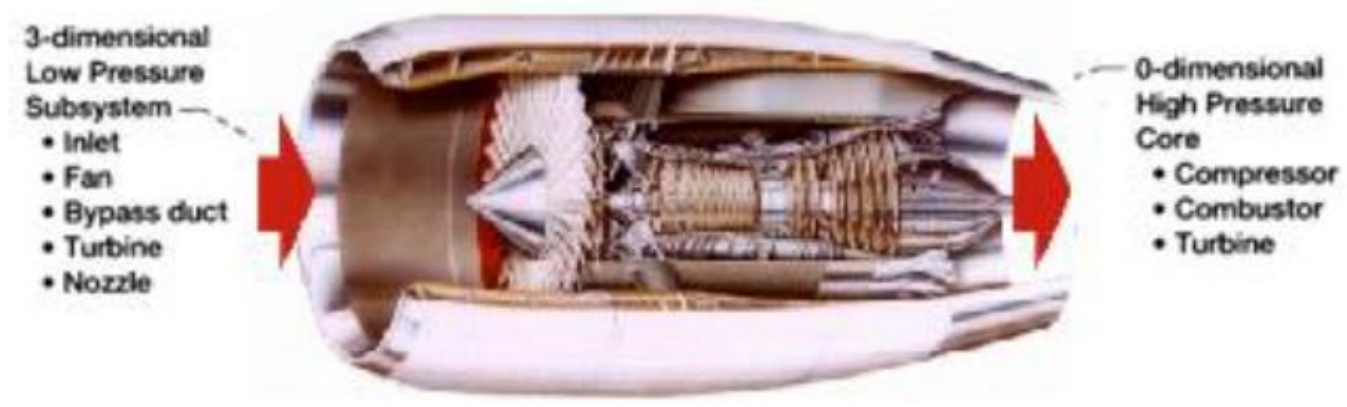

Figure 3-1 Hybrid Simulation: 3-Dimensional Low Pressure Subsystem Model Coupled to a 0-Dimensional High Pressure Core Model [20].

This can be done by isolated analysis, however, the interactions that occur between components can eventually be masked by the limited communication between teams or the codes which perform the individual numerical analysis [21]. When working with today's highly integrated propulsion systems where multidisciplinary issues can decrease drastically the overall system performance, this can introduce vital problems [21]. Thus, it is important that multifidelity analysis be performed by one unique software that handles all the components in order to ensure communication between components.

The physical processes that take place in an air-breathing gas turbine engine involves multiple disciplines [20]. For instance, the variations in the geometry of the highpressure compressor (casing, blade shape, tip clearances, etc.) that affect the efficiency and stability of the compressor is determined by aerodynamic, structural, and thermal loadings. In order to accurately predict the stall margin, simulation of all of these loadings is required [20]. As a result, to accurately simulate these processes, the coupling of all involved disciplines needs to be accounted for. 
The Numerical Propulsion System Simulation (NPSS) is a multidisciplinary, multifidelity computational simulation tool that meets all the above requirements. NPSS was developed by NASA in conjunction with other Government agencies, industries and universities [22]. It serves as a "virtual wind tunnel" that allows the engine manufacturer to find key design parameters early in the development process by performing detailed full engine simulations. The use of NPSS could cut the design and development time and cost by 30 to 40 percent, which is equivalent to $\$ 100$ million per year of development, as estimated by a major engine manufacturer [22].

NPSS brings about the following advantages: 1) minimize the expense for maintaining numerous software systems, 2) ameliorate multidisciplinary team work by granting all disciplines access to tools and system simulation capability, 3) facilitate collaboration by providing the industry with a common platform for engine system simulation, and 4) contain all engine design and operational data in one data base connected to the system simulation [23].

Alongside gas turbine engines, NPSS usage has also been expanded other fields such as spacecraft applications and energy applications.

\subsection{NPSS Simulation Environment}

The multidisciplinary framework of NPSS is illustrated in Figure 3-2, where three primary characteristics of the simulation environment: discipline coupling, component integration and zooming are shown. This framework allows an engineer to "plug and play" or "substitute at will" the components of an engine with any combination of $0,1,2,3$ dimensional component codes [24]. 


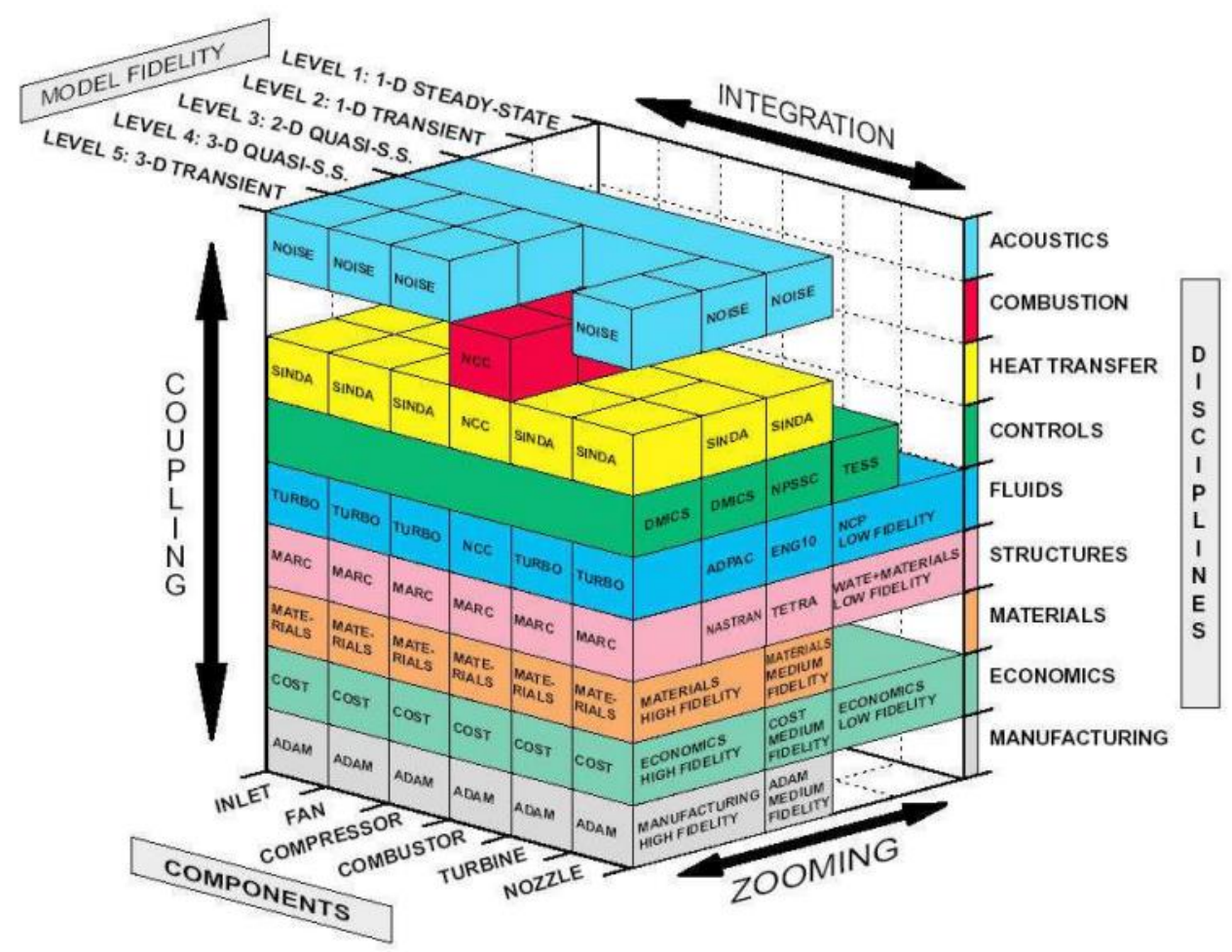

Figure 3-2 Illustration of the NPSS Multidisciplinary Framework [21].

Traditionally, the interaction between different disciplines is handled in a sequential fashion, with the use of translators to transfer and translate information from one discipline to the next. This is however lengthy, tedious and often inaccurate [20]. Three coupling techniques are investigated to be included in NPSS: loosely coupled, process coupled and tightly coupled. Loosely coupled is a rationalized version of the traditional approach. A component's aero, thermal and structural response is determined by separated programs. Then these data are coupled together by a set of generic translators and a subroutine library [20]. In process coupling, component codes are run under the control of an automated higher level system, the exchanged information between the codes is also managed by this system [20]. Tightly coupling connects the 
disciplines at a fundamental equation level. The matrix representing the whole system is solved simultaneously by implicit methods [20].

\subsection{NPSS Components}

\subsubsection{Architecture, code language and basic objects}

NPSS is built on an object-oriented architecture enabling an engineer to numerically assemble a propulsion system where component codes may have different dimensionality (Numerical Zooming), and different disciplines (Multi-Discipline coupling) from one another [24]. This architecture is illustrated in Figure 3-3. It takes advantage of the abilities of object-oriented programming (inheritance, polymorphism, and encapsulation) and modern object-oriented concepts such as frameworks, component objects, and distributed object standards [24]. There are three main areas: Interface Layer, Object Layer and Computing Layer. Within the Interface Layer, there is a command and a visual interface. The Object Layer is comprised of the fundamental engineering specifics and support objects for propulsion systems such as geometry and legacy FORTRAN codes that have been used by many companies. The Computing Layer carries out propulsion system simulations [24]. 


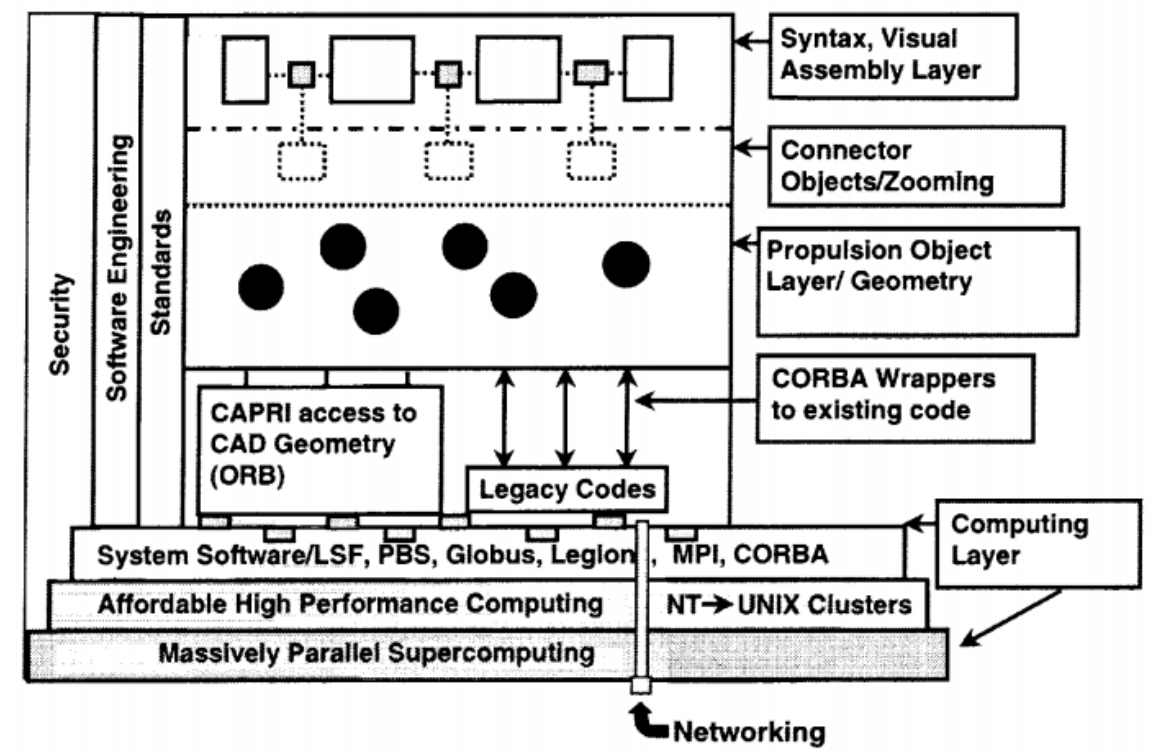

Figure 3-3 NPSS Object-Oriented Open Architecture [22].

NPSS utilizes a C++ type object-oriented programming language [25], with the following attributes: 1) maximum code reusability, 2) clear data connectivity, and 3) code modularity [20]. The problem can be divided into objects that consist of useful data and methods (functions) [26]. The basic objects used for a 0 and 1-dimensional analysis are: 1) elements, 2) subelements, 3) flow stations, 4) ports and 5) tables [24]. This object structure allows NPSS to have a wide range of applications amongst air breathing, rocket, fuel cell and ground based power propulsion and more by creating new functional objects for each particular application [24].

Elements are the building blocks of a model in NPSS. They account for the major components of the system [27]. Each element is a $\mathrm{C}++$ code can exchange data with each other [28]. An element can have subelements: element-like objects built to provide supporting data to the object they accompany [27]. NPSS has various built-in elements like Ambient, Compressor, Burner, Turbine, Nozzle, Shaft, etc... [29] and subelements such as CompressorRlineMap, TurbinePRmap, BurnEfficiency, ThermalMass, etc... [29]. 
Users can also define their own elements and subelements that are suitable for their model. Flow stations are found between elements. Elements communicate with one another through input and output ports that control the data flow through links. Elements may have none or an appropriate number of ports needed for their usage [27]. Functions and tables can also be written to execute special calculations [27].

Figure 3-4 shows an example of a turbojet model in NPSS. The square boxes represent the elements of this model. In this example, the compressor and turbine elements each have a subelement that would look up compressor and turbine map to provide off-design performance data to the element via sockets in the off-design case simulation [27]. The elements are connected together by links represented by the arrows pointing one port to another.
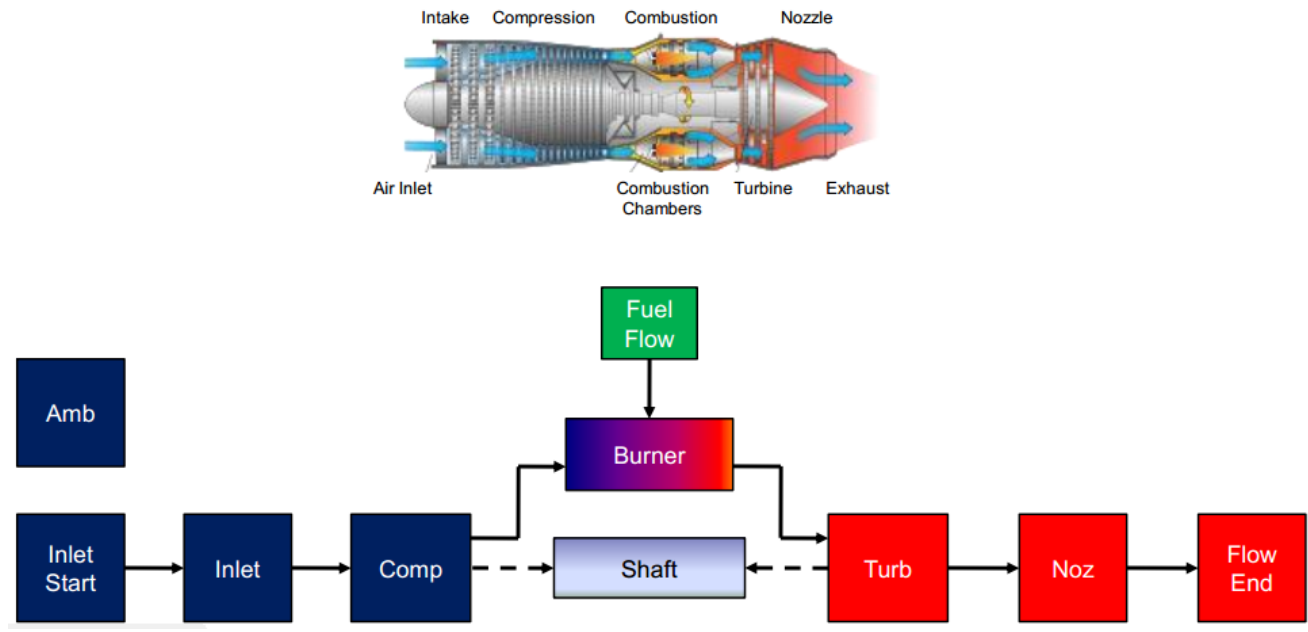

Figure 3-4 NPSS Turbojet Model [25].

\subsubsection{Thermodynamic packages}

NPSS provides a number of thermodynamic packages which can be defined by users at run time [19]. The thermodynamic packages store a database of the properties of single as well as mixtures of gases. These databases are used in the process of thermodynamic analysis and are collected from leading aerospace companies. The 
thermodynamic package is able to perform thermodynamic calculation at molecular level of the flow under extreme conditions such as gas vibration and dissociation [19]. There are six thermodynamic packages available in NPSS: 1. GasTbl - Pratt \& Whitney air \& fuel properties, 2. allFuel/GEFluid - General Electric air \& fuel properties, 3. Janaf Honeywell implementation of JANAF package, 4. CEA - NASA's Chemical Equilibrium Analysis package, 5. FPT - User customizable package, 6. REFPROP - Interface to NIST package [30].

\subsubsection{Solver}

The simulation process of a NPSS model involves solving the conservation equations of mass, energy, and momentum [31]. In the example of a gas turbine engine, some other interdependent equations also need to be solved and often time in an implicit fashion [27]. Moreover, to allow users to study the effect of important design parameters, the particular values that meet a desired condition are to be determined [31]. These are the jobs of the NPSS solver. Figure 3-5 illustrates its operation. The basic solution method is varying a set of independent inputs iteratively until an equal number of equations are satisfied [30].

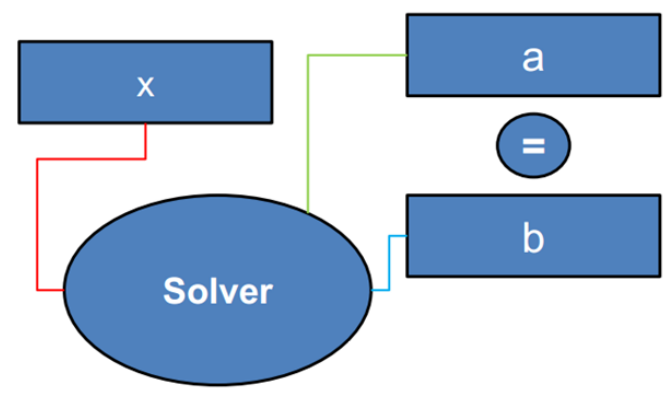

Figure 3-5 Basic NPSS Solver Operation [30].

Two typical examples of solver operation during the simulation process of a gas turbine engine are varying fuel-to-air ratio to match a given turbine inlet temperature as this is one of the key design parameters determined a priori based on the level of 
technology of the turbine (the material of the turbine blades); varying incoming air flow rate to obtain a desired value of engine net thrust. This operation is also called engine sizing: for a specific thrust requirement, the engine needs a high enough air flow rate to produce such amount of thrust and this in turn determines the diameter of the engine. 


\section{Chapter 4}

Quasi-one-dimensional Scramjet Isolator and Combustor Model

A quasi-one-dimensional analytical model that is simple enough to reduce the computational resources and time but is still able to capture the complex physics of the flow in a scramjet isolator and combustor is described in this chapter.

\subsection{Assumptions}

The following assumptions are made:

- The flow is quasi-one-dimensional, all parameters are either non dimensional or the axial position is the only independent spatial variable.

- Steady flow is assumed.

- The working gas is in thermodynamic and chemical equilibrium.

- Body forces are neglected.

\subsection{Conservation Equations}

The conservations equations are formed based on an elemental control volume inside the combustor as shown in Figure 4-1:

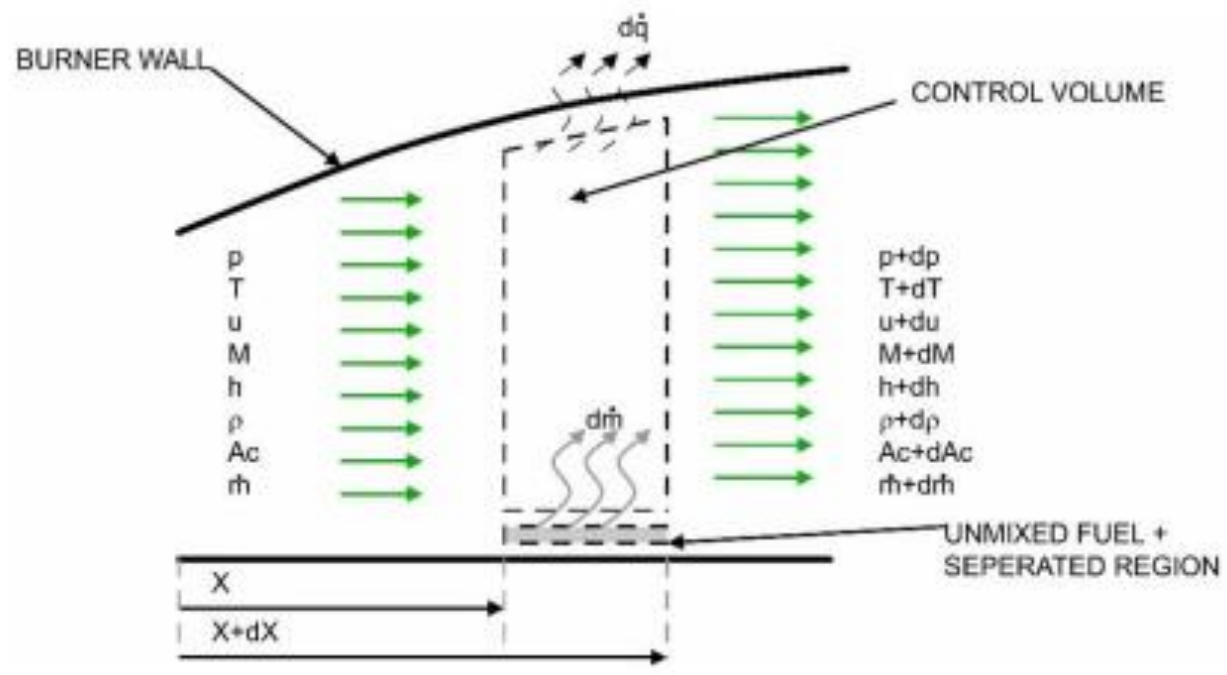

Figure 4-1 Schematic of elemental control volume for burner analysis [7]. 


\subsubsection{Conservation of Mass}

The conservation equation of mass is given by:

$$
\dot{m}=\rho u A_{c}
$$

Where the core flow area can be determined as the geometric area minus the separation area and the area of the fuel jet [7]:

$$
A_{c}=A-A_{\text {sep }}-A_{\text {jet }}
$$

\subsubsection{Conservation of Momentum}

The conservation equation of momentum is expressed in form of the change of static pressure across the elemental control volume $[1,11,7]$ :

$$
\frac{d p}{d x}=-\rho u \frac{d u}{d x}-\frac{u-u_{f x}}{A_{c}} \frac{d \dot{m}}{d x}-\frac{1}{2} \rho u^{2} C_{f} \frac{A_{w}}{A d x}
$$

Let $I_{m}$ be:

$$
I_{m}=-\frac{u-u_{f x}}{A_{c}} \frac{d \dot{m}}{d x}-\frac{1}{2} \rho u^{2} C_{f} \frac{A_{w}}{A d x}
$$

Therefore:

$$
\frac{d p}{d x}=-\rho u \frac{d u}{d x}+I_{m}
$$

\subsubsection{Conservation of Energy}

The change in the enthalpy of the flow is due to the heat added by the burnt fuel and the heat flux through the combustor wall. This is the conservation of energy $[1,7]$ :

$$
\frac{d h}{d x}=-u \frac{d u}{d x}-\left(h+\frac{u^{2}}{2}-h_{t f}\right) \frac{1}{\dot{m}} \frac{d \dot{m}}{d x}+\frac{\dot{q}_{n f} A_{w}}{\dot{m} d x}
$$

Let $I_{e}$ be: 


$$
I_{e}=-\left(h+\frac{u^{2}}{2}-h_{t f}\right) \frac{1}{\dot{m}} \frac{d \dot{m}}{d x}+\frac{\dot{q}_{n f} A_{w}}{\dot{m} d x}
$$

We have:

$$
\frac{d h}{d x}=-u \frac{d u}{d x}+I_{e}
$$

Written in terms of total enthalpy, equation (4.8) becomes:

$$
\frac{d h_{t}}{d x}=I_{e}
$$

We now have the three conservation equations which serve as the basis for the quasi-one-dimensional analytical model. The modification that needs to be made accordingly to each component will be described in the following sections.

\subsection{Combustor Analytical Model}

\subsubsection{Algebraic Manipulation Involving the Conservation Equations}

First, take the derivative of the conservation equation of mass, from equation (4.1), we obtain:

$$
\frac{d u}{d x}=-\frac{u}{A_{c}} \frac{d A_{c}}{d x}-\frac{u}{\rho} \frac{d \rho}{d x}+\frac{u}{\dot{m}} \frac{d \dot{m}}{d x}
$$

Substitute the derivative of flow velocity into equation (4.5) and (4.8):

$$
\frac{d p}{d x}=\frac{\rho u^{2}}{A_{c}} \frac{d A_{c}}{d x}+u^{2} \frac{d \rho}{d x}-\frac{\rho u^{2}}{\dot{m}} \frac{d \dot{m}}{d x}+I_{m}
$$

and:

$$
\frac{d h}{d x}=\frac{u^{2}}{A_{c}} \frac{d A_{c}}{d x}+\frac{u^{2}}{\rho} \frac{d \rho}{d x}-\frac{u^{2}}{\dot{m}} \frac{d \dot{m}}{d x}+I_{e}
$$

As a common procedure in CEA, the derivative of each flow property can be calculated from those of static pressure and static temperature. In this case, the usage of static enthalpy as one of the independent variables instead of static temperature proves 
to be more convenient as we already establish an equation involving the rate of change of static enthalpy. In addition, another independent variable is introduced because there is fuel added and burnt in the flow. The third independent variable is the equivalence ratio $\phi$.

The derivative of density can be written as follows:

$$
\frac{d \rho}{d x}=\frac{\partial \rho}{\partial p} \frac{d p}{d x}+\frac{\partial \rho}{\partial h} \frac{d h}{d x}+\frac{\partial \rho}{\partial \phi} \frac{d \phi}{d x}
$$

Each of the three partial derivatives is calculated using the finite difference method.

Substitute equation (4.13) into equations (4.11) and (4.12), we will have a system of two equations in which $\frac{d p}{d x}$ and $\frac{d h}{d x}$ are treated as unknowns. Solving for these two quantities and combining them with equation (4.9), we arrive at three equations of the following forms:

$$
\frac{d p}{d x}=f\left(p, h, h_{t}\right)
$$

and:

$$
\frac{d h}{d x}=f\left(p, h, h_{t}\right)
$$

and:

$$
\frac{d h_{t}}{d x}=f\left(p, h, h_{t}\right)
$$

These are the ultimate forms that can be solved numerically by the $4^{\text {th }}$ order Runge-Kutta marching scheme, which will be outlined in the next section. 


\subsubsection{Friction Coefficient}

The reference temperature method is used to determine the friction coefficient and later the wall heat flux.

First, we need to determine if the flow is laminar or turbulent. This is done by comparing the Reynolds number of the flow to the transition Reynolds number $\operatorname{Re}_{T}$ which is computed as follows [7]:

$$
\log \left(\operatorname{Re}_{T}\right)=6.421 \exp \left(1.209 \times 10^{-4} M^{2.641}\right)
$$

If the flow Reynolds number is higher than the transition Reynolds number, it is turbulent, otherwise, it is laminar.

The second step is to compute the reference temperature.

- $\quad$ For laminar flow [7]:

$$
T^{*}=0.45 T+0.55 T_{W}+\frac{0.16 \operatorname{Pr}^{0.5}(\gamma-1) T M^{2}}{2}
$$

- For turbulent flow [7]:

$$
T^{*}=0.5 T+0.5 T_{W}+\frac{0.16 \operatorname{Pr}^{1 / 3}(\gamma-1) T M^{2}}{2}
$$

where: $T_{W}$ is the wall temperature and $\operatorname{Pr}$ is the Prandtl number.

Thirdly, the reference Reynolds number is calculated as follows [7]:

$$
\operatorname{Re}^{*}=\frac{\rho^{*} u D}{\mu^{*}}
$$

The reference density and viscosity are assumed to vary with temperature and are computed as follows [1, 7]:

$$
\rho^{*}=\frac{\rho T}{T^{*}}
$$

and: 


$$
\mu^{*}=\mu\left(\frac{T^{*}}{T}\right)^{3 / 2} \frac{T+111 K}{T^{*}+111 K}
$$

Lastly, the friction coefficient is determined from the reference Reynolds number:

- $\quad$ For laminar flow [7]:

$$
C_{f}=\frac{0.664}{\sqrt{\operatorname{Re}^{*}}}
$$

- For turbulent flow [7]:

$$
C_{f}=\frac{0.02296}{\left(\operatorname{Re}^{*}\right)^{0.139}}
$$

\subsubsection{Wall Heat Loss}

The wall heat flux is computed using the Reynolds analogy:

- For laminar flow:

$$
\dot{q}_{W}=0.5 C_{f} \operatorname{Pr}^{-2 / 3} \rho u C_{p}\left(T_{W}-T_{A W}\right)
$$

- For turbulent flow:

$$
\dot{q}_{W}=0.5 C_{f} \operatorname{Pr}^{-1 / 3} \rho u C_{p}\left(T_{W}-T_{A W}\right)
$$

where: $T_{A W}$ is the wall adiabatic temperature, and is given by:

- For laminar flow:

$$
T_{A W}=T\left[1+\frac{\operatorname{Pr}^{1 / 2}(\gamma-1) M^{2}}{2}\right]
$$

- For turbulent flow:

$$
T_{A W}=T\left[1+\frac{\operatorname{Pr}^{1 / 3}(\gamma-1) M^{2}}{2}\right]
$$




\subsubsection{Mixing Efficiency Curve}

Not all the fuel injected into the air stream is mixed and burned. The area of the unmixed stream together with the separation area will compress the core flow area as equation (4.2) indicates. Thus, a mixing model is necessary to determine the amount of fuel that is mixed and burned as well as that of the unmixed fuel and its area.

There are different formula developed from experiments that are specific to certain type of fuel and injection scheme.

The simplest one is a curve fit proposed by Heiser and Pratt as follows [1]:

$$
\eta_{m}(x)=\eta_{c, t o t}\left[\frac{\vartheta\left(\frac{x-x_{3}}{x_{4}-x_{3}}\right)}{1+(\vartheta-1)\left(\frac{x-x_{3}}{x_{4}-x_{3}}\right)}\right]
$$

where: $\eta_{c, t o t}$ is the mixing efficiency at the end of the combustor, $\vartheta$ is an empirical constant whose value is from 1 to 10 [5]. This constant will determine which injection scheme the curve is fitted to. It has been observed that lower values of $\vartheta$ correspond to parallel injection and higher values results in a curve resembling to that of normal injection scheme.

The following are a couple of the aforementioned empirical formula that will be used for the code validation:

- Strut mixing model for hydrogen fuel:

The mixing efficiency is given by [7]:

$$
\eta_{m}(x)=\alpha\left[1-e^{-\left(\frac{k x}{L_{m i x}}\right) d}\right]
$$

$L_{\text {mix }}$ is the mixing length and can be determined as follows: 


$$
L_{\text {mix }}=\frac{D_{f} K^{*}}{f\left(M_{c}\right)} \sqrt{\frac{\rho_{f} u_{f}}{\rho_{a} u_{a}}}
$$

where: $f\left(M_{c}\right)=0.25+0.75 e^{-3 M_{c}^{2}}$ and $M_{c}=\frac{u_{f}-u_{a}}{a_{f}+a_{a}}$

$\alpha, k, d$ and $K^{*}$ are constant and take the following values: $a=1.065, k=3.696$,

$d=0.806$ and $K^{*}=390$

$D_{f}$ is the fuel jet diameter.

$M_{c}$ is the convective Mach number and is calculated from fuel velocity and air velocity as well as their acoustic speed.

- Normal injection model for hydrogen fuel:

The mixing efficiency is given by [7, 35]:

$$
\eta_{m}(x)=1.01+0.176 \ln \left(\frac{x}{x_{\phi}}\right)
$$

where:

$$
x_{\phi}=0.179 L_{m i x} e^{1.72 \phi}
$$

The mixing length in this case is estimated to be 60 times the spacing between injectors.

From the mixing efficiency, the area of the unmixed fuel jet is given by [7]:

$$
A_{j e t}(x)=A_{j e t, 3}\left[1-\eta_{c}(x)\right]
$$

where: $A_{j e t, 3}$ is the fuel jet area at Station 3.

\subsubsection{NPSS Calculation Procedure}

The combustor is "discretized" into $n$ infinitesimal elements of length $d x$ which is the same as the aforementioned elemental control volume. This corresponds to $n+1$ nodes along the axis of the combustor. The first node is at the entry of the combustor - 
Station 3 as denoted in Figure 4-2. A flow station called FII is connected to this node. Here after, another flow station called FI_O is attached to each following node and moves towards the end of the combustor - Station 4.

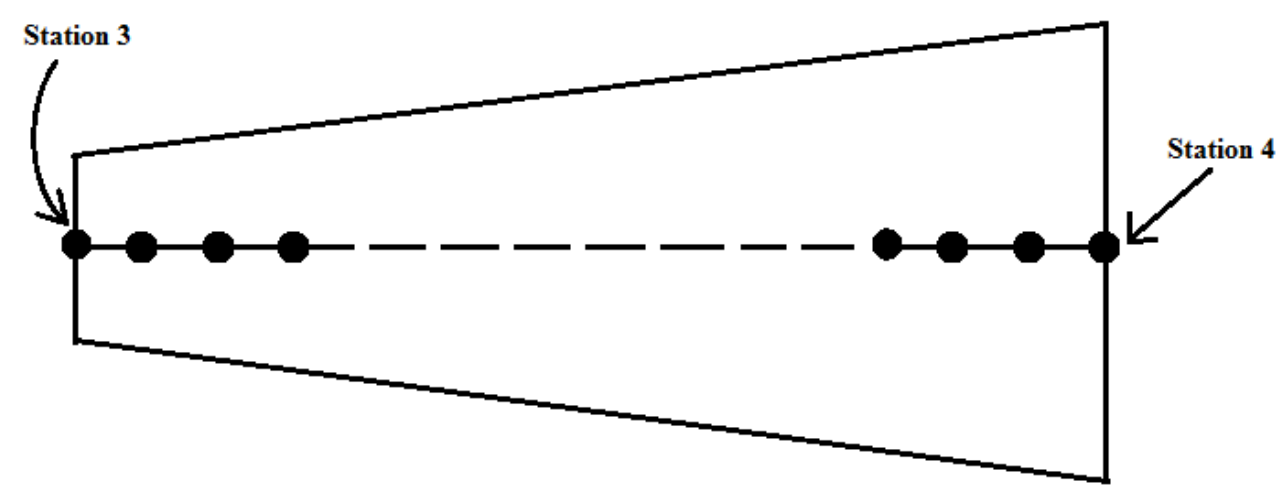

Figure 4-2 Discretization of the combustor.

The calculation procedure can be described in the following flow chart: 


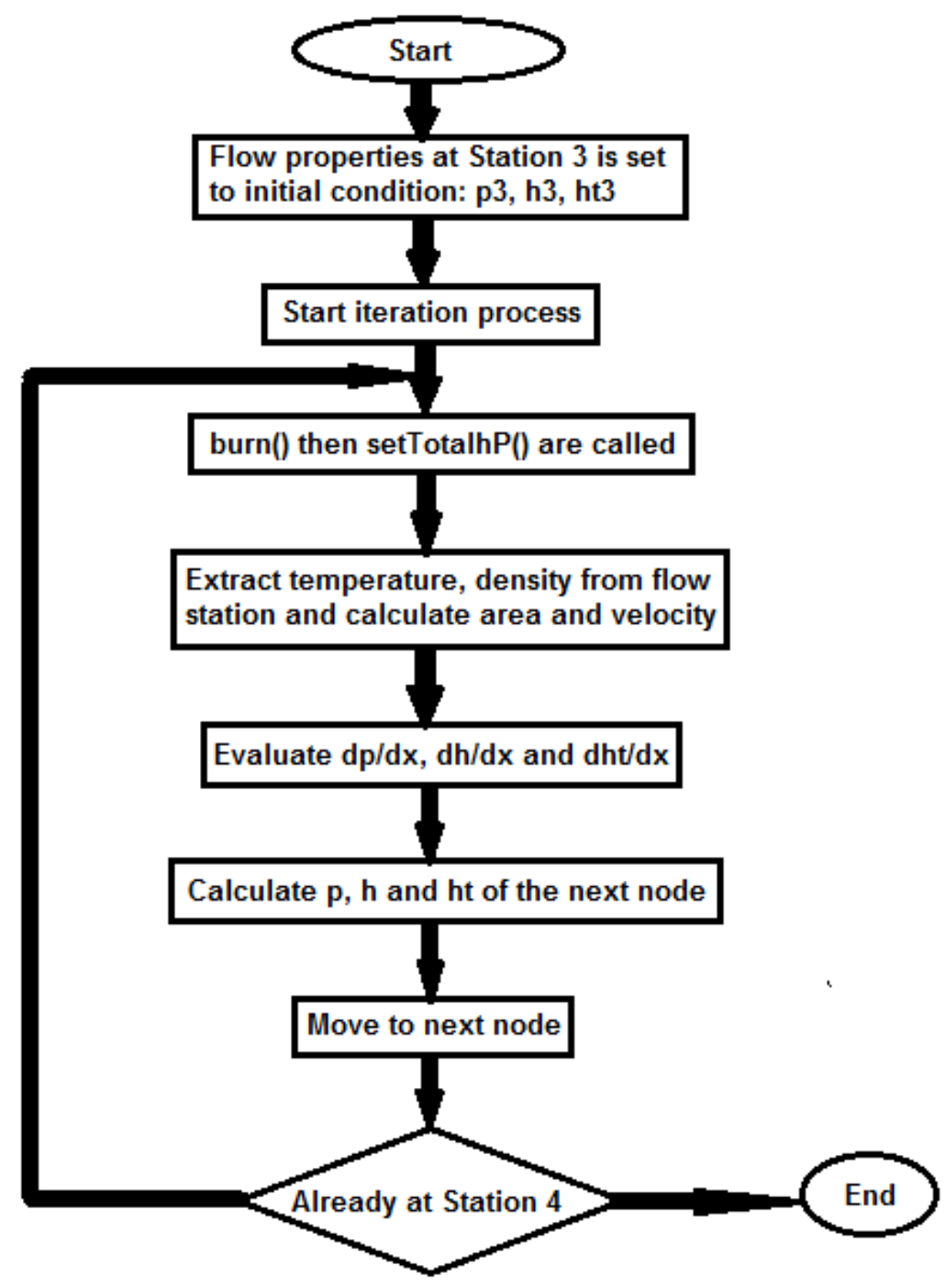

Figure 4-3 NPSS calculation procedure flow chart.

Overall, at each step, FI_O with the help of CEA calculates and stores the flow data at the node is currently connected to and the data is in turn used to find that of the next node in line. $F I O O$ is continuously updated until it reaches Station 4.

In detail, the three selected independent variables are used as follows: 
- Static enthalpy and static pressure of the flow are inserted into CEA through the use of a flow station function called setTotalhP(), which in turn gives out static temperature and density.

- Flow velocity is calculated from total enthalpy and static enthalpy:

$$
u=\sqrt{2\left(h_{t}-h\right)}
$$

Core flow area is determined from the geometric area and the fuel jet area.

In order to calculate the enthalpy change due to the burnt fuel, a built-in function in NPSS call burn() is used. This function will add and burn the fuel with the air. It keeps $p t$ of the mixture the same and calculate $h t$ based on the amount of fuel added and the $h p r$ of the fuel. In this code, $p, h$ and $h t$ is given and the mixture properties are to be set by those parameters. Thus, the burn() function is first used beforehand to add and burn the fuel first, then setTotalhP() is used to set flow properties to the right values.

With these properties and with the three numerically calculated values of partial derivative of density: $\frac{\partial \rho}{\partial p}, \frac{\partial \rho}{\partial h}$ and $\frac{\partial \rho}{\partial \phi}$, we now have all the needed variables to plug into equations (4.14), (4.15) and (4.16) to calculate the derivative of static pressure, static enthalpy and total enthalpy. Based on these derivatives, the values of $p, h$ and $h t$ at the next node are determined as follows:

$$
p_{i+1}=p_{i}+\frac{d p}{d x} \Delta x
$$

and:

$$
h_{i+1}=h_{i}+\frac{d h}{d x} \Delta x
$$

and: 


$$
h_{t_{i+1}}=h_{t_{i}}+\frac{d h_{t}}{d x} \Delta x
$$

where the terms: $d p / d x, d h / d x$ and $d h_{t} / d x$ are weighted average slope value calculated from the 4 approximate values as outlined in the $4^{\text {th }}$ order Runge-Kutta procedure.

The process is repeated until the end of the combustor.

\subsection{Isolator Analytical Model}

\subsubsection{Empirical Formula of Pressure Distribution}

The isolator is simpler than the combustor in the sense that it is usually a constant area duct and there is no heat addition from fuel. However, the flow is bound to separate, which introduces another unknown to the analytical model: the core flow area. Thus, another equation is required to make the set of equations solvable and further modification to the original conservation equations is also needed.

The added equation is the specified pressure distribution. This is an empirical formula developed by Ortwerth $[18,17]$ based on experimental data with different Mach number, Reynolds number and duct geometry:

$$
\frac{d p}{d x}=\frac{89}{D_{H}} \frac{\rho u^{2}}{2} C_{f_{0}}
$$

where: $D_{H}$ is the hydraulic diameter of the duct and $C_{f_{0}}$ is the friction coefficient at the separation start point [17].

As we now have an explicit pressure distribution from equation (4.39), we can eliminate the $d u / d x$ term in both equations (4.5) and (4.8), resulting in a new equation calculating the derivative of static enthalpy:

$$
\frac{d h}{d x}=\frac{1}{\rho} \frac{d p}{d x}-\frac{I_{m}}{\rho}+I_{e}
$$


Equations (4.39), (4.40) and (4.9) are used for the $4^{\text {th }}$ order Runge-Kutta method in the case where flow separation occurs.

\subsubsection{NPSS Calculation Procedure}

The isolator is divided into two regions: the attached region and the separated region.

In the attached region where flow remains attached, the same equations and calculation procedure as the one implemented for the combustor the combustor is used. Heat addition from fuel is not present so there is no need to use the burn() function.

In the separation region, generally the same NPSS calculation procedure is used, the only difference is that core flow area is now a new unknown and is calculated from flow rate, velocity and density using the conservation equation of mass. Therefore, we will also have core flow area distribution as an output of the quasi-one-dimensional code.

The point separating these two regions is the separation start point $x_{u}$. This point will be iterated until the Mach number or pressure at Station 3 matches the specified value given in the experimental data. 


\section{Chapter 5}

\section{Results}

This chapter describes the quasi-one-dimensional code validation by comparison to experimental data available in the literature.

\subsection{Combustor Code Validation}

The first validation is done by comparing the results of the analytical model to that of the experimental results obtained from the $\mathrm{T} 4$ free piston shock tunnel experiment conducted at the University of Queensland [16].

The geometry of the combustor section in the T4 experiment is shown in the following figure:

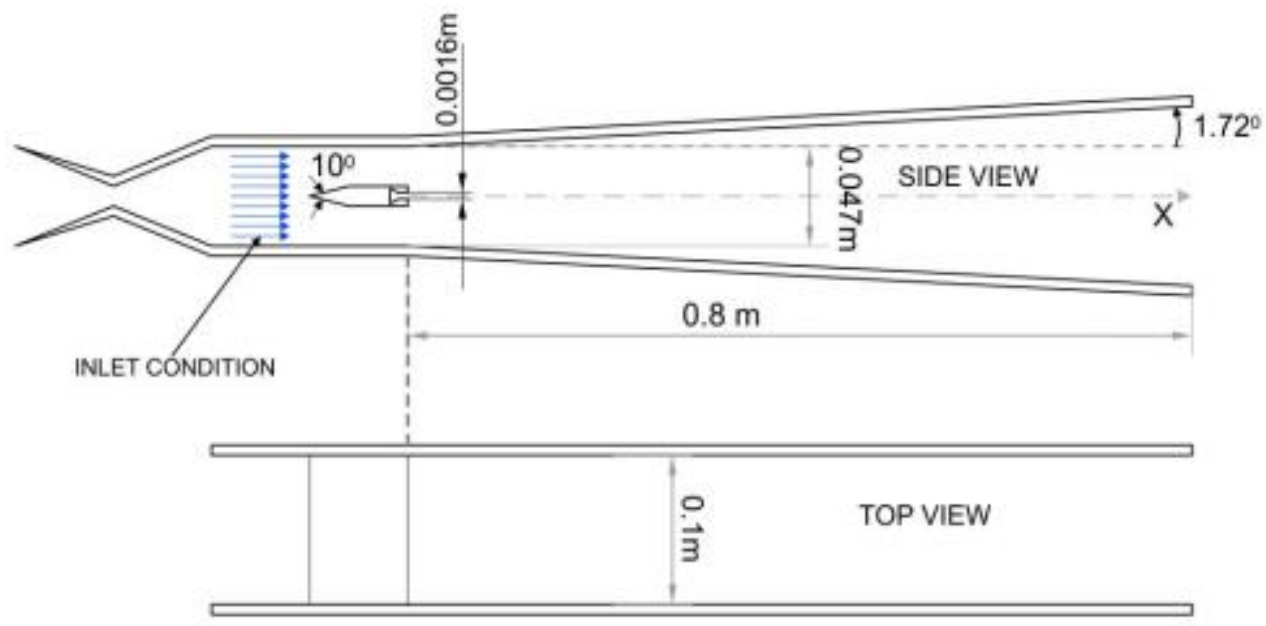

Figure 5-1 T4 scramjet geometry [7].

The combustor is a diverging duct with a rectangular initial cross section of dimension $0.047 \mathrm{~m} \times 0.1 \mathrm{~m}$. The upper and lower walls diverge symmetrically at an angle of $1.72^{\circ}$ over a length $0.8 \mathrm{~m}[7,33]$. 
The fuel injector is a strut type injector with a $0.0016 \mathrm{~m}$ slot width. Hydrogen fuel is injected parallel to the incoming airflow at the point where the combustor cross section starts to increase. Fuel is injected at sonic speed [7].

There are three cases in the experiment. All have the same incoming condition and same wall temperature of $300 \mathrm{~K}$ but the equivalence ratio is varied. The inlet conditions along with the equivalence ratio of each case are shown in the following table $[33,7]$ :

Table 5-1 T4 experiment data

\begin{tabular}{|c|c|c|c|c|}
\hline Case & $\mathrm{M}_{3}$ & $\mathrm{P}_{3}(\mathrm{kPa})$ & $\mathrm{T}_{3}(\mathrm{~K})$ & Equivalence ratio \\
\hline 1 & 2.47 & 59 & 1025 & 0.19 \\
\hline 2 & 2.47 & 59 & 1025 & 0.38 \\
\hline 3 & 2.47 & 59 & 1025 & 0.58 \\
\hline
\end{tabular}

In order to model the mixing efficiency of this experiment, the hydrogen fuel strut injector empirical formula described in Section 4.3.4 is used.

The following plots compare the analytical results with data from the experiment. The horizontal axis represents the axial position from the start of the combustor (Station 3) to the end of the combustor (Station 4). The vertical axis represents the nondimensionalized static pressure, which is the static pressure at the corresponding position divided by the combustor inlet static pressure. 


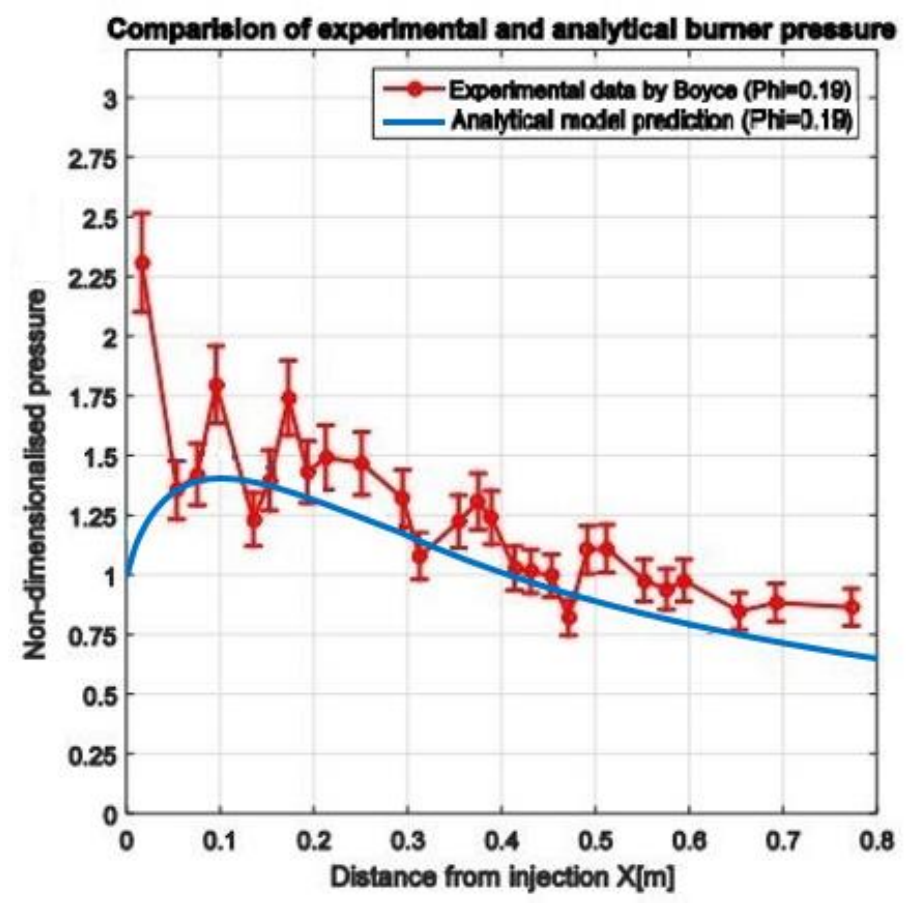

Figure 5-2 Pressure distribution comparison for Case 1 - T4 experiment.

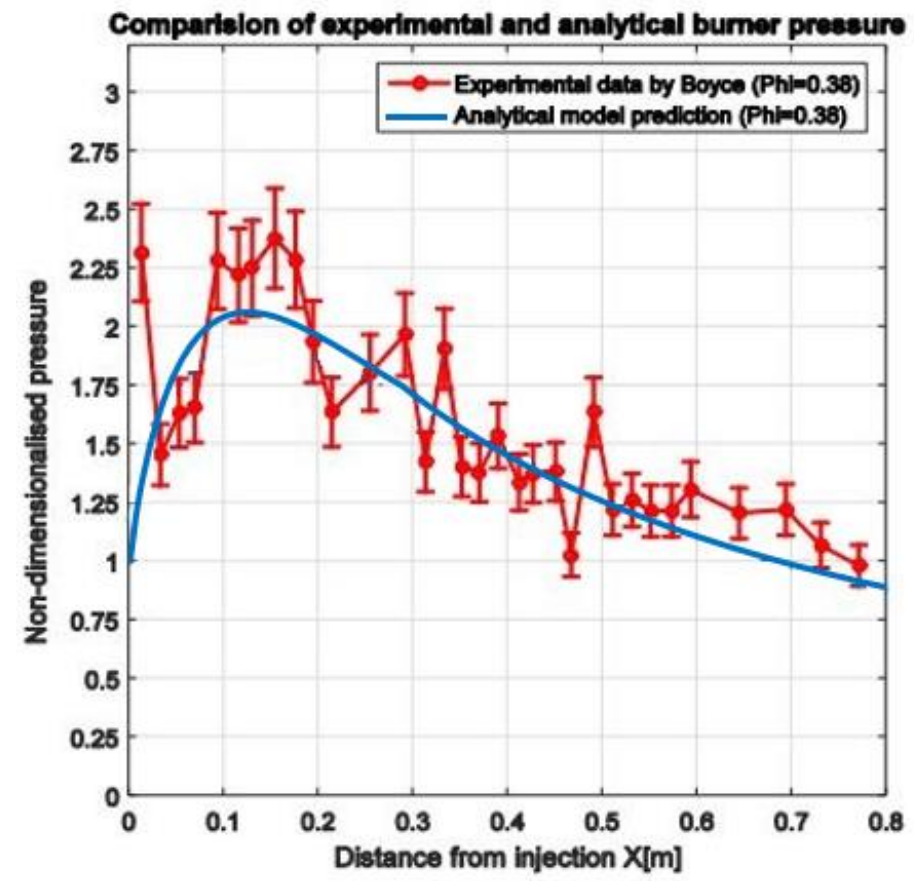

Figure 5-3 Pressure distribution comparison for Case 2 - T4 experiment. 


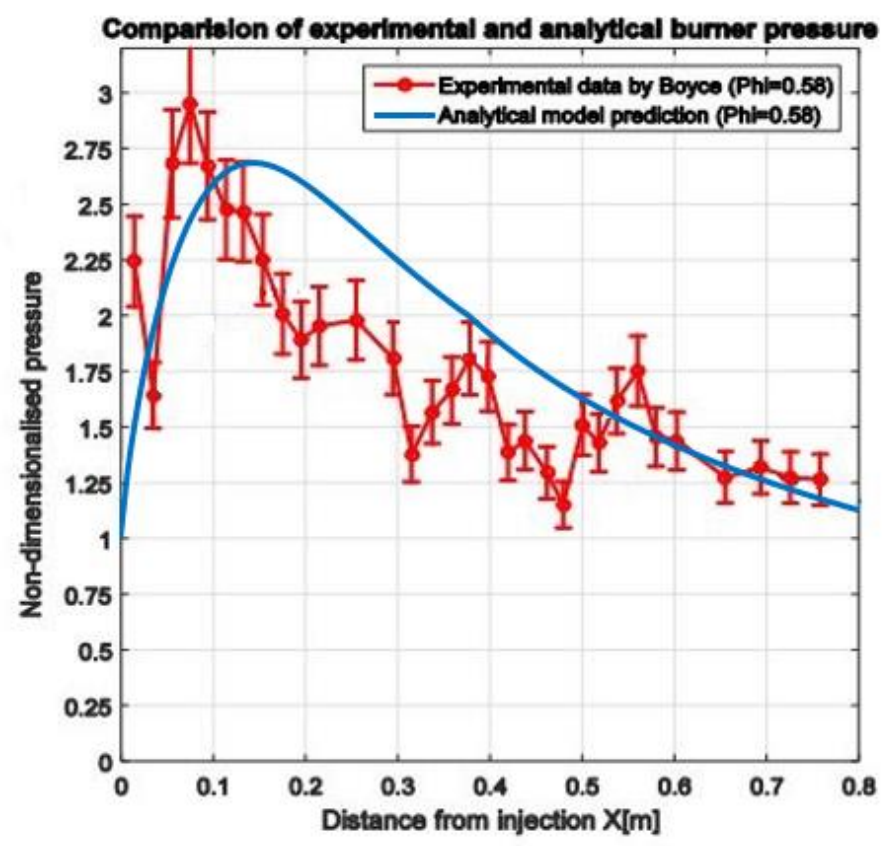

Figure 5-4 Pressure distribution comparison for Case 3-T4 experiment.

Figures 5-2 to 5-4 shows that the quasi-one-dimensional code provides reasonably accurate results that agree with the experimental data. The pressure increases sharply initially due to the effect of heat addition from burnt fuel then decreases after reaching a peak value. Fuel is mixed and burnt more efficiently right after the injector. After the point of maximum pressure, other effects, i.e. friction, heat loss and area expansion become more dominant. The initial pressure spike can be the result of the shockwave created by the injector strut. It can also be seen that with higher equivalence ratio, meaning more fuel is burnt, higher peak pressure is observed. This peak pressure is the cause of shock train inside the isolator.

The second validation is carried out by comparison to the experimental results obtained from the Hyshot 2 flight test data [17].

The geometry of the Hyshot 2 scramjet is described in the following figures: 


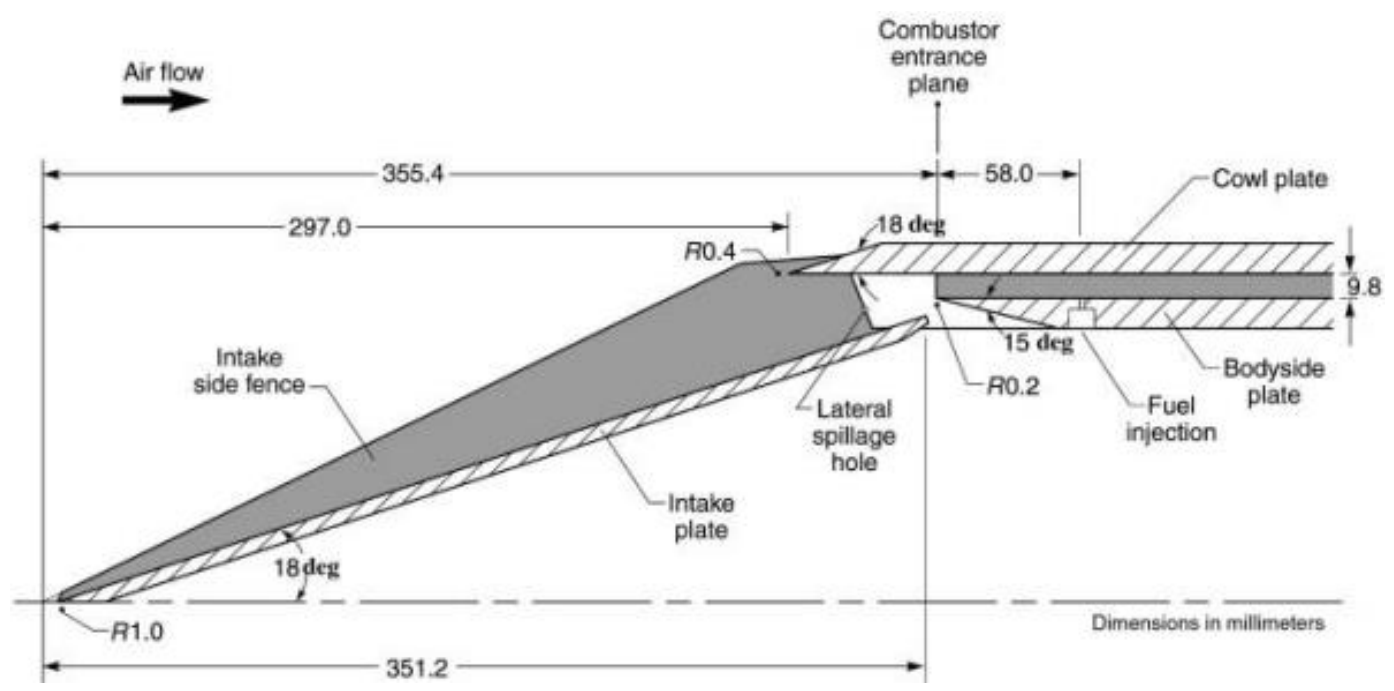

Figure 5-5 Schematic of Hyshot 2 scramjet geometry (dimensions are in millimeters) [17].

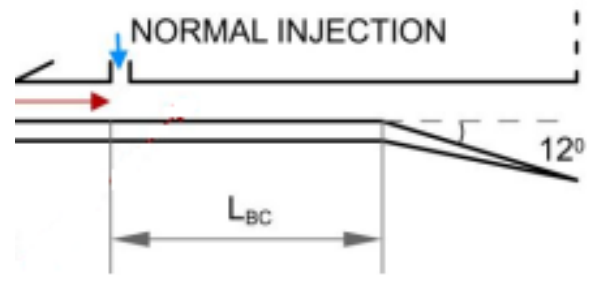

Figure 5-6 Hyshot 2 combustor section geometry [7].

The combustor is a constant area duct with a rectangular initial cross section of dimension $0.0098 \mathrm{~m} \times 0.075 \mathrm{~m}$. The internal nozzle section after the combustor expands at an angle of $12^{\circ}$. The length of the constant area section is $0.242 \mathrm{~m}$ from the fuel injection position and the internal nozzle spreads over a length of $0.147 \mathrm{~m} \mathrm{[7]}$.

The fuel injector is a normal injection type where hydrogen fuel enters the incoming flow at a 90 degree angle. The position of the fuel injector is $0.058 \mathrm{~m}$ downstream of the combustor entrance plane. Fuel is injected at sonic speed [7, 17].

The flight test data comprises of two categories: unfueled combustor and fueled combustor, each of which contains 4 cases [17]. One case from each category is chosen for comparison with the quasi-one-dimensional code output. The wall temperature is 
assumed to be constant at $350 \mathrm{~K}$ [7]. The other combustor entrance data are shown in the following table:

Table 5-2 Hyshot 2 experiment data

\begin{tabular}{|c|c|c|c|c|}
\hline Case & $\mathrm{M}_{3}$ & $\mathrm{P}_{3}(\mathrm{kPa})$ & $\mathrm{T}_{3}(\mathrm{~K})$ & Equivalence ratio \\
\hline 1 (unfueled) & 2.436 & 55.256 & 1388.4 & 0 \\
\hline 2 (fueled) & 2.393 & 44.847 & 1416.6 & 0.346 \\
\hline
\end{tabular}

The hydrogen normal injection empirical formula described in Section 4.3.4 is used to model the mixing efficiency.

For each case, the non-dimensionalized static pressure, which is the static pressure at the corresponding position divided by the combustor inlet static pressure is plotted versus the axial position from the injection point to the end of the combustor. The comparison to the flight data is as follows:

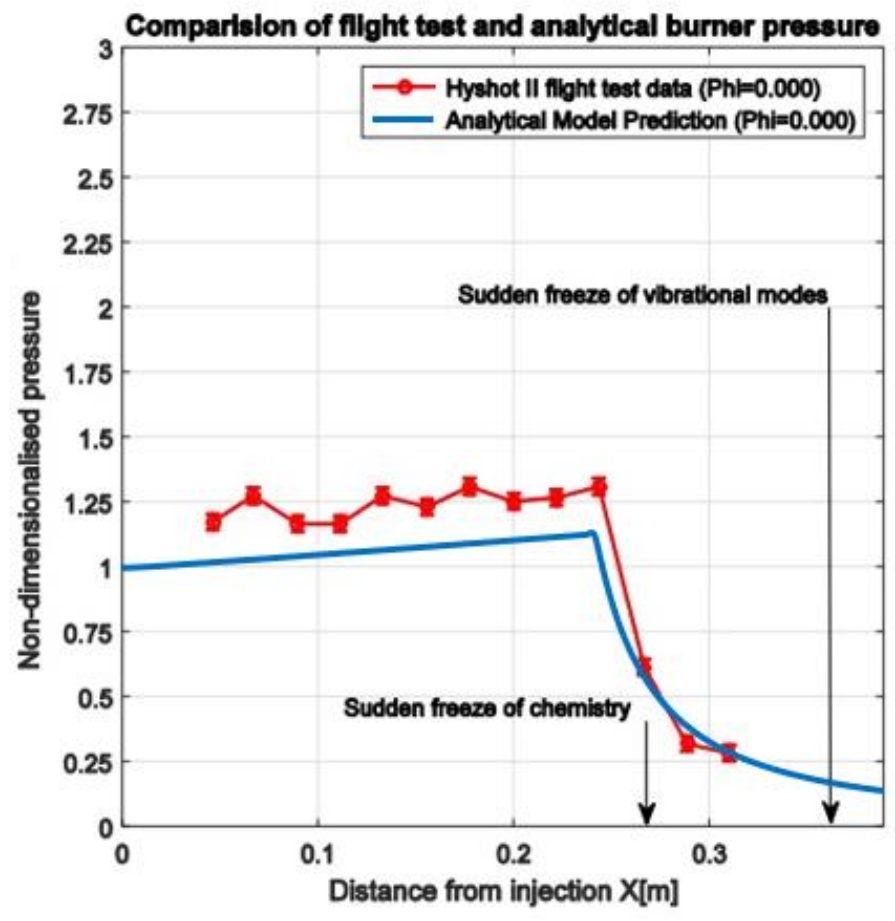

Figure 5-7 Pressure distribution comparison for Case 1 - Hyshot 2. 


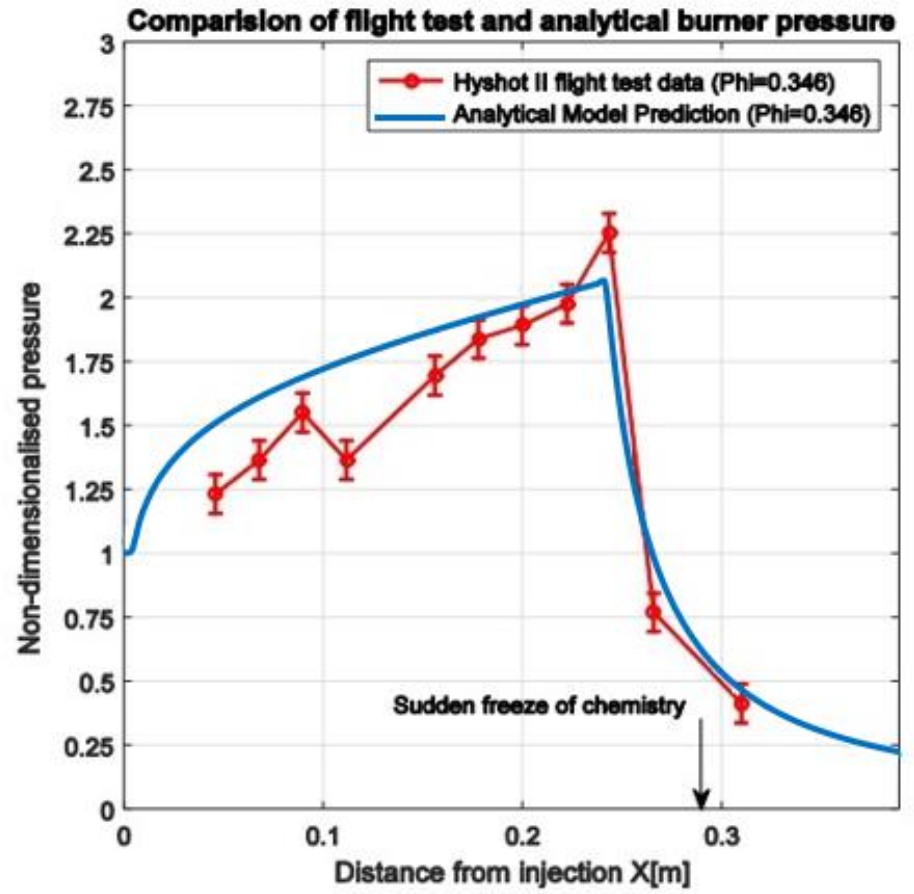

Figure 5-8 Pressure distribution comparison for Case 2 - Hyshot 2.

Once again, the results show agreement between the analytical data and the flight test data. This also validates the accuracy of the normal injection mixing efficiency curve in modeling the heat addition process.

To conclude the combustor validation, it can be stated that the quasi-onedimensional code has been validated with experimental data and provided accurate results in terms of the pressure distribution through the combustor.

\subsection{Isolator Code Validation}

The isolator code is essentially the same analytical model as the combustor code with modification to the system of differential equations by adding a prescribed pressure distribution and removing heat addition. The validation of this modified code is done by comparing its results to that of the experiments done in the reflected shock tunnel $\mathrm{TH} 2$ at the Shock Wave Laboratory by Fisher [18]. 
The following figure describes the schematic of the isolator in the experiment:

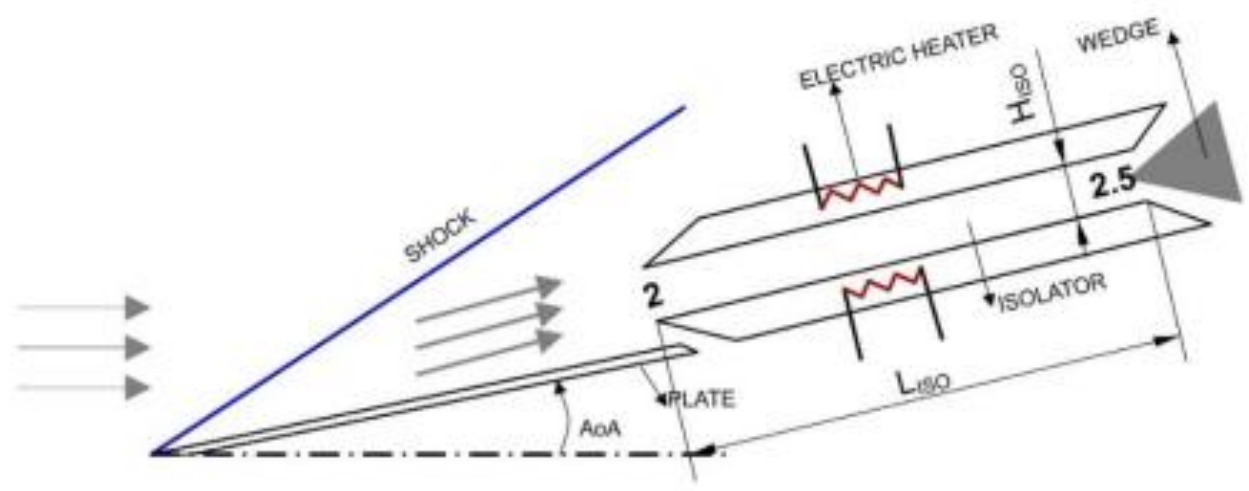

Figure 5-9 Heated isolator experiment setup [7].

The isolator is a duct with rectangular cross section. The length of the isolator is $0.2067 \mathrm{~m}$ but the pressure probe for the back pressure is at $0.18 \mathrm{~m}$ from Station 2 [18], thus, the length used for the code is $0.18 \mathrm{~m}$. The height and width of the isolator are $0.018 \mathrm{~m}$ and $0.1 \mathrm{~m}$ respectively [18]. The gas used in the experiment is Helium [18].

Two cases are chosen for validation. All have the same wall temperature of 1000 $\mathrm{K}$ except for the first case which is run at wall temperature of $300 \mathrm{~K}$ and the same inlet condition which is shown in the following table:

Table 5-3 Fisher experiment data

\begin{tabular}{|c|c|c|c|c|}
\hline Case & $\mathrm{M}_{2}$ & $\mathrm{P}_{2}(\mathrm{kPa})$ & $\mathrm{T}_{2}(\mathrm{~K})$ & $\mathrm{M}_{3}$ \\
\hline 1 & 3.5 & 12.440 & 333 & 3.4 \\
\hline 2 & 3.5 & 12.440 & 333 & 2.4 \\
\hline 3 & 3.5 & 12.440 & 333 & 2.3 \\
\hline 4 & 3.5 & 12.440 & 333 & 2.1 \\
\hline
\end{tabular}

The Mach number at the end of the isolator $M_{3}$ in each case is prescribed. The validation procedure is done by iterating the location of the separation start point until the back pressure obtained from the code matches the experimental data except for the first 
case, where no separation occurs. Static wall pressure is then compared between the analytical results and experimental results to assess the accuracy of the code.

The following plots show the aforementioned comparison. The horizontal axis represents the axial position from the start of the isolator to the last pressure probe. The vertical axis represents the pressure coefficient $C_{p}$, which is defined as follows:

$$
C_{p}=\frac{p-p_{0}}{0.5 p_{0} \gamma_{0} M_{0}^{2}}
$$

where the parameters with subscript 0 denote the free stream condition and are given the following values: $p_{0}=460 \mathrm{~Pa}, M_{0}=7.5$ and $\gamma_{0}=1.67$ for Helium [21].

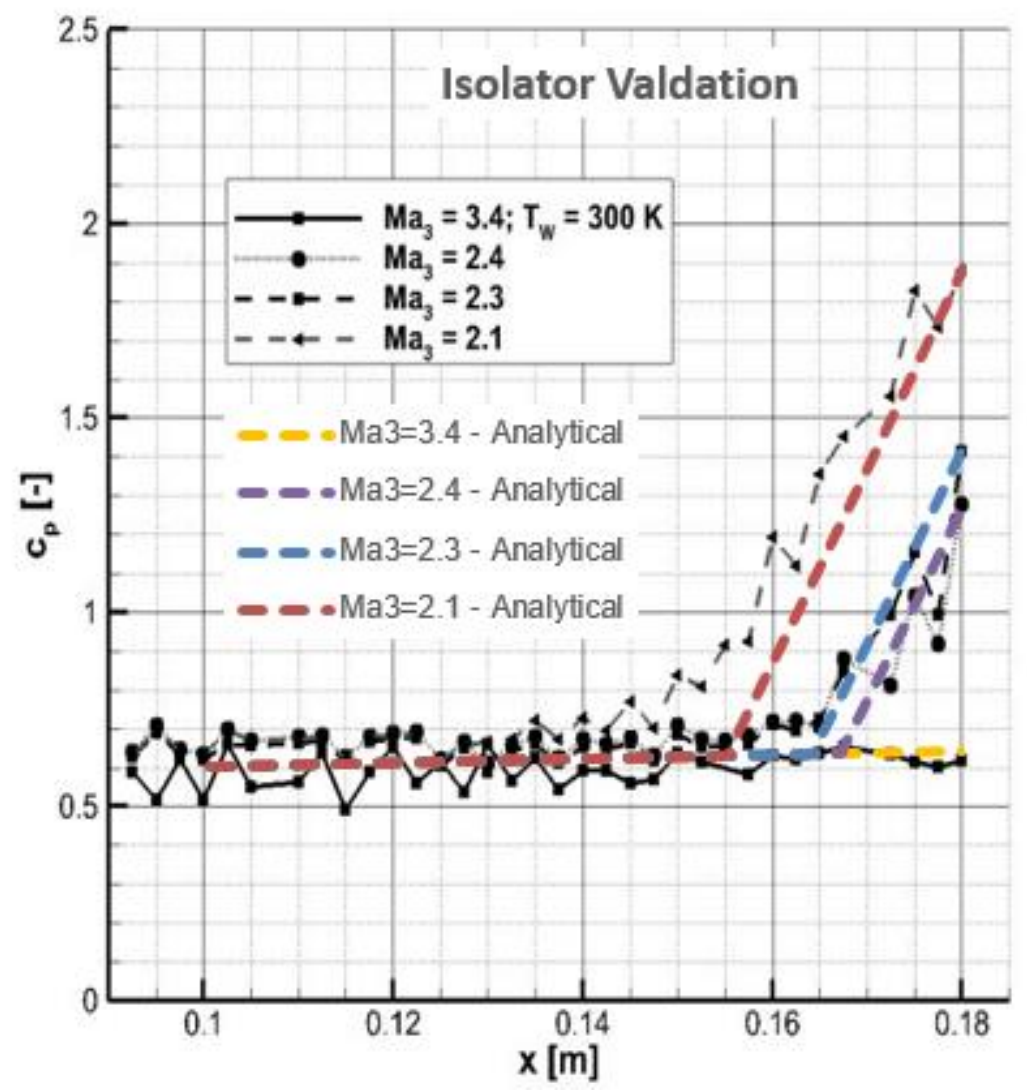

Figure 5-10 Pressure distribution comparison for the isolator - Fisher. 
The Mach number at Station 3 obtained from the code is compared to the prescribed values as follows:

Table 5-4 Ma3 comparison - Fisher experiment

\begin{tabular}{|c|c|c|c|}
\hline Case & $\mathrm{Ma}_{3}$ - Analytical & $\mathrm{Ma}_{3}$ - Experimental & Error (\%) \\
\hline 1 & 3.203 & 3.4 & $6.150 \%$ \\
\hline 2 & 2.677 & 2.4 & $10.347 \%$ \\
\hline 3 & 2.595 & 2.3 & $11.368 \%$ \\
\hline 4 & 2.395 & 2.1 & $12.317 \%$ \\
\hline
\end{tabular}

The error increases as the shock train lengthens. This indicates that the reference temperature method over predicts the pressure coefficient, which in turn makes the slope of the pressure line become stiffer than the experimental data. This becomes more prominent as the shock train length increases.

It can be seen that the analytical results demonstrate reasonable accuracy in terms of separation start point and pressure gradient across the shock train. However, the given data only represent wall pressure. The flow structure inside an isolator is rather complex due to shock train formation, thus, the pressure of the flow changes from the center line outwards and is different from the wall pressure. As a result, a higher order analysis is needed to obtain a complete pressure distribution of the isolator.

The modification of the combustor code only provides limited information on predicting the separation start point, which in turn can be used to determine the length of the isolator in the preliminary step of the design process. 


\section{Chapter 6}

\section{Conclusion}

A summary of the work done in this thesis as well as some aspects of future work are presented in this chapter.

\subsection{Summary}

A quasi-one-dimensional analytical model has been developed to solve for flow properties inside a scramjet combustor. The basis of the model is the conversation equations of mass, momentum and energy combined with thermodynamics and concepts of boundary layer theory. The analytical model treats the working fluid as real reacting gas in equilibrium and takes into account the following aspect of the physics of flow through a scramjet combustor: geometric area change, friction, wall heat loss and the heat addition from the reaction of the air and fuel. A $4^{\text {th }}$ order Runge-Kutta method is chosen to be the numerical integration scheme as it is one of the methods that provide results of high order of accuracy and the algebraic manipulation of the differential equations to arrive at the form outlined in this scheme is straight forward.

The platform for code development is the Numerical Propulsion System Simulation (NPSS), which allows multidiscipline and multifidelity analysis as well as provides the flexibility of model customization. Thus, the NPSS code can be easily reused and expanded beyond the application to scramjet engines.

A modification to the system of governing equation is also made to solve for the flow through the isolator by prescribing a pressure gradient. Although this model only provides limited information of separation start point and wall pressure, the data obtained is crucial in determining the length of the isolator, which is an important parameter in the preliminary design process. 
The code is validated by comparing its results to multiple experimental and flight test data. The comparison shows that the code provides results with acceptable level of accuracy, both for the combustor and isolator.

\subsection{Future Work}

Some aspects of the current work can be expanded as follows:

- Mixing efficiency of different fuel other than hydrogen

- Interaction between the combustor and isolator

- Validation of said interaction 
Appendix A

$4^{\text {th }}$ order Runge-Kutta Method 
The $4^{\text {th }}$ order Runge-Kutta method is a numerical method used to solve differential equations that take the form as follows:

$$
\frac{d x}{d t}=f(x, t)
$$

The essence of this method is calculating $x=x\left(t_{0}+\Delta t\right)$ from a known $x_{0}=x\left(t_{0}\right)$ by estimating the slope $k$ of the line connecting the two points.

The slope $k$ is estimated as follows:

$$
\begin{gathered}
k_{1}=f\left(x_{0}, t_{0}\right) \\
k_{2}=f\left(x_{0}+k_{1} \frac{\Delta t}{2}, t_{0}+\frac{\Delta t}{2}\right) \\
k_{3}=f\left(x_{0}+k_{2} \frac{\Delta t}{2}, t_{0}+\frac{\Delta t}{2}\right) \\
k_{4}=f\left(x_{0}+k_{3} \Delta t, t_{0}+\Delta t\right) \\
k=\frac{k_{1}+2 k_{2}+2 k_{3}+k_{4}}{6}
\end{gathered}
$$

Having obtained $k$, we can easily calculate $x$ :

$$
x=x\left(t_{0}+\Delta t\right)=x_{0}+k \Delta t
$$

From the point that we have just calculated, we can continue to calculate $x=x\left(t_{0}+2 \Delta t\right)$ and so on until we reach the end of the concerned domain.

For a system of numerous equations, the same procedure is applied for each unknown. Each differential equation is calculated based on all the values of unknowns found at each step. 
Appendix B

Code outline 


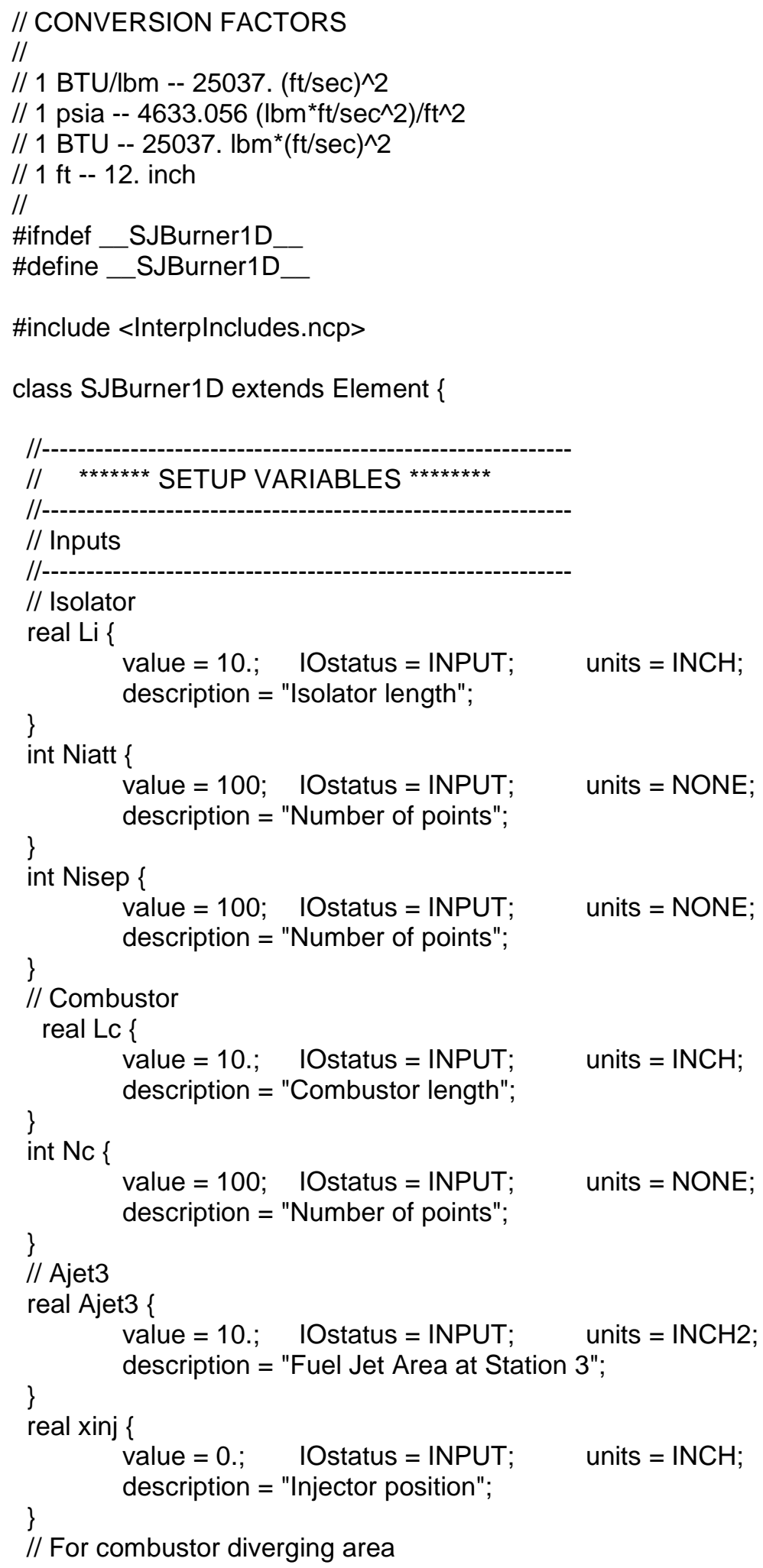




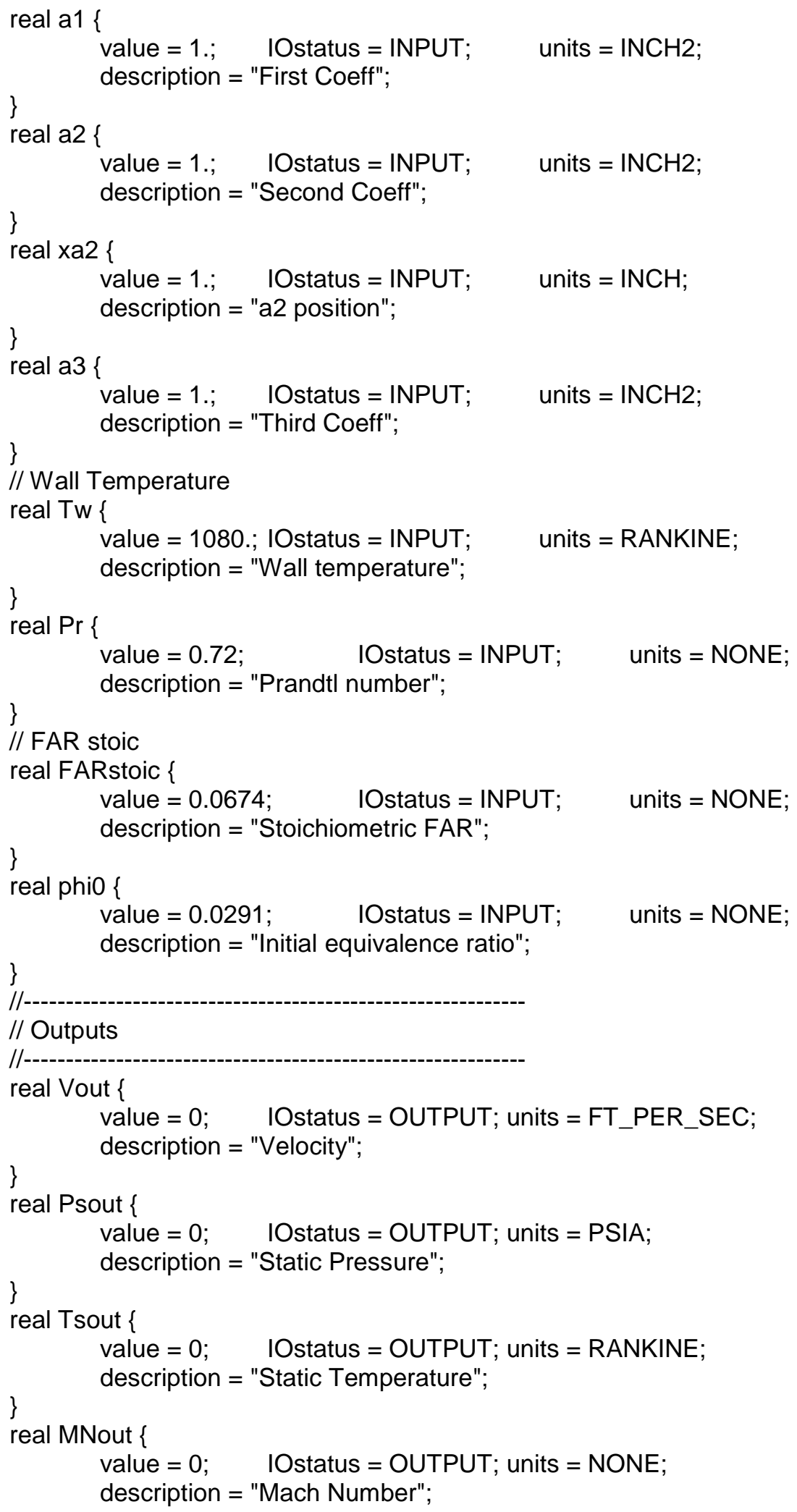




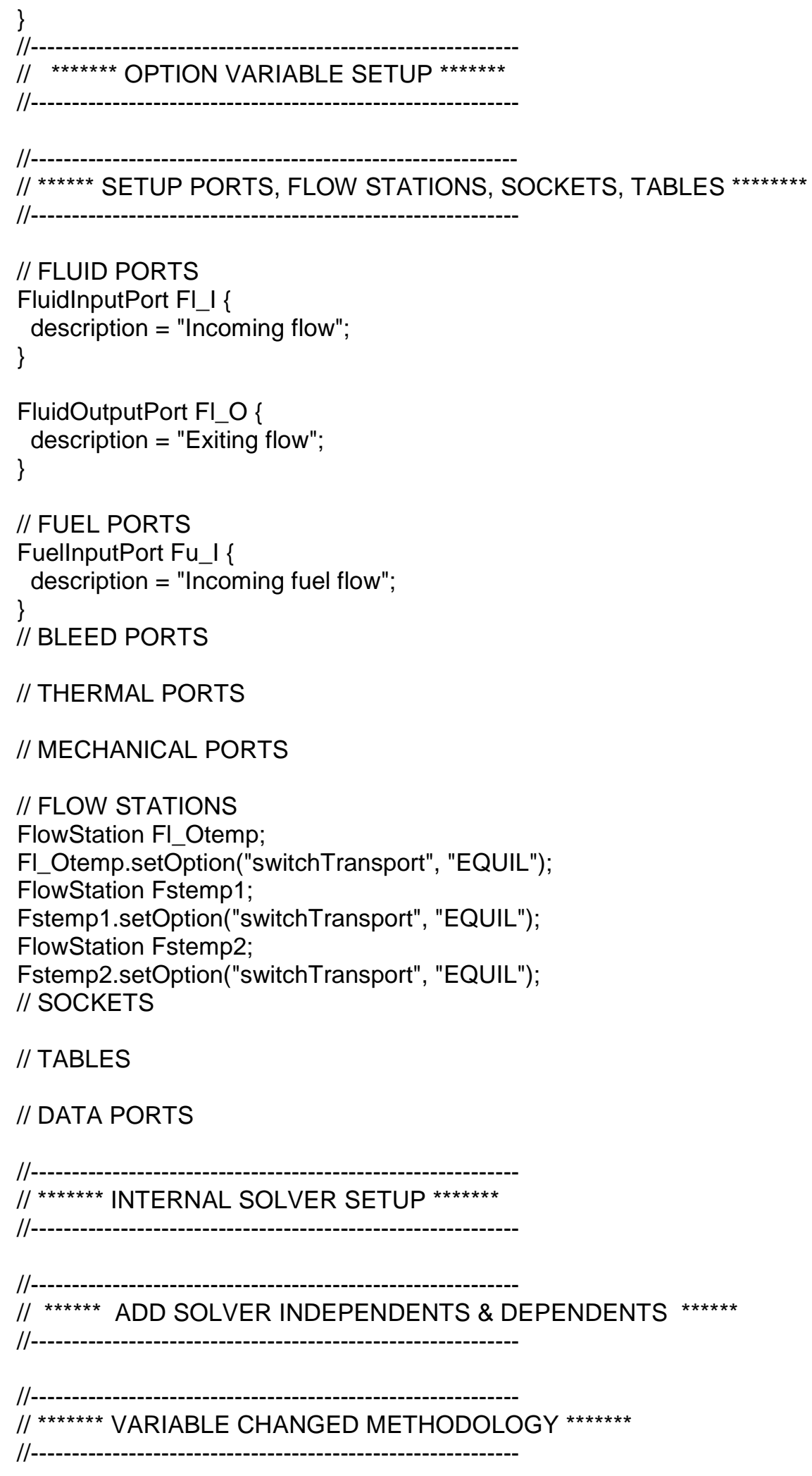




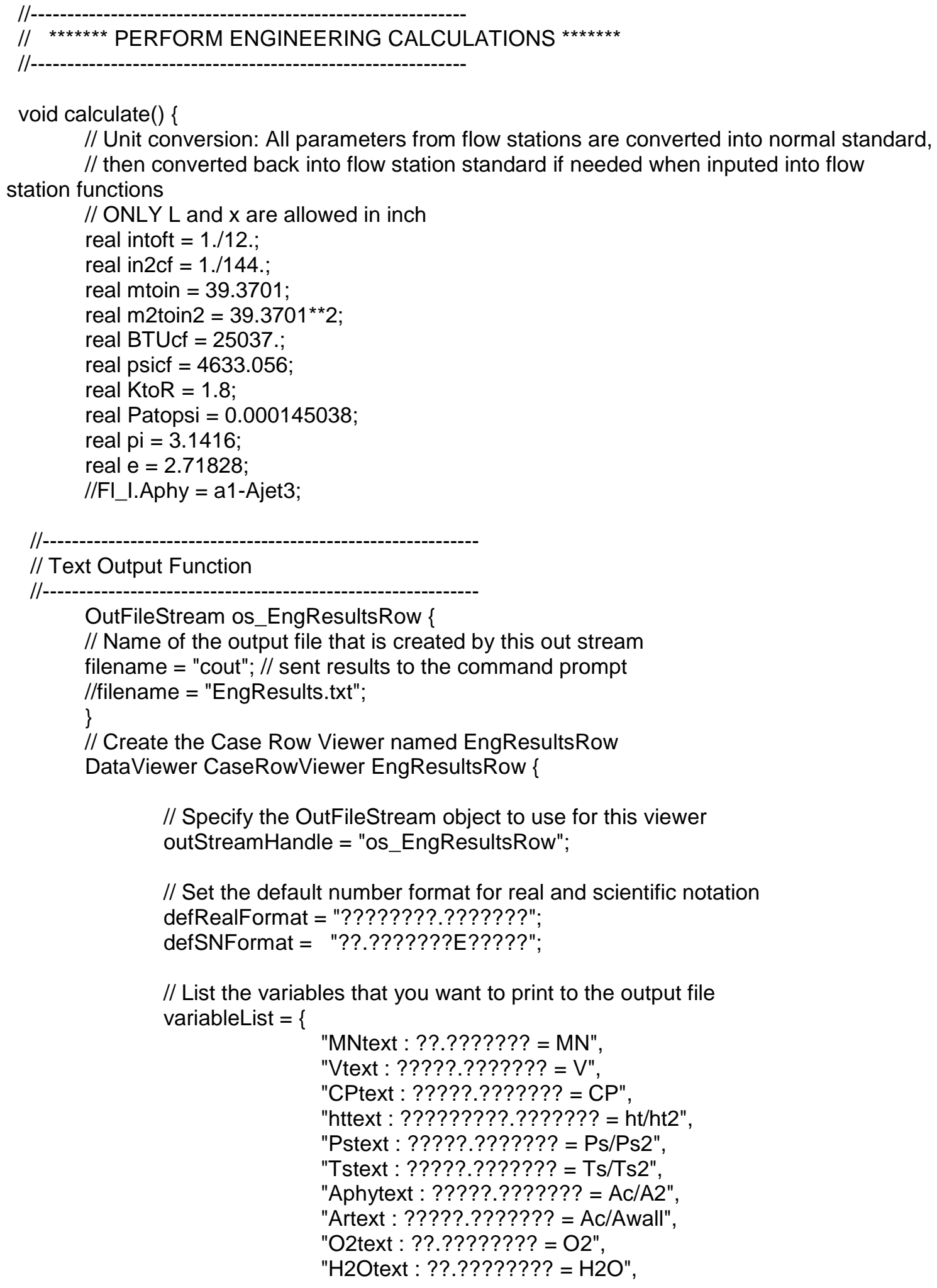

// Specify the OutFileStream object to use for this viewer outStreamHandle = "os_EngResultsRow";

// Set the default number format for real and scientific notation defRealFormat = "????????.???????";

"MNtext : ??.??????? = MN",

"Vtext : ?????.??????? = V",

"CPtext : ?????.??????? = CP",

"httext : ?????????.??????? = ht/ht2",

"Pstext : ?????.??????? = Ps/Ps2",

"Tstext : ?????.??????? = Ts/Ts2",

"Aphytext : ?????.??????? = Ac/A2",

"Artext : ?????.??????? = Ac/Awall",

"O2text : ??.???????? = O2",

"H2Otext : ??.???????? = H2O", 


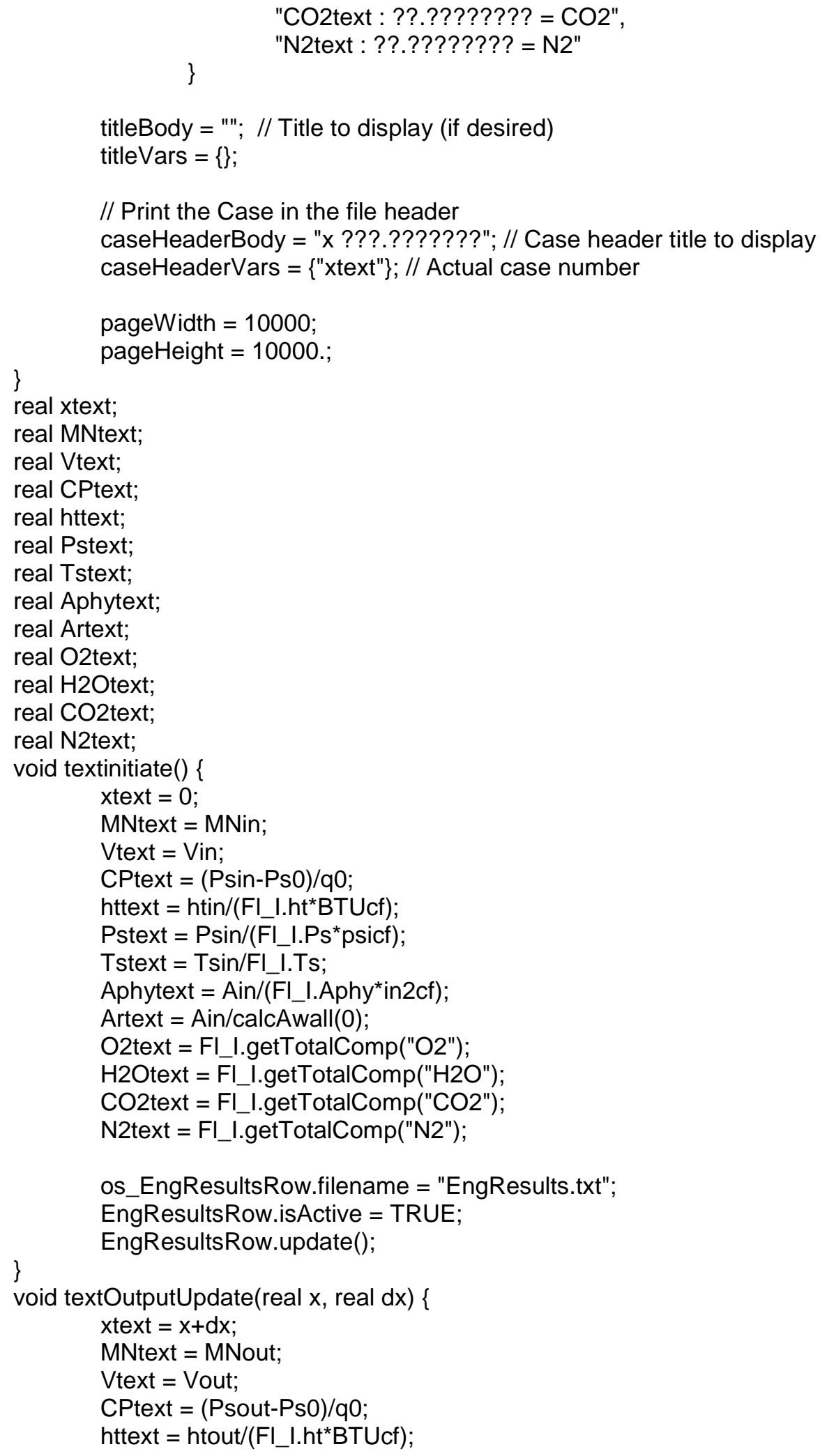




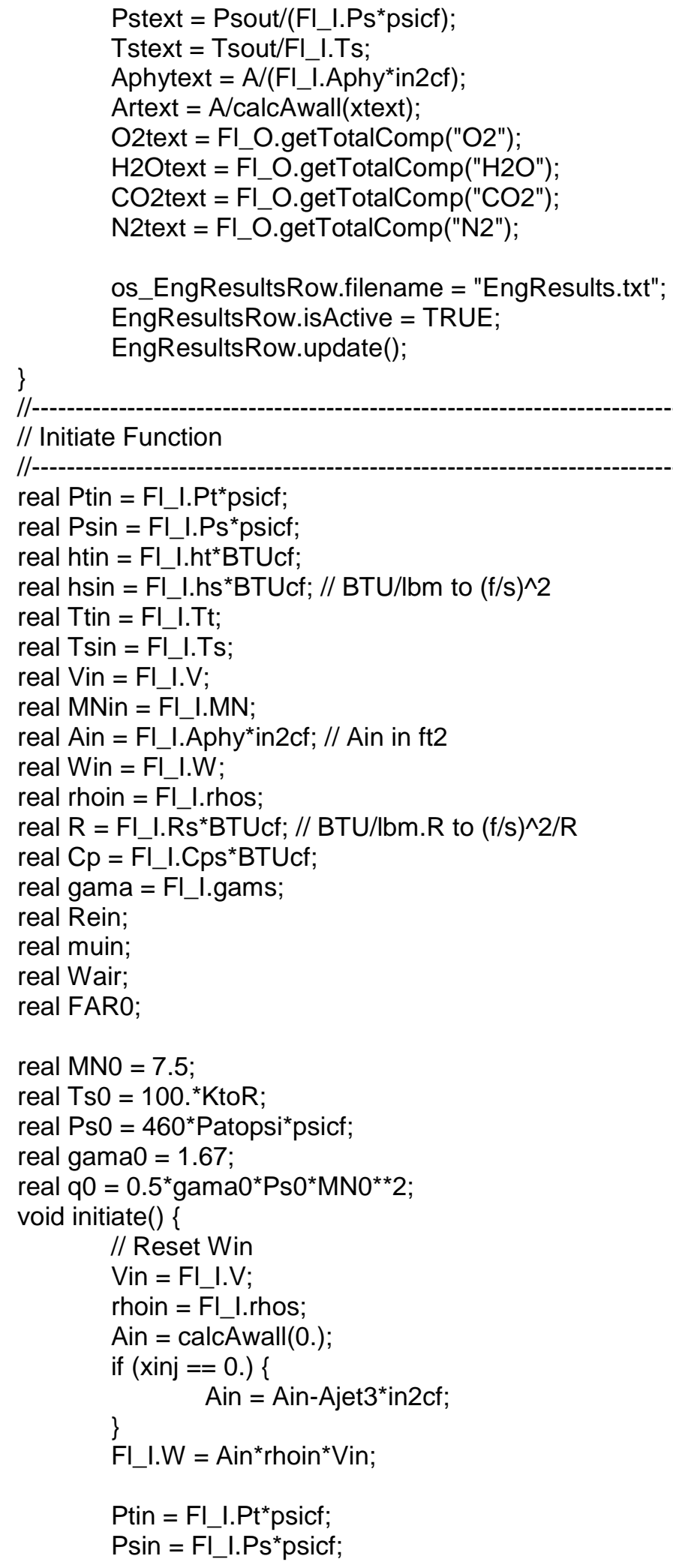




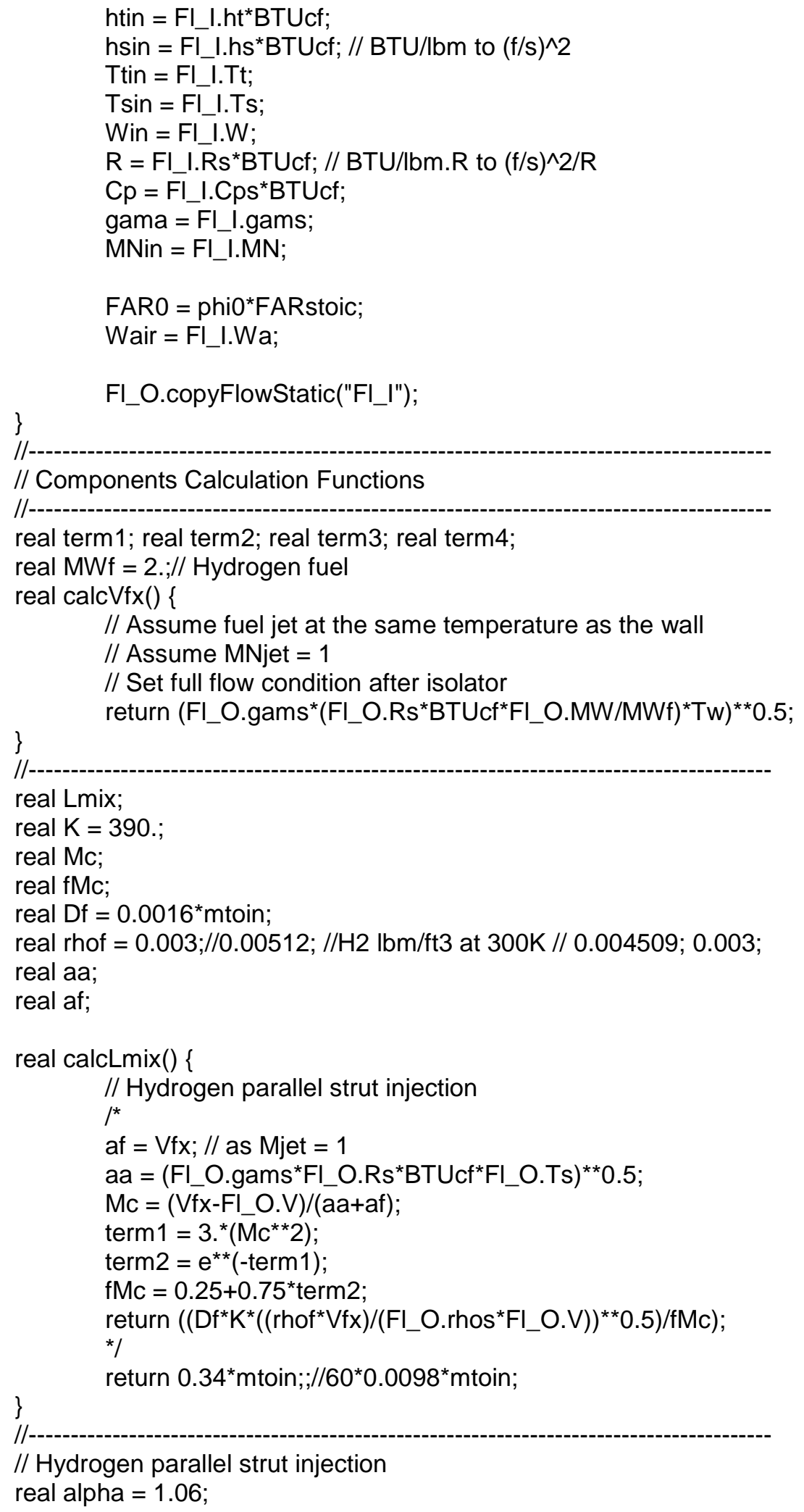




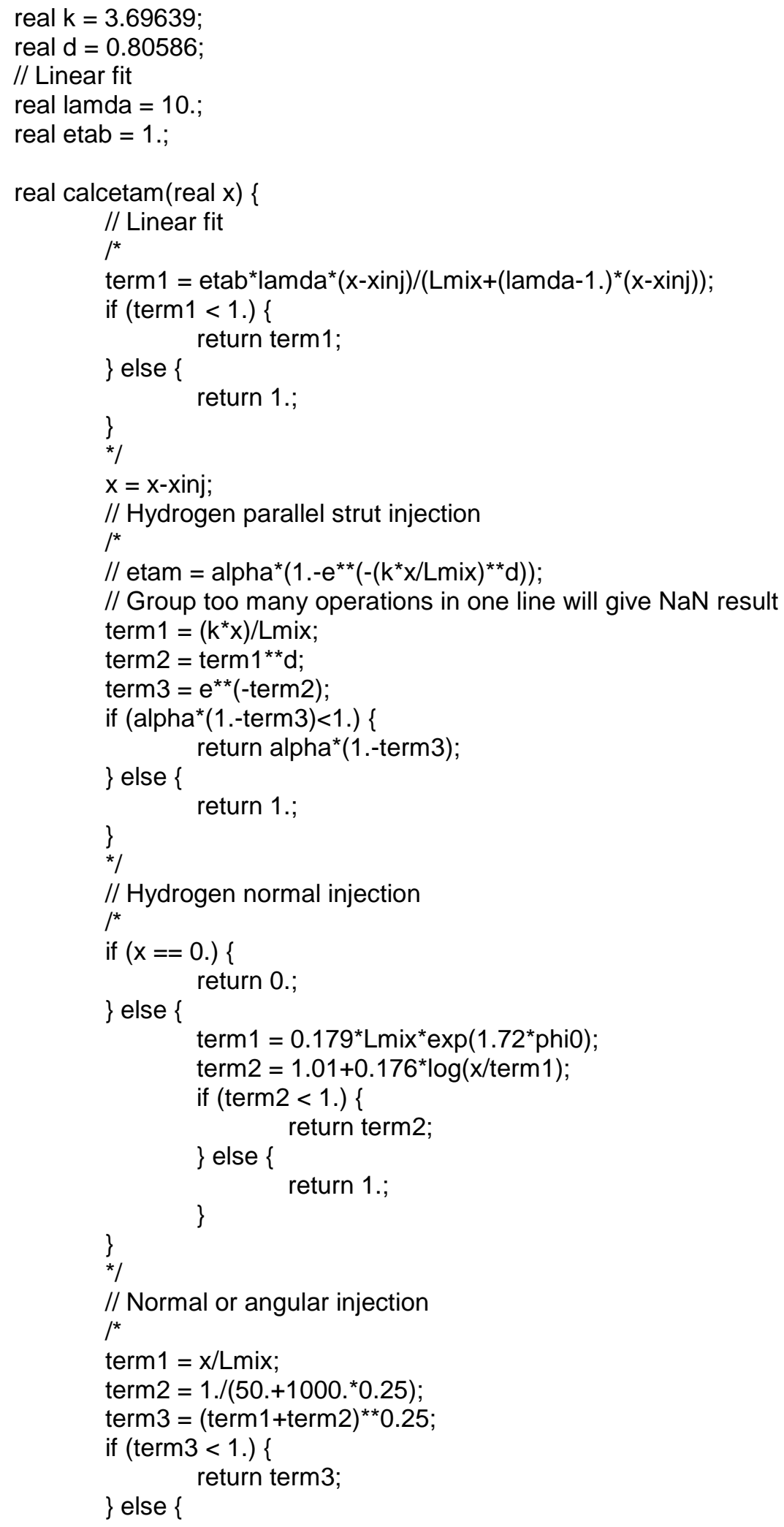




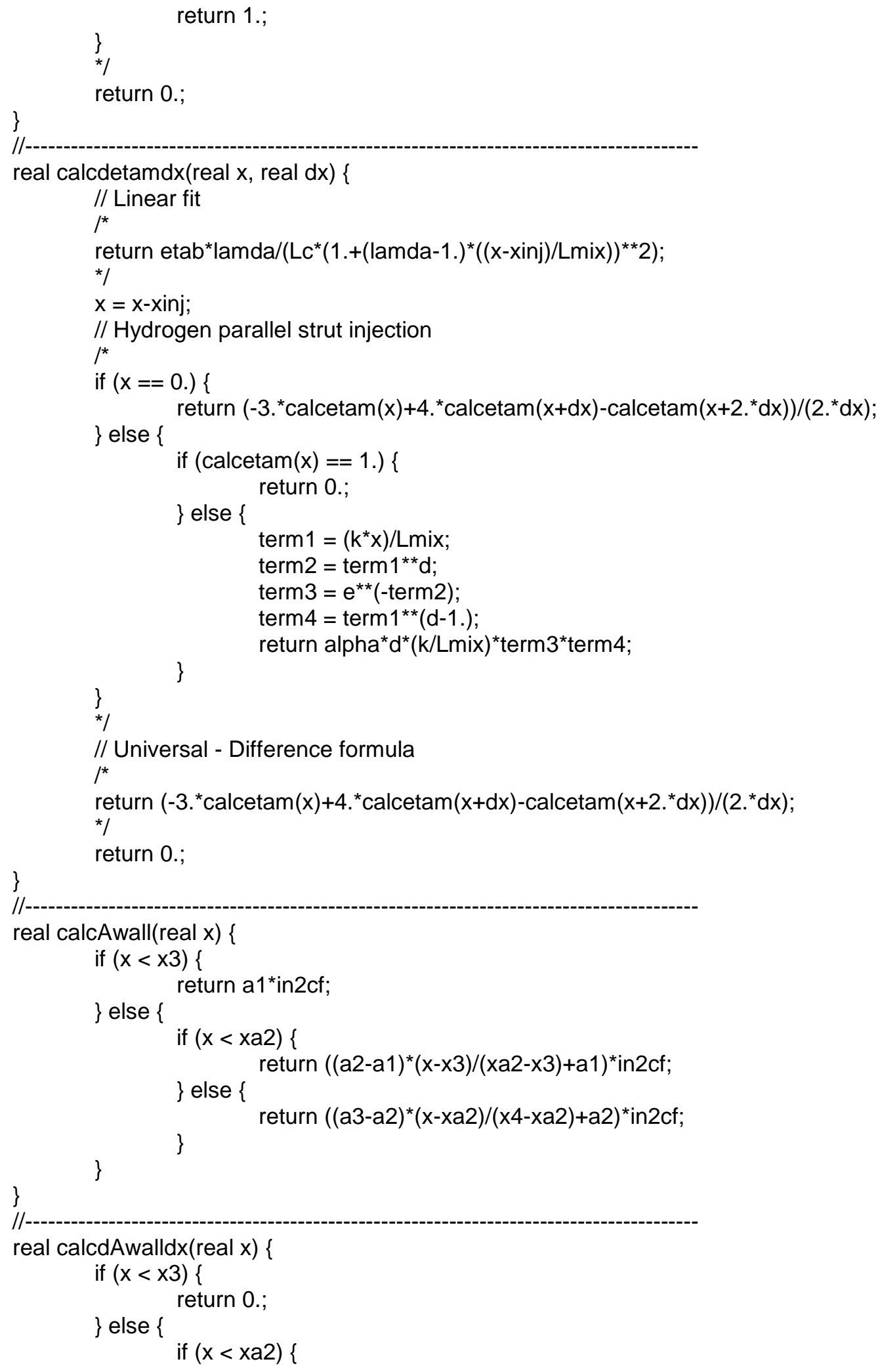




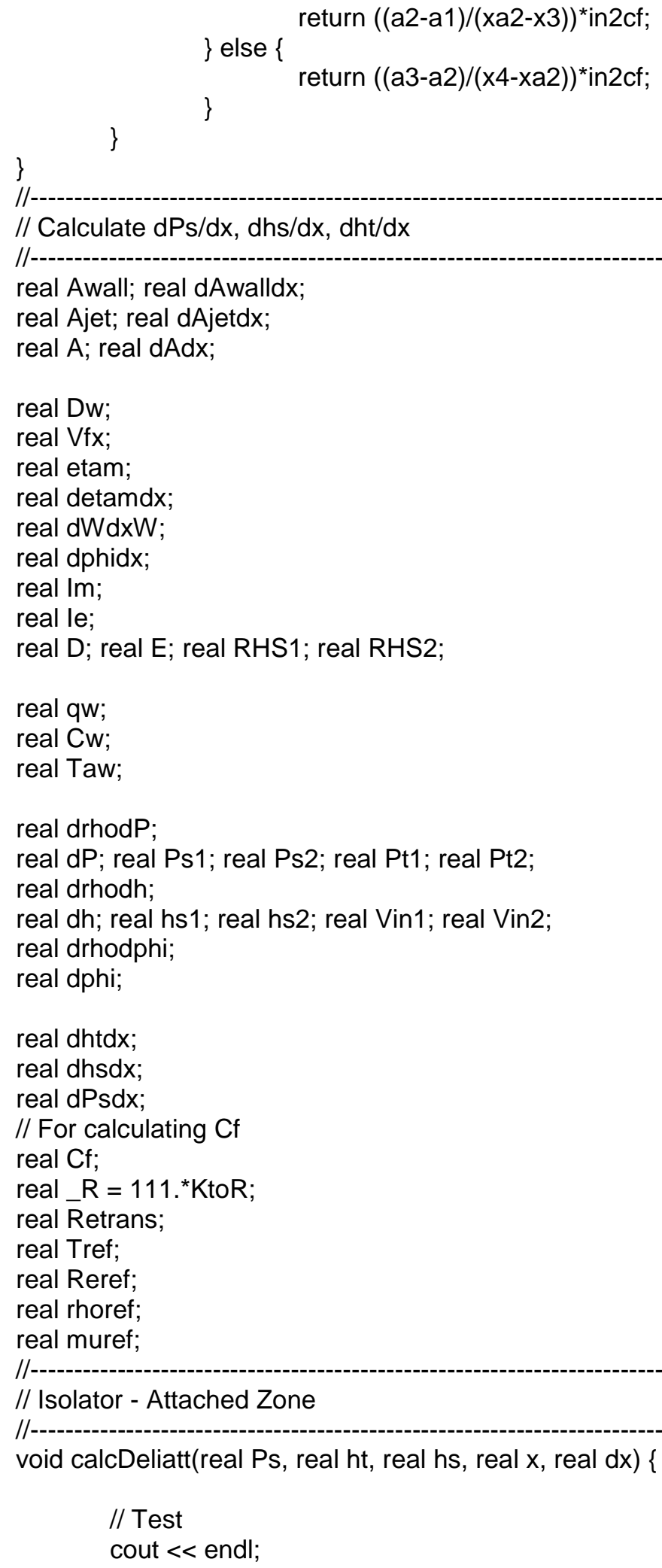




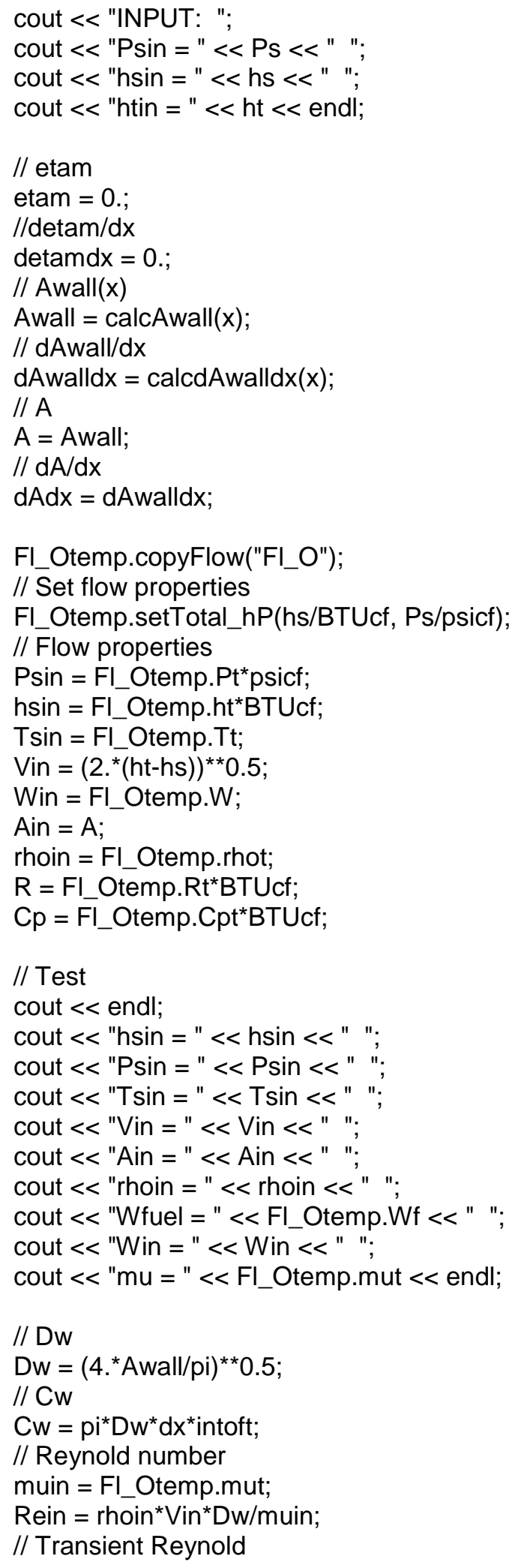




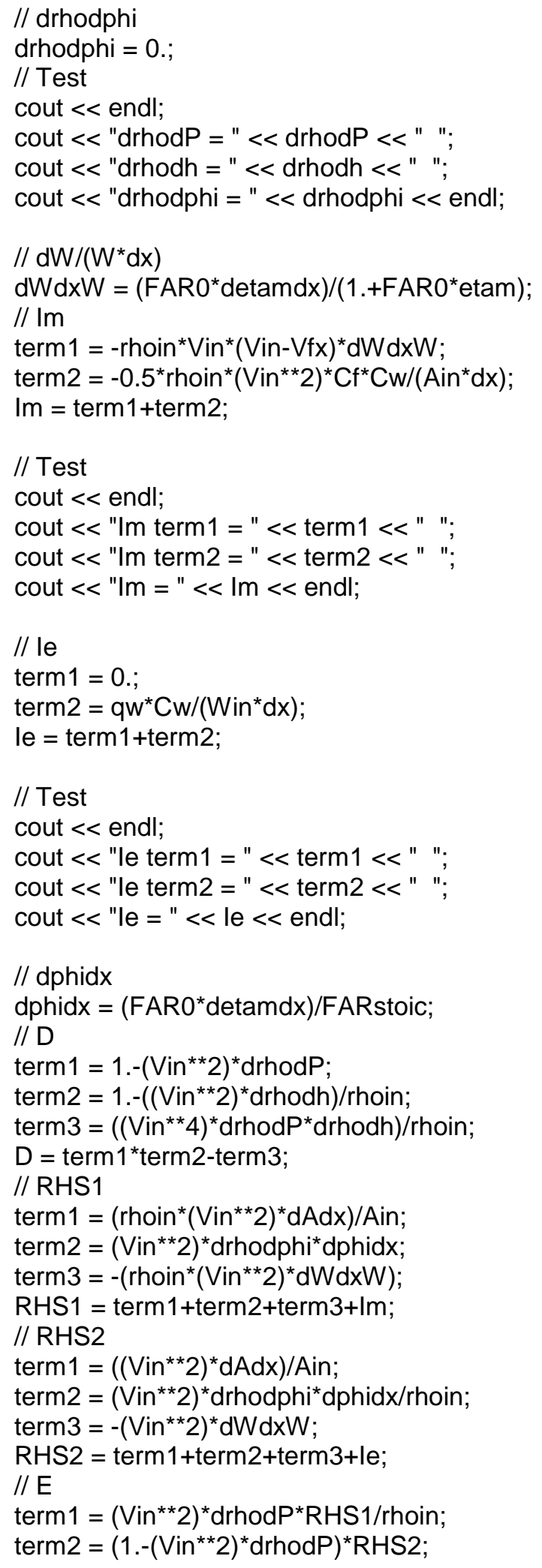




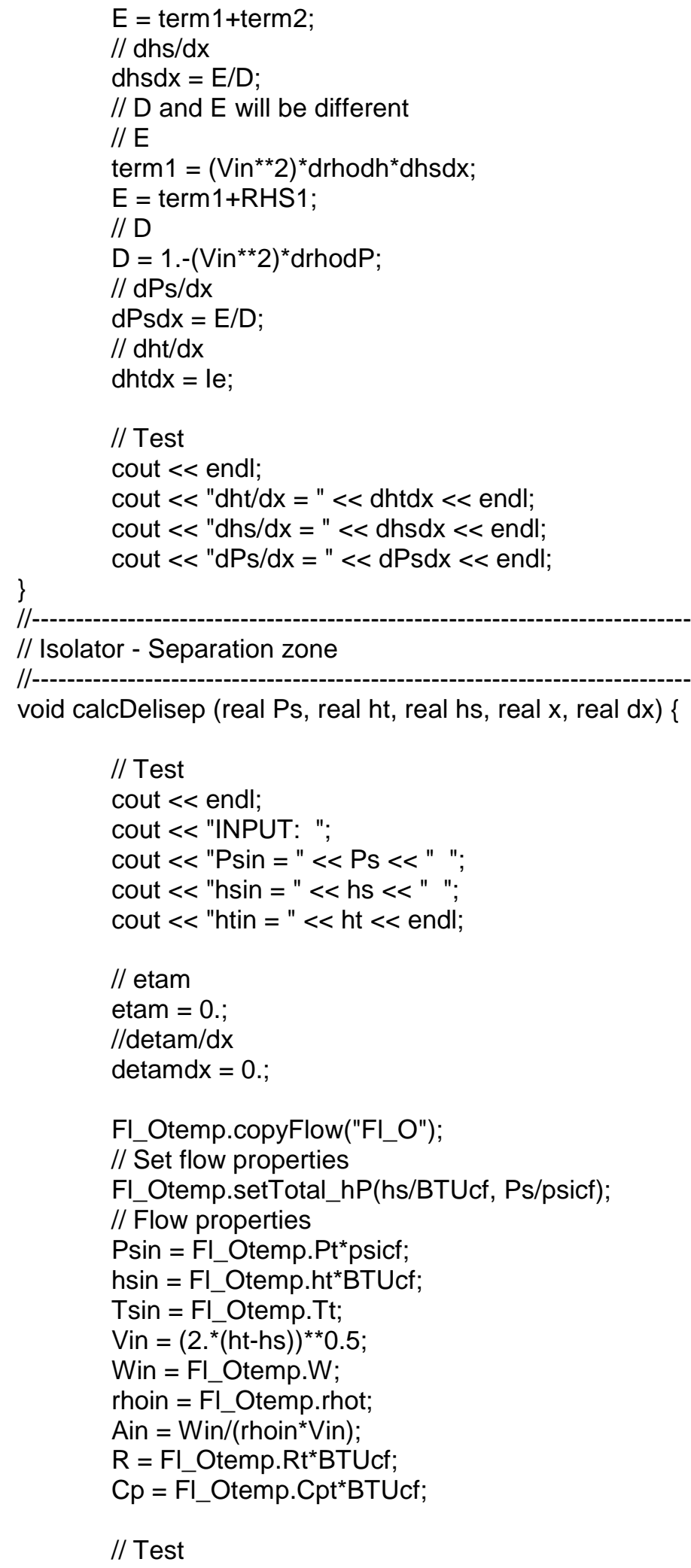




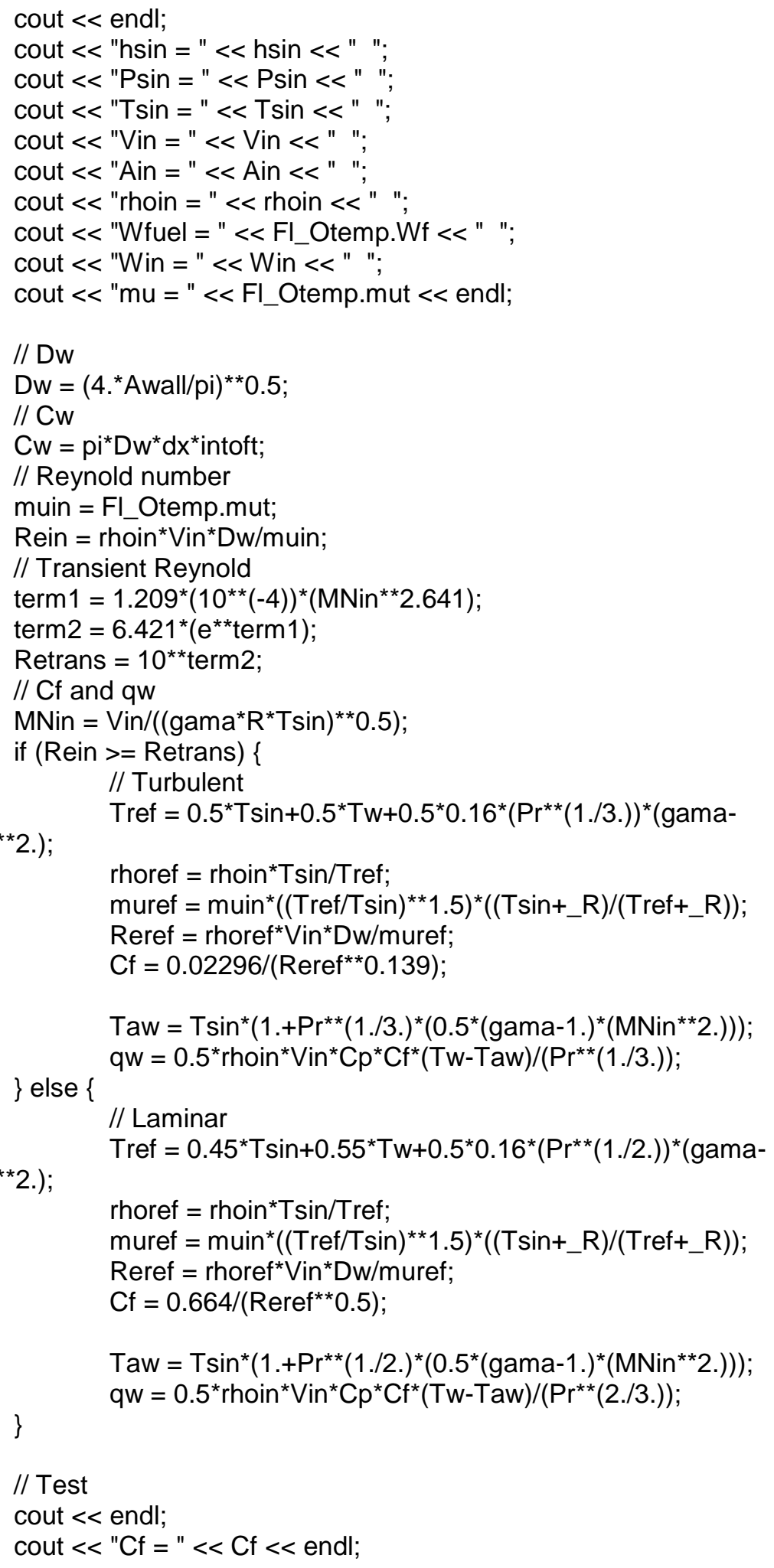




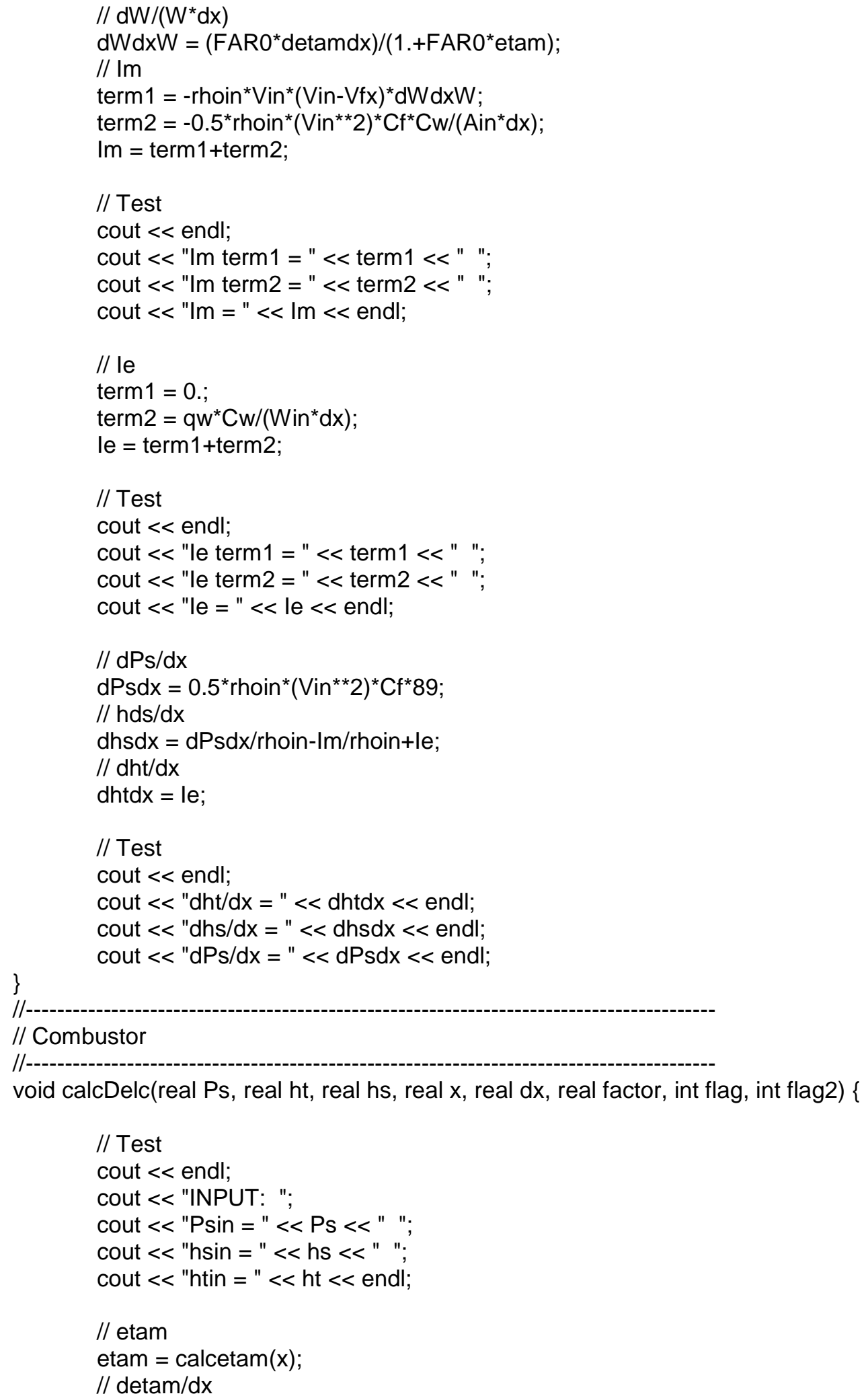




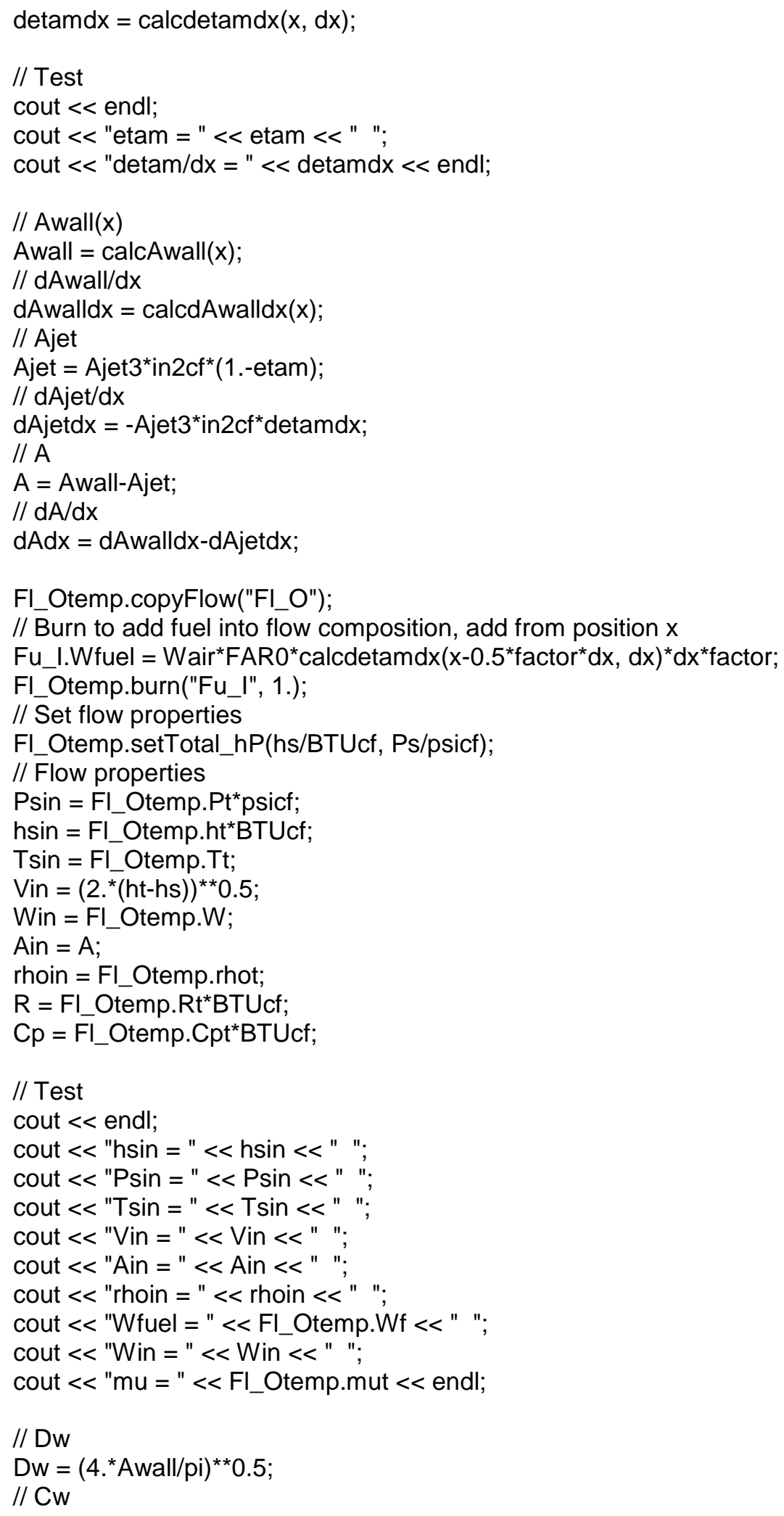




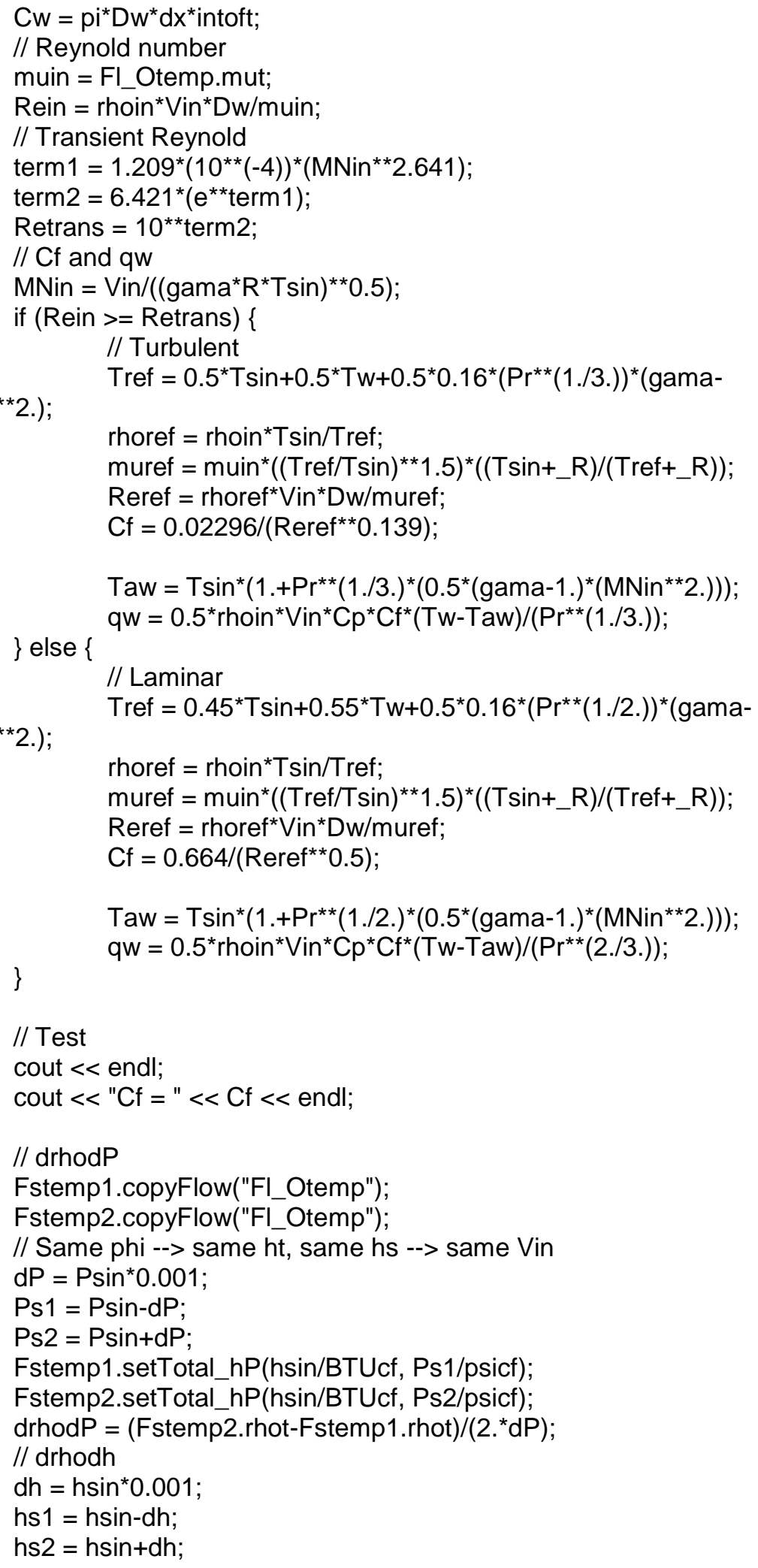


Fstemp1.setTotal_hP(hs1/BTUcf, Psin/psicf);

Fstemp2.setTotal_hP(hs2/BTUcf, Psin/psicf);

drhodh $=($ Fstemp2.rhot-Fstemp1.rhot $) /\left(2 .{ }^{*} \mathrm{dh}\right)$;

// drhodphi

Fstemp1.copyFlow("FI_Otemp");

Fstemp2.copyFlow("FI_Otemp");

diverge at 0.0001

dphi $=0.001^{*}$ FAR0/FARstoic; // $0.1 ; 0.01 ; 0.001$ give close results, starts to

Fu_I.Wfuel = Wair ${ }^{*}$ FARstoic ${ }^{*}$ dphi;

Fstemp1.burn("Fu_l", 1.);

Fstemp1.setTotal_hP(hsin/BTUcf, Psin/psicf);

Fu_I.Wfuel = 2. *Wair*FARstoic ${ }^{*}$ dphi;

Fstemp2.burn("Fu_l", 1.);

Fstemp2.setTotal_hP(hsin/BTUcf, Psin/psicf);

drhodphi = (-3. ${ }^{*} F$ I_Otemp.rhot+4. $\left.{ }^{\star} F s t e m p 1 . r h o t-F s t e m p 2 . r h o t\right) /\left(2 .{ }^{*} \mathrm{dphi}\right)$;

// Test

cout $<<$ endl;

cout $<<$ "drhodP = " $<<$ drhodP $<<"$ ";

cout $<<$ "drhodh = " $<<$ drhodh $<<"$ ";

cout $<<$ "drhodphi = " < drhodphi $<<$ endl;

$/ / \mathrm{dW} /\left(\mathrm{W}^{*} \mathrm{dx}\right)$

$\mathrm{dWdxW}=($ FAR0*detamdx $) /\left(1 .+\mathrm{FAR} 0^{*}\right.$ etam $) ;$

// Im

term1 $=$-rhoin ${ }^{*} \operatorname{Vin}^{*}(\operatorname{Vin}-\mathrm{Vfx})^{*} \mathrm{dWdxW}$;

term2 $=-0.5^{\star}$ rhoin $^{*}\left(\operatorname{Vin}^{\star *} 2\right)^{*} \mathrm{Cf}{ }^{\star} \mathrm{Cw} /\left(\right.$ Ain $\left.^{*} \mathrm{dx}\right)$;

Im = term1+term2;

// Test

cout $<<$ endl;

cout $<<$ "Im term1 = " $<<$ term1 $<<" ~ "$;

cout $<<$ "Im term2 = " $<<$ term2 $<<" ~ " ;$

cout $<<$ "Im = " $<<$ Im $<<$ endl;

// le

Fstemp2.setTotal_hP(hsin/BTUcf, Psin/psicf);

Fu_I.Wfuel $=$ Wair ${ }^{\star}$ FAR0 ${ }^{*}$ calcdetamdx $\left(x+0.5^{*} \mathrm{dx}, \mathrm{dx}\right)^{\star} \mathrm{dx}$;

Fstemp2.burn("Fu_l", 1.);

term1 = -(Fstemp2.ht ${ }^{\star}$ BTUcf-hsin $) / d x$;

term2 $=q w^{*} \mathrm{Cw} /\left(\mathrm{Win}^{*} \mathrm{dx}\right)$;

$l e=$ term $1+$ term 2

// Test

cout $<<$ endl;

cout $<<$ "le term $1=$ " $<<$ term $1<<" ~ " ;$

cout $<<$ "le term2 = " $<<$ term2 $<<" ~ " ;$

cout $<<$ "le = " $<$ le $<<$ endl;

// dphidx 


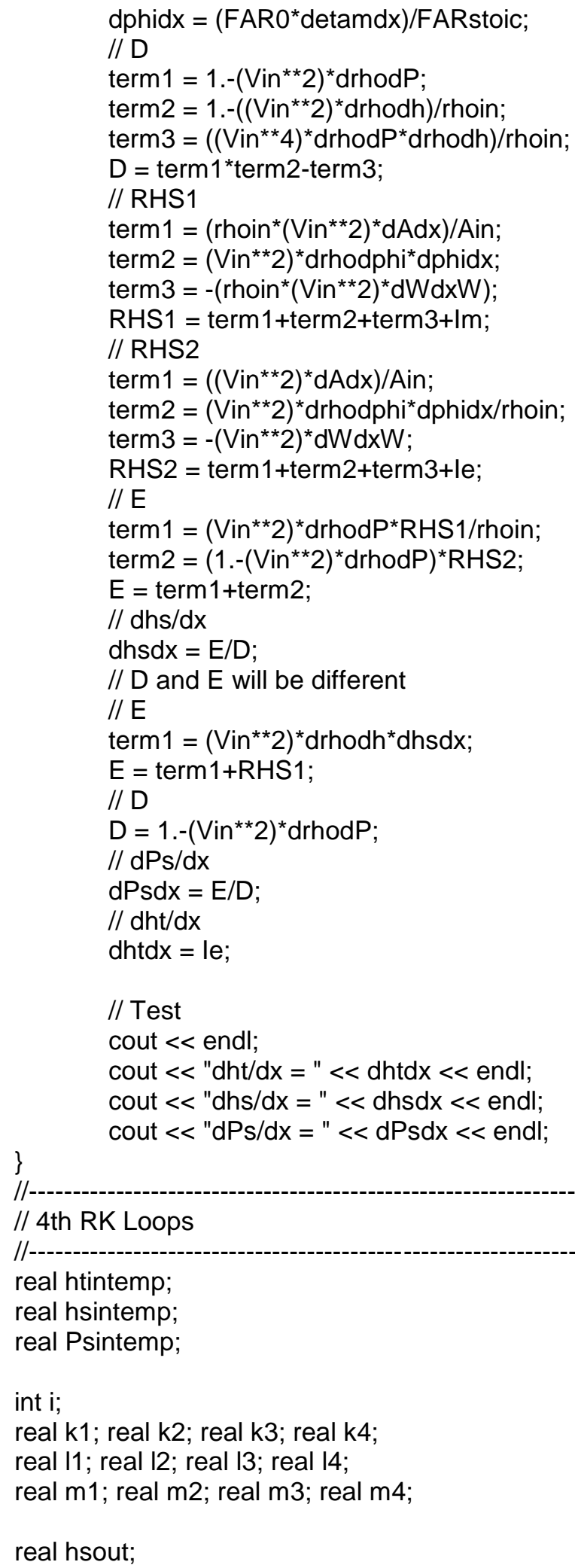




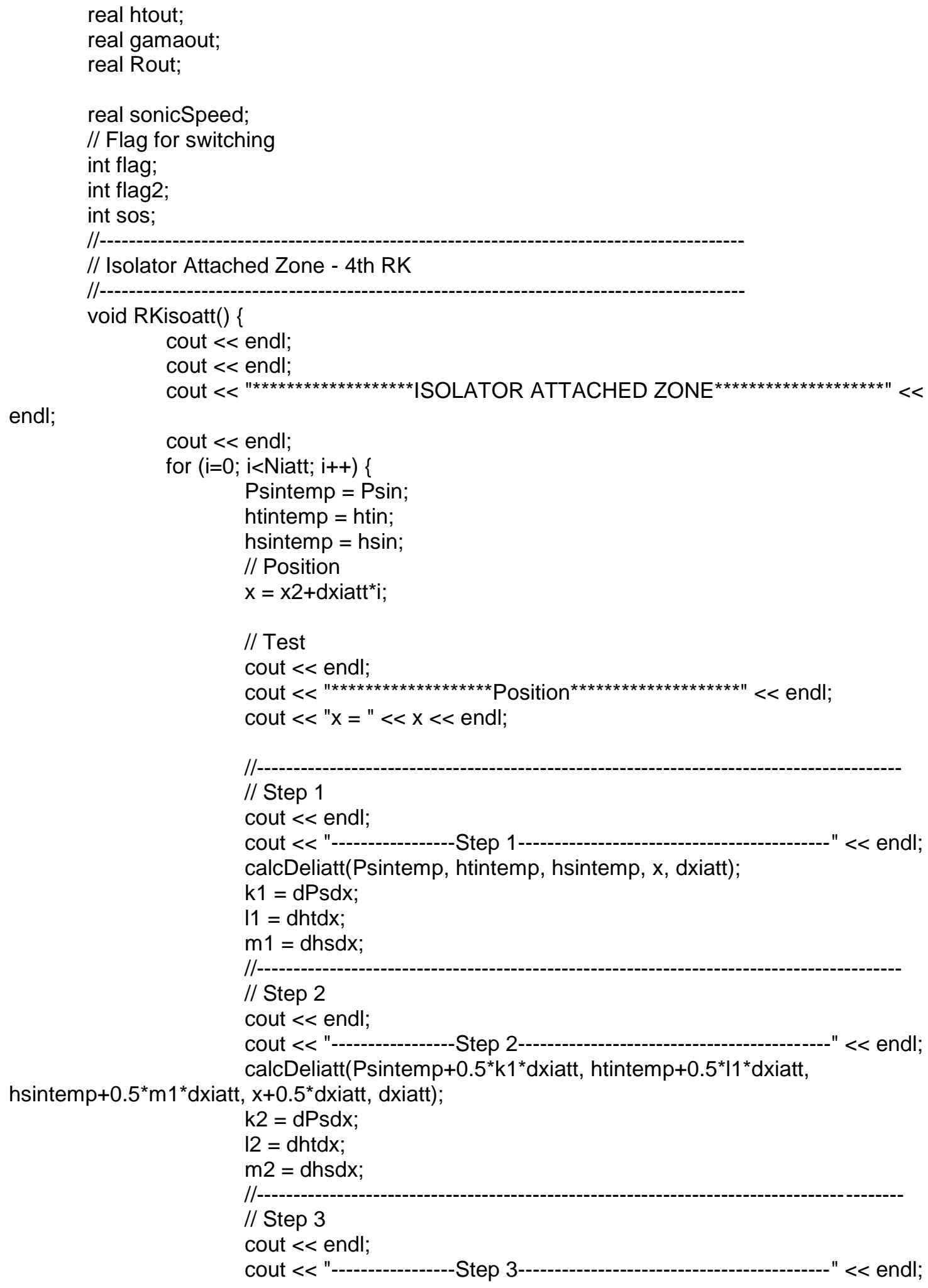

endl; 
calcDeliatt(Psintemp $+0.5^{*} \mathrm{k} 2^{*} \mathrm{dxiatt}$, htintemp $+0.5^{*} \mathrm{I} 2^{*} \mathrm{dxiatt}$, hsintemp $+0.5^{\star} \mathrm{m} 2^{*} \mathrm{dxiatt}, \mathrm{x}+0.5^{\star} \mathrm{dxiatt}$, dxiatt);

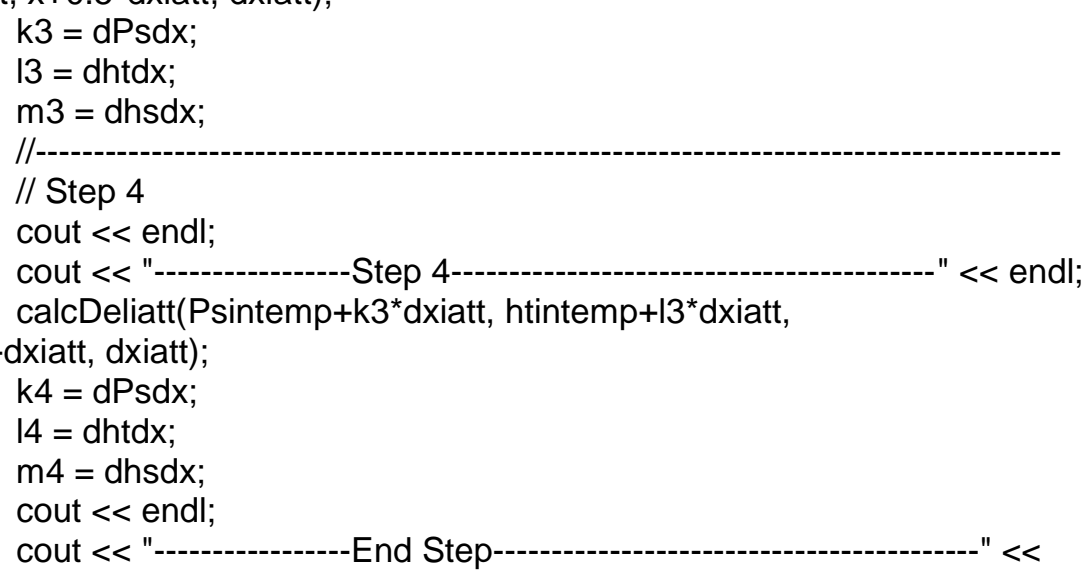

endl;

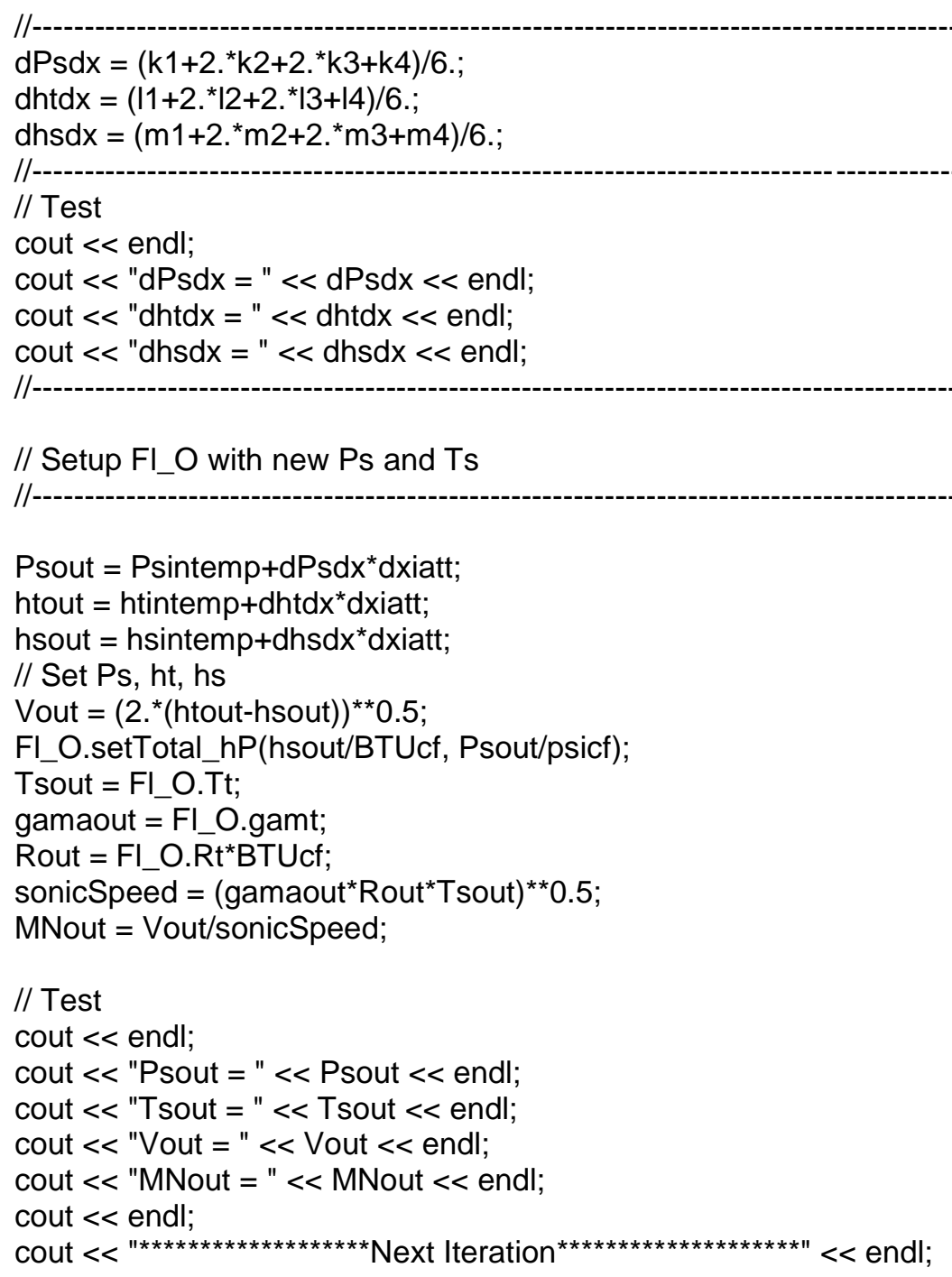




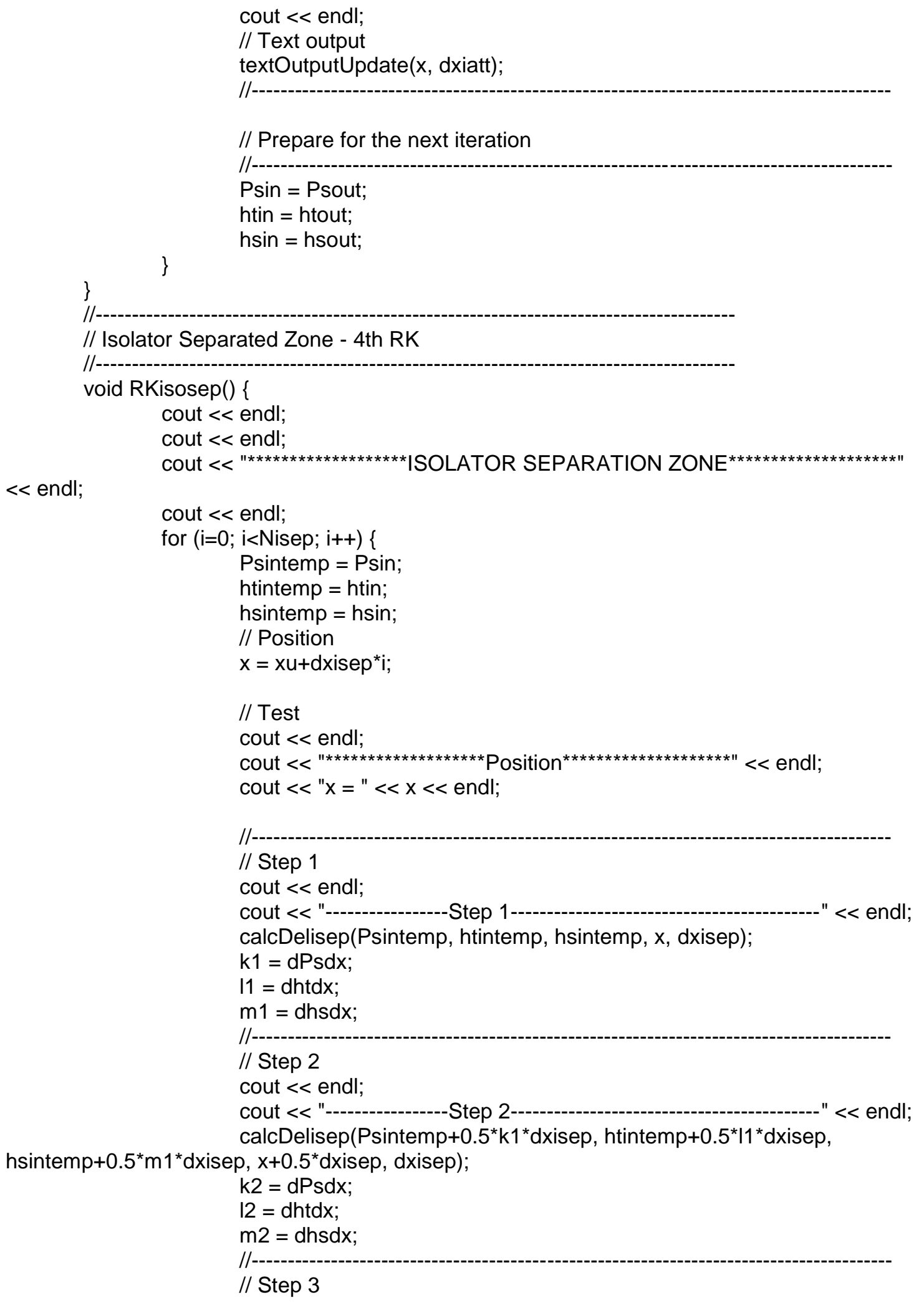


cout $<<$ endl;

cout $<<"---$

Step 3" < endl;

calcDelisep(Psintemp $+0.5^{*} \mathrm{k} 2^{*} \mathrm{dxisep}$, htintemp $+0.5^{\star} \mathrm{I} 2^{*} \mathrm{dxisep}$,

hsintemp $+0.5^{\star} m 2^{*} d x$ isep, $x+0.5^{\star} d x i$ sep, dxisep);

$\mathrm{k} 3=\mathrm{dPsd} ;$

$13=d h t d x$

$\mathrm{m} 3=\mathrm{dhsdx}$;

//--------.

cout $<<$ endl;

cout $<<"$ " $<$ endl;

calcDelisep(Psintemp+k3*dxisep, htintemp+l3*dxisep,

hsintemp+m3*dxisep, $x+d x i s e p, d x i s e p)$;

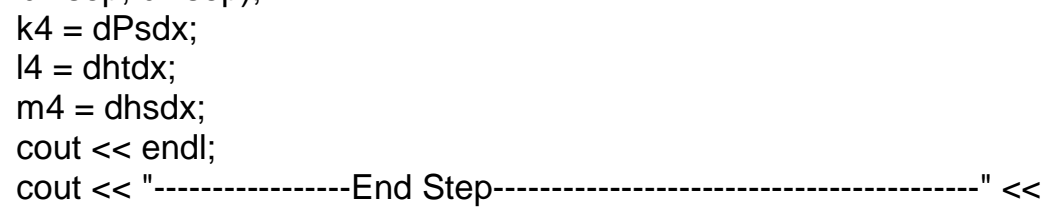
cout $<<"$ -End Step- $<<$

endl;

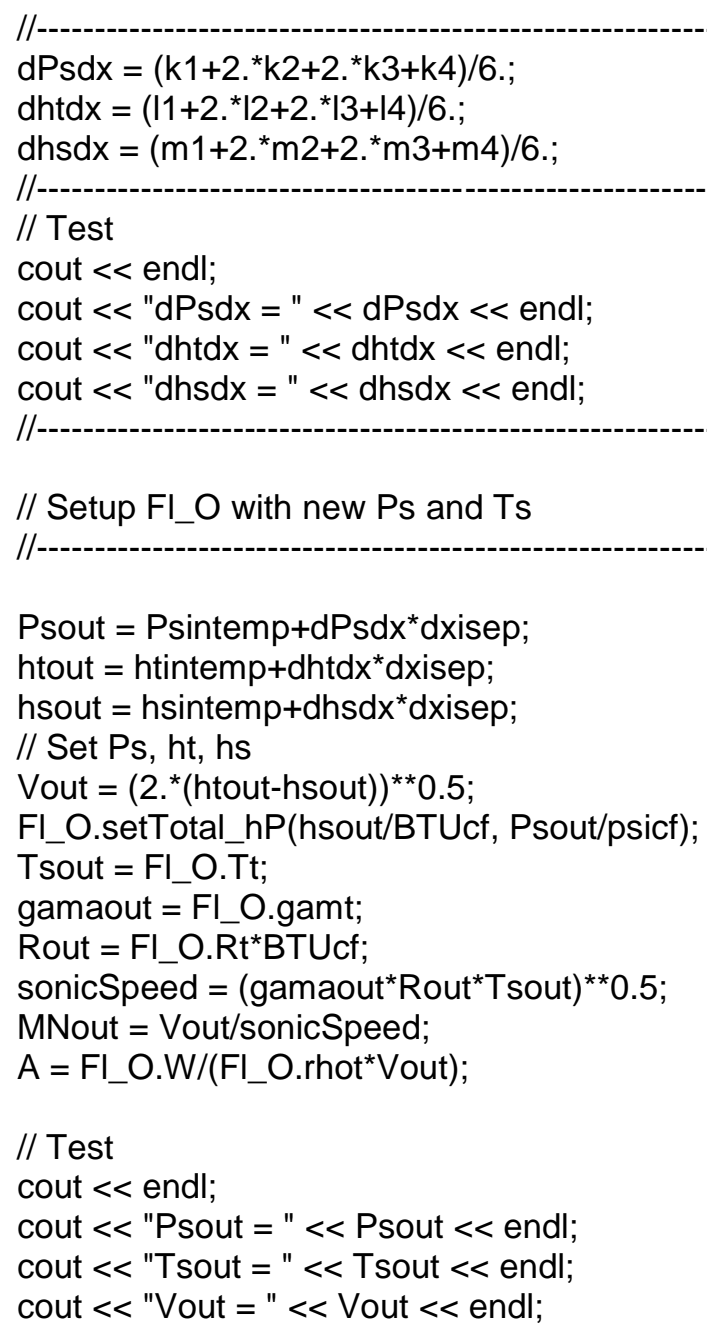




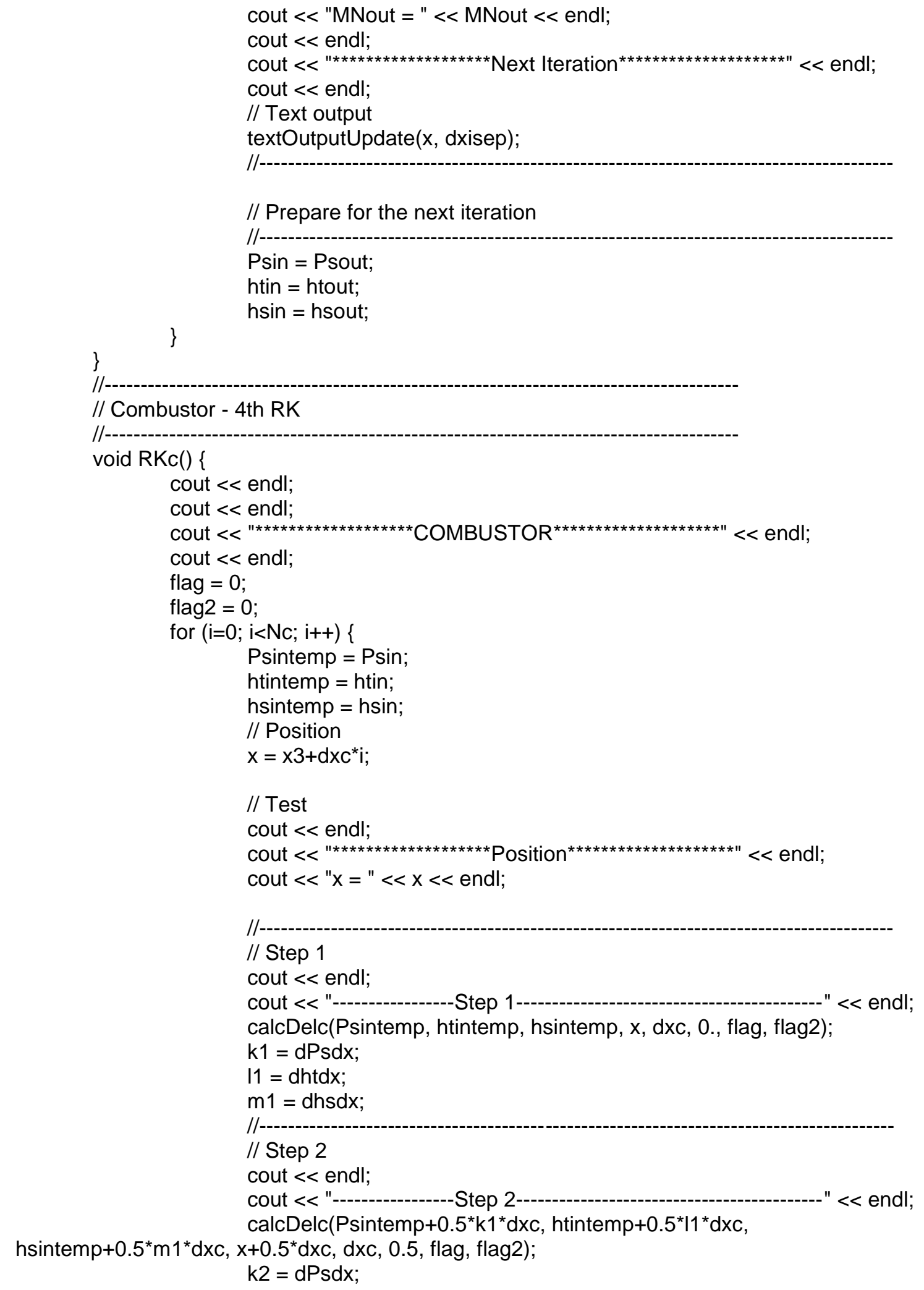


$12=d h t d x$

$\mathrm{m} 2=\mathrm{dhsdx}$;

$/ /$ Step 3

cout $<<$ endl;

cout << "-----------------Step 3-----------------------------------------" < endl;

calcDelc(Psintemp $+0.5^{*} \mathrm{k} 2^{*} \mathrm{dxc}$, htintemp $+0.5^{*} \mid 2^{*} \mathrm{dxc}$,

hsintemp $+0.5^{\star} \mathrm{m} 2^{*} \mathrm{dxc}, \mathrm{x}+0.5^{\star} \mathrm{dxc}, \mathrm{dxc}, 0.5$, flag, flag2);

k3 = dPsdx;

$13=$ dhtdx;

$\mathrm{m} 3=\mathrm{dhsdx}$;

// Step 4

cout $<<$ endl;

cout $<<$ "------------Step 4--------------------- endl;

dxc, 1., flag, flag2);

calcDelc(Psintemp+k3*dxc, htintemp+l3*dxc, hsintemp+m3*dxc, $x+d x c$,

endl;

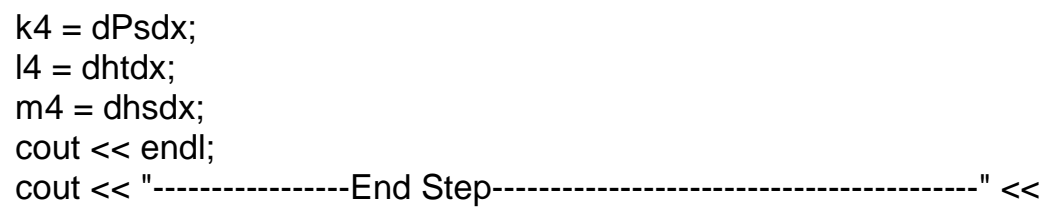




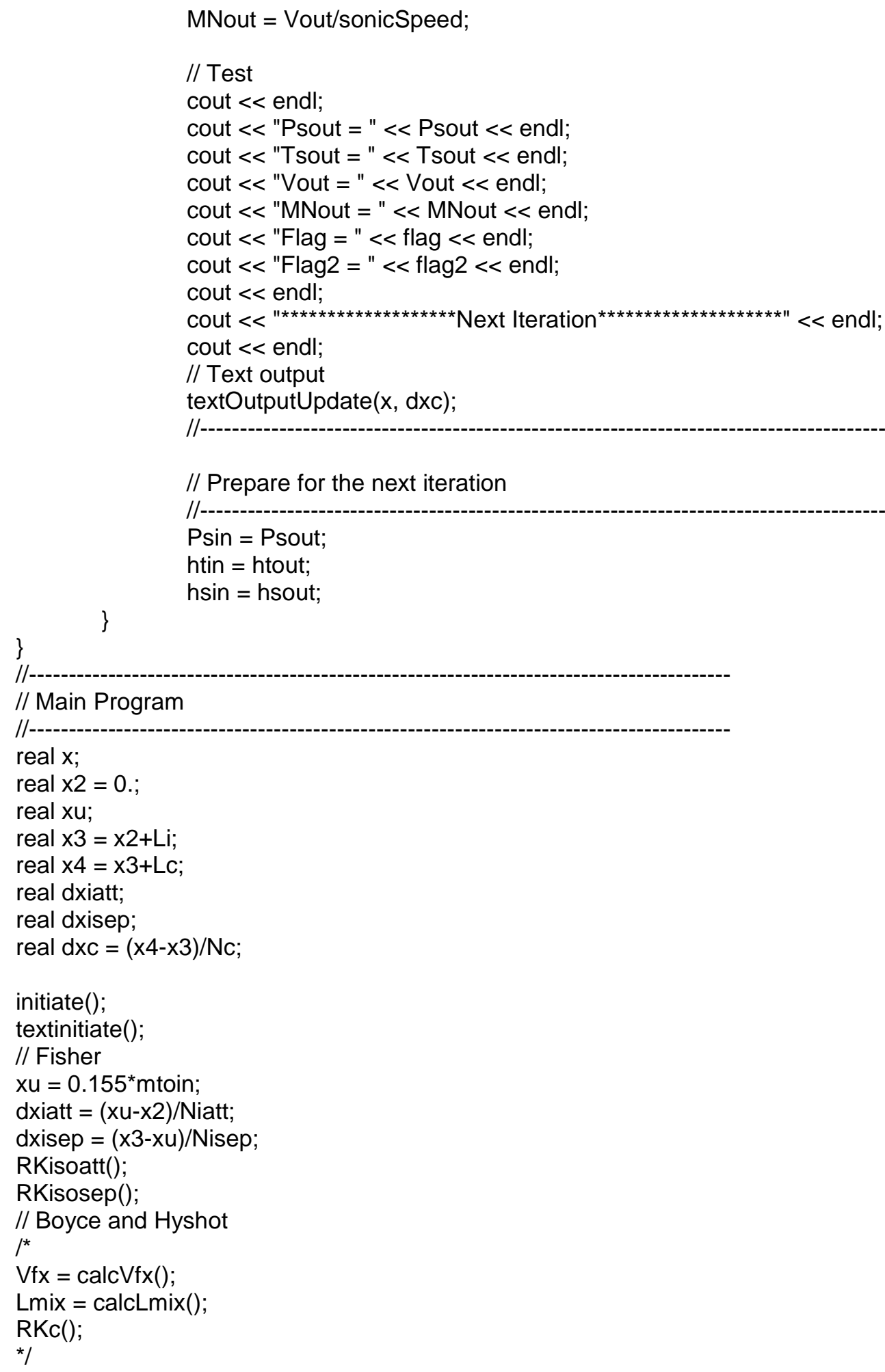




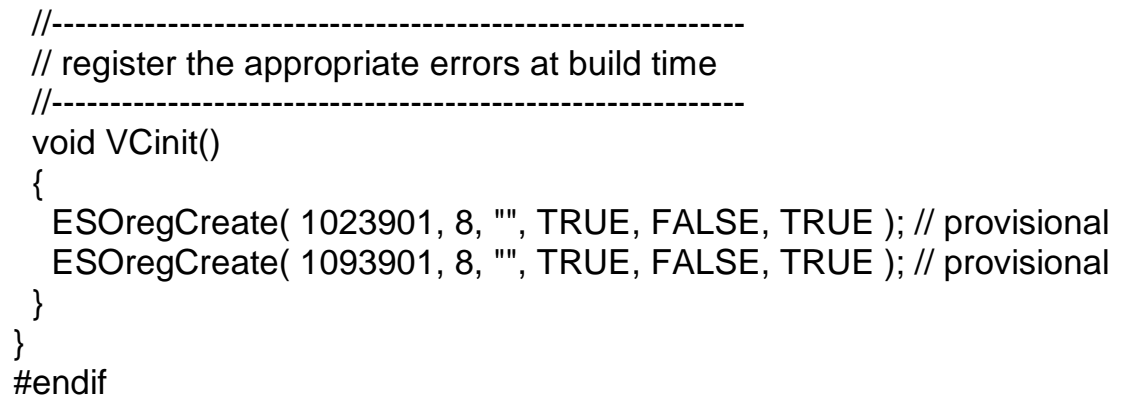


References

[1] Heiser, W. H.; Pratt, D. T., "Hypersonic Airbreathing Propulsion," Washington, DC, American Institute of Aeronautics and Astronautics, Inc., 1994.

[2] Smart, Michael K., "Scramjet Inlets," Centre for Hypersonics, The University of Queensland, Brisbane, Australia, September 2010.

[3] Kanda, T.; Chinzei, N.; Kudo, K.; Murakami, A., "Dual-mode Operation in a Scramjet Combustor," in AIAA/NAL-NASDA-ISAS 10th International Space Planes and Hypersonic Systems and Technologies Conference, Kyoto, Japan, April 2001.

[4] Vijayakumar, Nandakumar; Wilson, Donald. R.; Lu, Frank. K., "Multifidelity Simulation of a Dual Mode Scramjet Compression System using Coupled NPSS and FLUENT Codes," in 50th AIAA/ASME/SAE/ASEE Joint Propulsion Conference, Cleveland, OH, July 28-30, 2014.

[5] Curran, E. T.; Murthy, S. N. B., "Scramjet Propulsion," Reston, Virginia, American Institute of Aeronautics and Astronautics, Inc., 2000.

[6] Vu, L. N., "Analysis and Design of a Dual-mode Scramjet Engine Inlet and Isolator," Hanoi University of Science and Technology, Hanoi, Vietnam, May 2016.

[7] Gopal, V., "Reduced-order Analysis of Dual-mode Supersonic Combustion Ramjet Propulsion System," The University of Texas at Arlington, Arlington, TX, December 2015.

[8] Mateu, M. M., "Study of an Air - Breathing Engine for Hypersonic Flight," Polytechnic University of Catalonia, Catalonia, Spain, September 2013.

[9] Gibbs, Y., "NASA Armstrong Fact Sheet: Hyper-X Program," nasa, 28 Febuary 2014. [Online]. Available: https://www.nasa.gov/centers/armstrong/news/FactSheets/FS040-DFRC.html.

[10] Mutzman, R.; Murphy, S., "X-51 Development: A Chief Engineer's Perspective," in 17th AIAA International Space Planes and Hypersonic Systems and Technologies Conference, San Francisco, California, 13 April 2011.

[11] Thompson, E.; Henry, K.; Wiliams, L., "Faster Than a Speeding Bullet: Guinness Recognizes NASA Scramjet," NASA, June 2005.

[12] Wall, M., "Air Force's X-51A Hypersonic Scramjet Makes Record-Breaking Final Flight," Space.com, 3 May 2013. [Online]. Available: https://www.space.com/20967air-force-x-51a-hypersonic-scramjet.html.

[13] Norris,G., "Skunk Works Reveals SR-71 Successor Plan," Aviation Week \& Space Technology, November 2013.

[14] Shapiro, A. H., "The Dynamics and Thermodynamics of Compressible Flow," Ronald Press, New York, 1953.

[15] Fotia, Matthew L.; Driscoll, James F. , "Ram-Scram Transition and Flame/ShockTrain Interactions in a Model Scramjet Experiment," Journal of Propulsion and Power, vol. Vol. 29, no. No. 1, January-February 2013.

[16] Smart, Michael K., "Scramjets," Centre for Hypersonics, The University of Queensland, Brisbane, Australia, 2008.

[17] Smart, Michael K., "Scramjet Isolators," Centre for Hypersonics, The University of 
Queensland, Brisbane, Australia, September 2010.

[18] Ortwerth, P. J., "Scramjet Vehicle Integration," American Institute of Aeronautics and Astronautics, Washington DC, 2001.

[19] Boyce, R. R.; Wendt, M.; Paull, A.; Chinzei, N.; Stalker, R. J.; Miyajima, H., "Supersonic Combustion - A Shock Tunnel and Vitiation-heated Slowdown Tunnel Comparison," in 36th Aerospace Sciences Meeting \& Exhibit, Reno, NV, January 1998.

[20] Smart, M. K.; Hass, N. E.; Paull, A., "Flight Data Analysis of the HyShot 2 Scramjet Flight Experiment," AIAA Journal, vol. 44, no. 10, October 2006.

[21] Fisher, C. M., "Investigation of the Isolator Flow of Scramjet Engines," Aachen University, München, 2014.

[22] N. Vijayakumar, "Design and Multifidelity Analysis of a Dual Mode Scramjet Compression System Using Coupled NPSS and FLUENT Simulation," University of Texas at Arlington, Arlington, TX, May 2014.

[23] J. K. Lytle, "NASA/TM-1999-209194, The Numerical Propulsion System Simulation: A Multidisciplinary Design System for Aerospace Vehicles," NASA Glenn Research Center, Cleveland, Ohio, July 1999.

[24] Claus, Russell W.; Lavelle, Thomas; Townsend, Scott; Tuner, Mark, "Coupled HighFidelity Engine System Simulation," in 26th International Congress of the Aeronautical Sciences, September 2008.

[25] J. K. Lytle, "NASA/TM-2000-209915, The Numerical Propulsion System Simulation: An Overview," NASA Glenn Research Center, Cleveland, Ohio, June 2000.

[26] J. K. Lytle, "Multi-fidelity Simulations of Air Breathing Propulsion Systems," in 42nd AIAA/ASME/SAE/ASEE Joint Propulsion Conference \& Exhibit, Sacramento, California, 9 - 12 July 2006.

[27] G. J. Follen, "An Object Oriented Extensible Architecture for Affordable Aerospace Propulsion Systems," in Applied Vehicle Technology Conference, Paris, France, 2226 April, 2002.

[28] "NPSS Basics," Wolverine Ventures Inc, Jupiter FL, 2014.

[29] S. Coogan, "Object-Oriented Aircraft Mission Analysis Using NPSS," in 54th AIAA Aerospace Sciences Meeting, San Diego, California, 4-8 January 2016.

[30] "NPSS User Guide," Numerical Propulsion System Simulation Consortium, February 2, 2016.

[31] N. Vijayakumar, "Re-Engineering the Northrop YB-49," The University of Texas at Arlington, Arlington, TX, June 15, 2015.

[32] "NPSS User Guide Reference Sheets," Numerical Propulsion System Simulation Consortium, February 1, 2016.

[33] "Introduction to system modeling," Wolverine Ventures Incorporated, Jupiter FL, 2014.

[34] S. M. Jones, "An Introduction to Thermodynamic Performance Analysis of Aircraft Gas Turbine Engine Cycles Using the Numerical Propulsion System Simulation Code," Glenn Research Center, Cleveland, Ohio, March 2007.

[35] Segal, C., "The scramjet engine: processes and characteristics," New York, Cambridge University Press, 2009. 
[36] Doolan, C. J.; Boyce, R., "A Quasi-One-Dimensional Mixing and Combustion Code for Trajectory Optimisation and Design Studies," in 15th AIAA International Space Planes and Hypersonic Systems and Technologies Conference, Dayton, Ohio, 2008. 
Biographical Information

Long Vu was born in Ho Chi Minh city (formerly known as Saigon), Vietnam on the first day of 1993. Long developed his interest for Physics since he took his first Physics class in $7^{\text {th }}$ grade. He was accepted to high school program of Hanoi University of Science specializing in Physics. He attended Hanoi University of Science and Technology after high school and earned his Bachelor of Science Degree in Aerospace Engineering in 2016. In the summer after his junior year, Long was selected to join the summer internship program of GE Hitachi and had the opportunity to work within the mechanical team at GE Hitachi in Wilmington, NC.

Long came to the United States for a second time to pursue his Master of Science in Aerospace Engineering degree at the University of Texas at Arlington. During his education at UTA, Long worked under the supervision of Dr. Donald Wilson at the Aerodynamic Research Center.

Long plans to continue pursuing his goals to become an engineer to contribute to the development of the next generation of aerospace vehicles. 